MARIA LÚCIA DE MOURA SILVA SOBOLL

\author{
/CANCER DE RETO \\ Estudo caso-controle no Município \\ de são Paulo
}

Tese apresentada à Faculdade de Saúde Pú blica da Universidade de São Paulo, Departamento de Epidemiologia, para obtenção do título de Doutor em Saúde Pública

Orientador: Prof. José Maria Pacheco de Souza

São Paulo

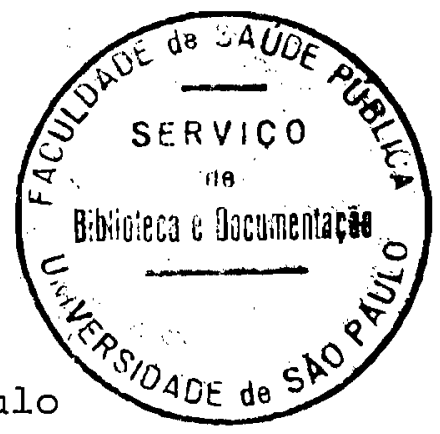

1985 
A

Maria Jandira e

Antonio (em memória)

A

walter

Marcelo e

Maurício 
AGRADECIMENTOS

- Ao Professor José Maria Pacheco de Souza, orientador des ta tese pela especial dedicação e colaboração que nos proporcionou em todas as fases de elaboração deste trabalho.

- Ao Fernão Dias de Lima pela efetiva cooperação no processamento dos dados, etapa fundamental na elaboração deste trabalho.

- A Professora Sabina Léa Davidson Gotlieb pelo contínuo es tímulo e pela valiosa revisão crítica.

- Ao Doutor Antonio Pedro Mirra pelas sugestões apresentadas.

- Ao Doutor Vicente Odone Neto, pela revisão crítica dos originais.

- Ao Professor João Yunes pelo apoio e incentivo constantes no nosso caminhar intelectual.

- Ao Professor Eduardo Marcondes pelo incentivo prestado quando de nossa atuação no Instituto da Criança "Professor Pedro de Alcantara".

- À equipe do Centro de Informaçães de Saúde pela cooperação e compreensão de nosso afastamento.

- A Doutora Maria Bernadete de Paula Eduardo por nos ter substituído na direção do CIS com total empenho e amizade. 
- As bibliotecárias Daisy Pires Noronha e Nancy Bueno pelo apoio prestado na obtenção e organização da bibliografia.

- A Maria Angélíca dos Santos Mendes pela cuidadosa elabora ção dos gráficos.

- A Telma Garcia de Mattos pela colaboração efetiva na datị lografia deste trabalho: 
Trata-se de um estudo caso-controle de câncer de reto como parte do "Estudo Epidemiológico de Câncer de Esôfago e de Reto no Município de São Paulo".

- estudo compreendeu 92 casos de câncer de reto e 200 controles categorizados em 3 sub-conjuntos (amostra pareada, global e estratificada).

Foram objeto de análise as variáveis: local de nascimento do indivíduo e de seus pais, zona de nascimento (rural/urbana) consumo de alimentos (carnes, ovos, verduras, temperos) característi cas do hábito intestinal, tabagismo e consumo de bebidas (cerveja, vinho e pinga).

As estimativas dos Riscos Relativos (RR) por ponto e respectivos testes de significância foram calculados para cada tipo de amostra. Utilizou-se análise multivariada, através do procedimento de máxima verossimilhança condicional para a amostra estratificada e os procedimentos clássicos para as amostras pareada e global.

A análise estatística dos'resultados evidenciou associação positiva apenas entre o consumo de queijo e câncer de reto $(R R=1,41 \longmapsto-4,30)$. Não está afrastada a possibilidade de que a significância encontrada seja devido a um artefato estatístico, dada a multiplicidade de testes efetuados. A possível assiciação entre o consumo queijo e câncer de reto, portanto, deve ser interpretada com reserva. 
SUMMARY

This is a case-control study of rectal cancer and is part of "The Epidemiological study of Esophagus and Rectal Cancers in the City of São Paulo, Brazil".

The study included 92 cases of rectal cancer and 200 controls (classified in three types: matched, global and stratified samples).

The analised variables were: state of birth classified in great regions of Brazil, place of birth (rural/urban), food consumption (meats, eggs, fruits, vegetables, cereals, beans, seasonings, dairy products) caracteristics of the bowel movements, smoking habits and alcohol consumption (beer, wine and hard liquor-"pin $\left.g a^{\prime \prime}\right)$.

The point estimates of the Relative Risks and their significance tests were calculated for each type of sample. Multivariate analysis was done, for the stratified sample the conditional maximum likelihood procedure was used and classical procedures (Me Nemar and Cross Ratio estimate) for the other samples.

The statistical analysis indicated a positive/associa tion only between cheese consumption and cancer of the rectum $(R R=1,41 \longmapsto-4,30)$.

There is the possibility that the observed statistical significance is a statistical artefact due to the multiplicity of tests that have been perfomed. Because of this, the possible association between cheese comsumption and cancer of the rectum must be viewed with caution. 
Pag.

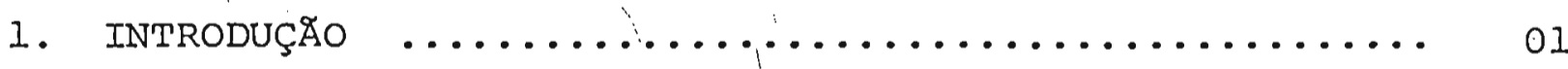

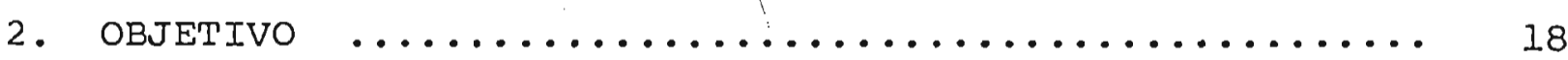

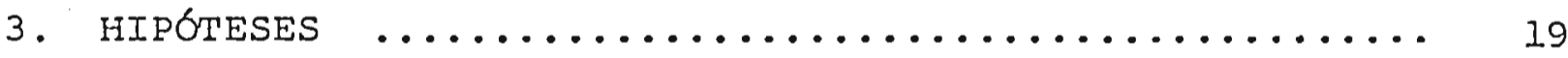

4. MATERIAL E MÉtODO $\ldots \ldots \ldots \ldots \ldots \ldots \ldots \ldots \ldots \ldots \ldots \ldots \ldots . \ldots \ldots \ldots$

4.1. Seleção dos casos e dos controles ............ 20

4.2. Instrumento de coleta de dados ............ 30

4.3. Descrição das variáveis de estudo ........... 30

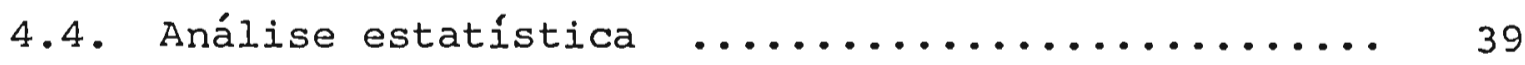

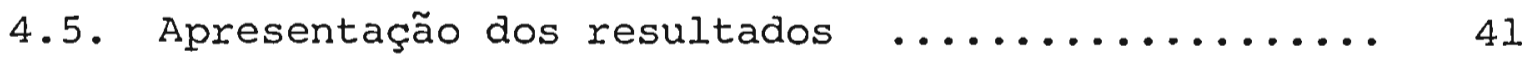

5. RESULTADOS ........................... 42

5.1. Caracterização sócio-demográfica dos indivíduos

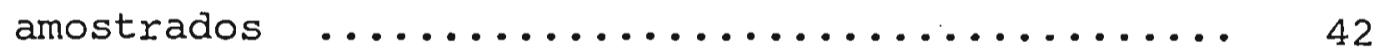

5.2. Consumo habitual de alimentos ............. 44

5.2.1. Carnes em geral, aves, peixes e ovos ... 45

5.2.2. Produtos lácteos .............. 46

5.2.3. Verduras, legumes, leguminosas e frutas. 47

5.2.4. Cereais, tubérculos e doces $\ldots \ldots \ldots \ldots .48$

5.2.5. Condimentos e temperos ........... 48

5.3. Característica do hábito intestinal ......... 49

5.4. Outras características ................. 49

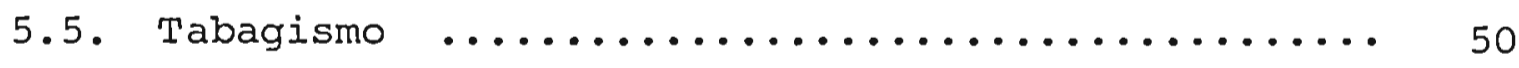

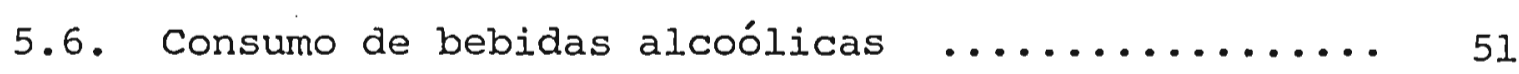

5.7. Análise multivariada $\ldots \ldots \ldots \ldots \ldots \ldots \ldots \ldots \ldots$

5.7.1. Análise multivariada para NPAMA, QUEIJO E

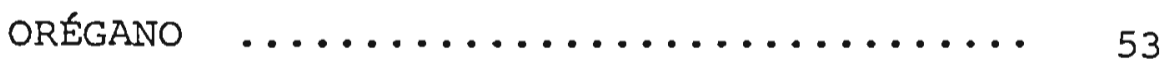

5.7.2. Análise multivariada para reto baixo ... 55

5.7.3. Análise multivariada para bebidas - análí se para cerveja $\ldots \ldots \ldots \ldots \ldots \ldots \ldots \ldots$ 


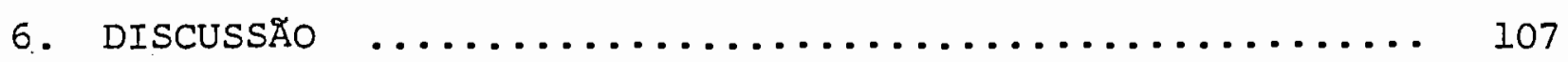

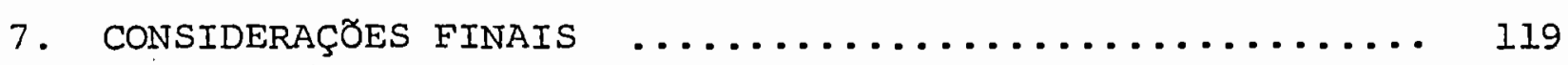

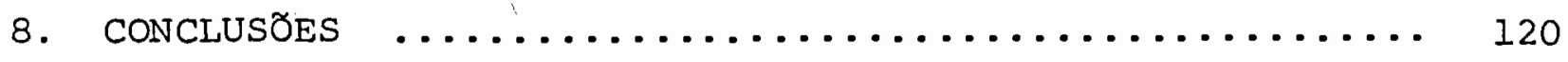

9. REFERENCIAS BIBLIOGRAFICAS $\ldots \ldots \ldots \ldots \ldots \ldots \ldots \ldots \ldots \ldots \ldots \ldots$

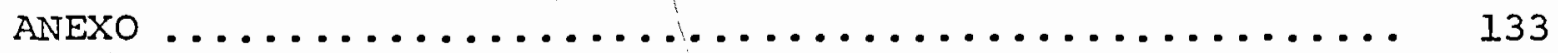


Nos países industrializados os tumores malígnos do intestino grosso constituem, após o câncer de pulmão entre homens e - câncer de mama entre mulheres, (excluídos os cânceres de pele) o grupo de cânceres mais importantes. 85,86

A distribuição por área geográfica e por etnia do câncer de cólon e de reto caracteriza-se principalmente pela sua alta incidência nos países da Europa Ocidental e nos países povoados por migrantes europeus, como Austrália, Canadá, Nova Zelândia e Estạ dos Unidos da América do Norte. Taxas intermediárias de incidencia são encontradas em países da Europa oriental e Japão e as mais baixas taxas de incidência são registradas na Africa, Asia e América do Sul. 12, 38, 82, 83 A gravidade do quadro foi evidenciada em estatís tica americana 18 quando se estimou que em 1980 ocorreriam 114.000 novos casos de câncer de cólon e de reto, sendo que, 53.000 levariam à morte no mesmo ano. Apesar de uma incidência menor no Brasil, o es tudo epidemiologico, envolvendo a análise dos possíveis fatores de risco, é de importância para a promoção de ações preventivas.

Histologicamente o câncer de intestino grosso é um tụ mor do tipo adenocarcinoma. Sabe-se que hoje 95 a $99 \%$ dos tumores malígnos de cólon e do reto são representados por esses adenocarcinomas, sendo a percentagem complementar composta por leiomiossarcomas e linfomas. $16,20,27$

Embora em vários estudos se analise o câncer de intes tino grosso como um todo, sem especificar as localizações, a distribuição dos tumores nos segmentos anatômicos do intestino não é homo- 
gênea. o padrão de distribuição é semelhante em áreas de incidência alta ou intermediária: há um decréscimo de incidência do cólon ascendente em direção ao cólon descendente com um acentuado aumento de incidência do cólon sigmóide, seguido de alta incidência de câncer de reto, maior do que a de sigmóide. Em áreas de baixa incidência existe uma distribuição mais uniforme dos tumores nas várias lo calizações do intestino grosso, com uma menor incidência de cânceres do sigmóide, em comparação com a distribuição em áreas de incidência alta ou intermediária. 30, 52 .

A Figura 1 apresenta a incidência do câncer de intes tino grosso segundo localizações referentes a doze registros selecionados da South Metropolitan Cancer Registry - International Agen cy for Reserch on Cancer 1976, cuja distribuição é típica de áreas com taxas de incidência alta e intermediária ${ }^{30}$.

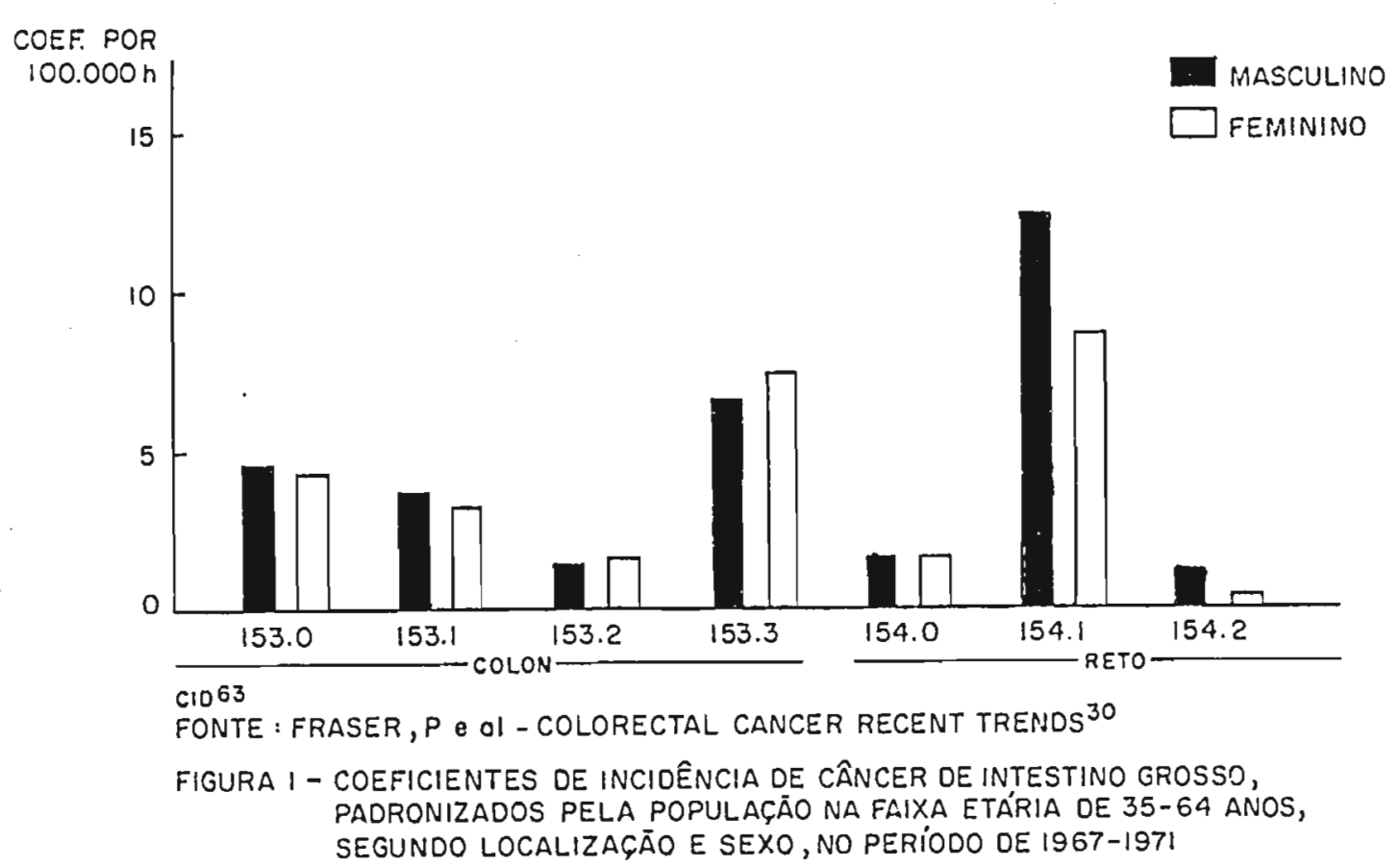


A separação da doença em: câncer de cólon e câncer de reto, gera problemas de classificação (Figuras 2, 3). De acordo com a $8^{a}$ e 9a revisões da Classificação Internacional de Doenças, 62, 63 a lesão no sigmóide é classificada como pertencente ao cólon (Código 153.3), enquanto que o tumor que se desenvolve na junção reto-sigmói de é considerado como pertencente ao reto (Código 154.0). A inclusão deste tumor em um ou outro código pode alterar a respectiva estatística de incidência. Contudo, em levantamento específico realizado no registro de tumores de Nova York, verificou-se que apenas 15 a $25 \%$ dos cânceres de reto estão localizados na junção reto-sigmóide, fazendo supor que esta percentagem não seja suficientemente elevada pa ra alterar as variações classificatórias encontradas. $30,38,52$.

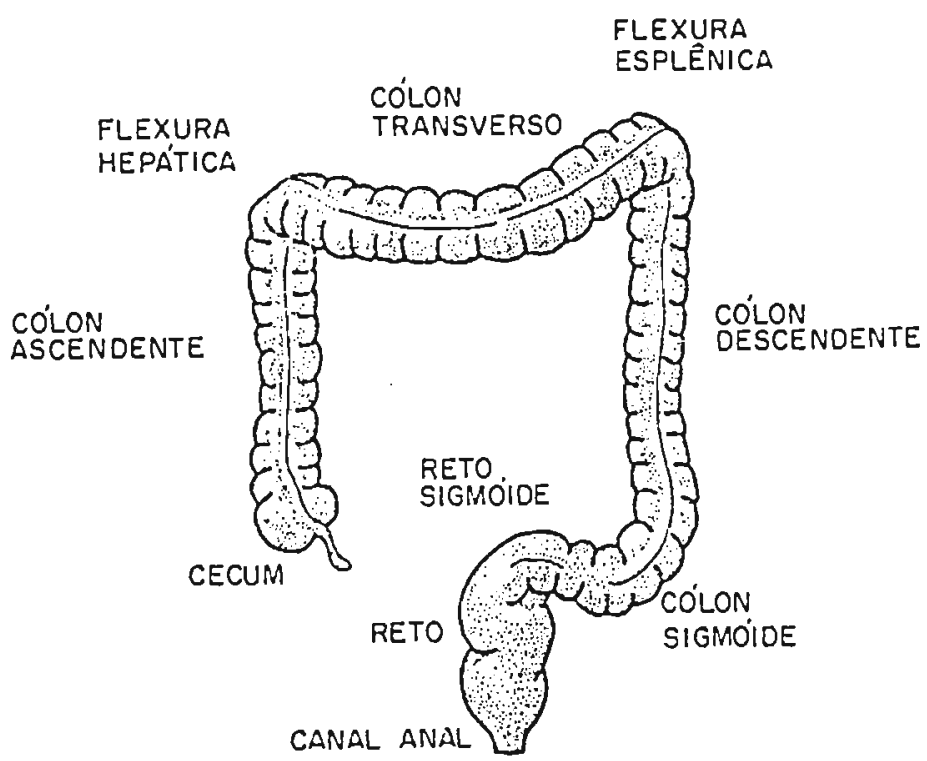

FONTE: NETTER, F.H. - DIGESTIVE SYSTEM LOWER DIGESTIVE TRACT ${ }^{74}$ FIGURA 2 - CLASSIFICAÇÃO ANATOMICA DO INTESTINO GROSSO 
Segundo alguns autores, há necessidade de se especifí car o tumor de reto baixo e o de reto alto por responderem por padrões epidemiológicos distintos. Os mesmos autores salientaram, no entanto, que o câncer de reto alto e do cólon sigmóide devem ter padrões semelhantes. Por sua vez, as dúvidas quanto à localização do câncer de reto alto ou reto baixo em relação ao ânus ou à linha pectínea ainda não levou a uma classificação padronizada (Figura 3).

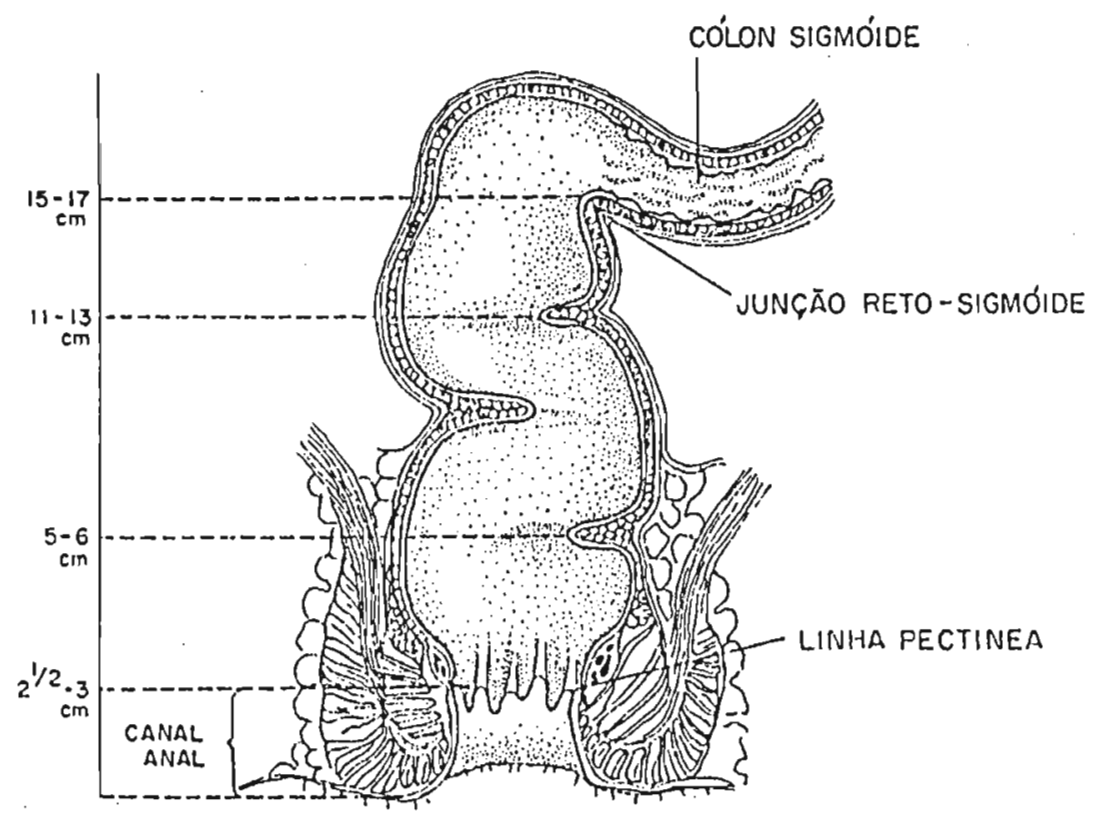

FONTE: NETTER, F.H. - DIGESTIVE SYSTEM LOWER DIGESTIVE TRACT ${ }^{74}$ FIGURA 3 - ANATOMIA DO RETO 
A Tabela 1 mostra a incidência diferenciada de câncer, segundo as localizações dos tumores no cólon e no reto, em áreas de alta incidência (Connecticut 1968-72), incidência incilência intermediária (São Paulo 1969) e baixa (Cali 1967-71). Chama a atenção a elevada incidência de câncer do trato intestinal sem especificação, comparativamente com as demais localizações nas cidades de São Paulo e Cali, refletindo a precariedade de classificação anatômica.

Na comparação das incidências de câncer de reto e de cólon entre localidades em séries geográficas em anos próximos a 1975, 86 destaca-se o alto coeficiente para Connecticut (EEUU) e Birmingham (Inglaterra), o intermediário para Osaka (Japão) e para o Mu nicípio de são Paulo (Brasil) e o baixo coeficiente para Cali (Colom bia) (Tabela 2). 
COEFICIENTES DE INCIDENCIA* DE CANCER DE CÓLON E DE RETO POR LOCALIZAÇð̃ES DO TUMOR SEGUNDO SEXO, EM ALGUMAS CIDADES

$$
1968-1972
$$

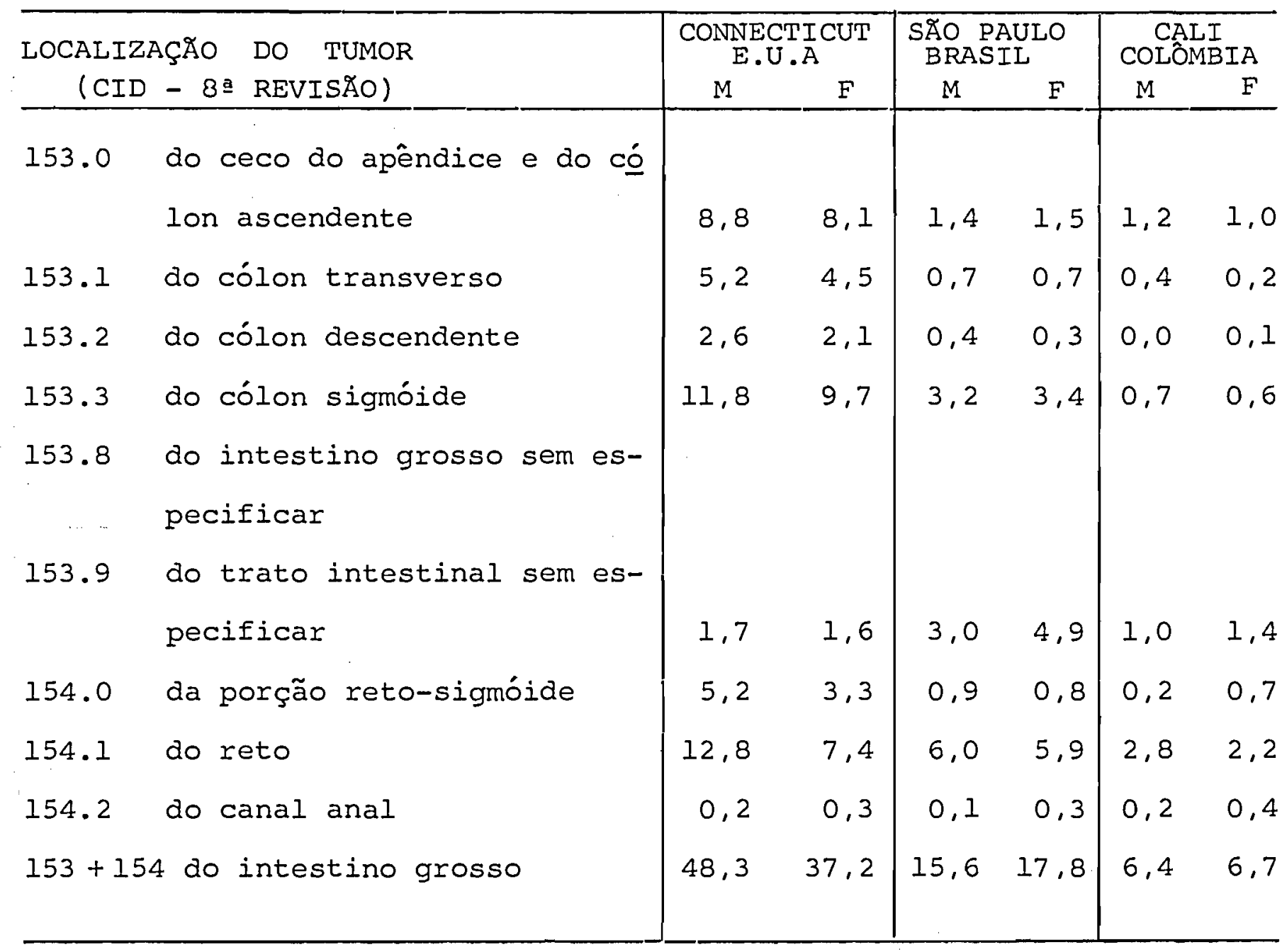

* Padronizada pela população mundial, por 100.000 habitantes

$M=$ Masculino

$F=$ Feminino

Fonte: Cancer incidence in five continents. 85 
COEFICIENTES DE INCIDÊNCIA DE CÂNCER DE RETO E DE CÓLON SEGUNDO SEXO E LOCAIS - 1972 - 1977

\begin{tabular}{l|rrrr}
\hline \multicolumn{1}{c|}{ LOCAIS } & \multicolumn{2}{c}{ RETO } & \multicolumn{2}{c}{ CóLON } \\
\hline São Paulo - 1973 & 7,9 & 6,9 & 11,4 & 9,7 \\
Israel - não judeus 72/76 & 3,1 & 1,5 & 3,3 & 1,8 \\
Cali - Colómbia 72/76 & 3,4 & 2,3 & 4,5 & 5,4 \\
Kingston, St. Andrew - Jamaica 73/77 & 3,7 & 3,8 & 8,7 & 7,5 \\
Cuba 1973/77 & 4,4 & 4,2 & 7,1 & 9,2 \\
Bombaim, fndia 1973/75 & 4,5 & 3,1 & 3,5 & 3,5 \\
Porto Rico, E.U.A.73/77 & 6,2 & 5,1 & 7,6 & 7,8 \\
Zaragoza, Espanha 73/77 & 6,2 & 5,2 & 6,6 & 6,4 \\
Alameda, Califórnia, E.U.A.73/77 pretos & 6,7 & 7,3 & 28,4 & 19,1 \\
Osaka, Japão 73/76 & 7,9 & 4,7 & 7,7 & 6,3 \\
Finlândia 7l/76 & 8,7 & 6,6 & 8,3 & 9,4 \\
Shangai, 1975 & 9,0 & 5,7 & 6,7 & 6,0 \\
Suécia 7l/75 & 10,9 & 7,2 & 16,3 & 15,1 \\
Noruega 73/77 & 11,7 & 8,0 & 14,3 & 14,5 \\
Israel, judeus 72/76 & 13,1 & 11,9 & 13,9 & 12,8 \\
Saskatchewan, Canadá 73/77 & 13,5 & 8,3 & 18,1 & 17,1 \\
Alameda, Califórnia, E.U.A.73/77 brancos & 14,6 & 9,1 & 25,6 & 22,9 \\
British Columbia, Canadá 73/77 & 14,9 & 10,3 & 21,5 & 21,1 \\
Birmingham, Inglaterra 73/76 & 16,7 & 9,1 & 16,3 & 15,8 \\
Connecticut, E.U.A. 73/77 & 17,7 & 11,1 & 32,3 & 26,4 \\
& & & & \\
\hline
\end{tabular}

* Padronizada - População Mundial, por 100.000 habitantes

$M=$ Masculino

$F=$ Feminino

Fonte: Cancer incidence in five continents. 
Nas localidades onde a incidência de câncer de reto e de cólon são baixas, não existem acentuadas diferenças entre os sexos. A medida em que aumèntam os coeficientes de incidencia, passa a haver maior diferencial por sexo. Os cânceres de reto são um pouco mais frequentes entre os homens que entre as mulheres e a razão homem/mulher é da ordem de 1,5; para os cânceres de cólon a razão homem/mulher é menor. 82,89

A incidência de câncer de cólon e de reto, rara em crianças e adolescentes, aumenta com a idade, porém este aumento varia em função da localização do tumor, população e sexo. Para Connec ticut, por exemplo, a incidência de câncer de reto na população masculina é claramente diferenciada do risco da população feminina, a partir da idade de 60 anos, e esta diferença se mantém até o fim da vida. Há um maior risco de câncer de cólon para a população masculina após 65 anos de idade. 38, 75

Estudos sobre câncer de cólon e de reto em populações migrantes indicam que, grupos que migram de áreas com baixa incidência para áreas com alta incidência passam a ter maior risco de câncer de cólon já na la geração de migrantes. 37,38 Japoneses que imi graram para os Estados Unidos da América apresentam mortalidade e morbidade por câncer de cólon semelhantes à população americana quan do se adaptaram ao estilo de vida americano, particularmente quanto aos hábitos alimentares. Com relação ao câncer de reto praticamente não se encontrou diferenças entre grupos imigrantes. A mortalidade por câncer de reto no Japão, tem a mesma magnitude que o da populaÇão branca dos Estados Unidos e também não tem sido observada nenhuma mudança profunda nas taxas para este tipo de câncer entre japoneses nos Estados Unidos. 37,38 
Estudos em outros países sugerem que o câncer de cóIon é mais frequente em pessoas de classe social mais elevada, enquanto que a situação sócio econômica não é significante para o cân cer de reto. 89,90 o aumento da incidência do câncer de cólon entre migrantes de áreas rurais para áreas urbanas tem sido citado para exemplificar a relevância dos fatores ambientais sobre a carcinogêne se do cólon. 83

Com relação ao Brasil, conhece-se a distribuição rela tiva de câncer sólido por localização anatômica do tumor, sexo, idade e área geográfica. Os dados, excluídos as neoplasias dos órgãos linfáticos e hematopoéticos, publicados em "Câncer no Brasil - Dados Histopatológicos $1976-80^{11}$, provém de diagnósticos de ciâncer coletados em 279 laboratórios brasileiros - 90\% dos laboratórios existentes no país. A Tabela 3 evidencia a importância do câncer do intestino grosso, tanto em indivíduos do sexo masculino, quanto nos de sexo feminino. 
DISTRIBUIÇÃO PORCENTUAL DAS DEZ PRIMEIRAS LOCALIZAÇÕES DE CANCER PRIMARIO SEGUNDO SEXO, NO PERIODO 1976 - 1980 BRASIL *

SEXO MASCULINO

\begin{tabular}{lr}
\hline LOCALIZAÇÃo & $\%$ \\
\hline Pele & 28,9 \\
Estômago & 10,6 \\
Roca & 8,5 \\
Glândula prostática & 6,0 \\
Intestino grosso & 4,3 \\
Esôfago & 4,3 \\
Laringe & 4,2 \\
Bexiga urinária & 3,8 \\
Traquéia, brônquio e pulmão & 3,8 \\
Gânglios linfáticos & 3,5 \\
Outras & 22,1 \\
\end{tabular}

SEXO FEMININO

\begin{tabular}{lr}
\hline LOCALIZAÇÃo & $\%$ \\
\hline Colo do útero & 23,7 \\
Pele & 23,4 \\
Mama & 16,5 \\
Intestino grosso & 4,3 \\
Estômago & 3,9 \\
Corpo do útero & 3,0 \\
Boca & 2,3 \\
Ovário & 1,8 \\
Gânglios linfáticos & 1,7 \\
Glândula tireóide & 1,7 \\
Outras & 17,7
\end{tabular}

Fonte: BRUMINI, R (ED) e cols. Câncer no Brasil dados histopatológi$\cos 1976-80^{11}$

* Excluidas neoplasias dos órgãos linfáticos e hematopoéticos 
As informaçōes relativas às regiões geo-econômicas brasileiras mostram que aparentemente, as percentagens de ocorrência de câncer de cólon e de reto no sexo feminino são mais elevadas nas regiões sudeste e Sul (Tabela 4 ).

A distribuição porcentual especifica dos diagnósticos de câncer de reto comunicados no Brasil, por regiões, revela a predo minância dos casos diagnosticados na Região sudeste, contrastando com as demais regiões (Tabela 5). Esta constatação confirma que o câncer de intestino grosso, de modo geral, deve estar relacionado com áreas mais desenvolvidas, com estilo de vida urbano.

T A B E I A

PORCENTAGEM DE CÂNCER DE CÓLON E DE RETO DENTRE AS LOCALIZAÇŌES DE CANCER PRIMARIO SEGUNDO SEXO POR REGIÕES BRASILEIRAS

$$
1976-1980 \text { * }
$$

\begin{tabular}{lcccc}
\hline & $\begin{array}{c}\text { CÂNCER DE CÓLON } \\
\text { MASCULINO }\end{array}$ & \multicolumn{2}{c}{ CÂNCER DE RETO } \\
& 1,3 & 0,9 & 1,8 & 2,1 \\
Região Norte & 1,3 & 1,0 & 1,8 & 1,5 \\
Região Nordeste & 2,0 & 1,3 & 2,3 & 1,4 \\
Região centro oeste & 2,3 & 2,4 & 2,3 & 2,4 \\
Região sudeste & 2,0 & 2,5 & 2,3 & 2,5 \\
Região sul & 2,1 & 2,1 & 2,2 & 2,2 \\
\hline Brasil & & & & FEMININO \\
\hline
\end{tabular}

Fonte: BRUMINI, R (ed) e cols. Câncer no Brasil dados histopato lógicos $1976-8011$

* Excluidas as neoplasias dos órgãos linfáticos e hematopoéticos 
PORCENTAGEM DE DIAGNÓSTICOS DE CÂNCER DE RETO DIAGNOSTICADOS NO BRASIL SEGUNDO SEXO E REGIAOO

$$
1976-1980 \text { * }
$$

\begin{tabular}{|c|c|c|}
\hline REGIX̃O & MASCULINO & FEMININO \\
\hline Norte & 1,5 & 2,3 \\
\hline Nordeste & 10,6 & 12,3 \\
\hline Centro Oeste & 4,3 & 3,3 \\
\hline Sudeste & 63,4 & 63,2 \\
\hline Sul & 20,2 & 18,9 \\
\hline \multirow{2}{*}{ Brasil } & 3791 & 4365 \\
\hline & 100,0 & 100,0 \\
\hline
\end{tabular}

Fonte: BRUMINI, $\mathrm{R}$ (ed) e cols. Câncer no Brasil dados histopatológicos 1976 - $1980^{11}$

* Excluidas as neoplasias dos órgãos linfáticos e hematopoéticos

Com relação à distribuição etária, os pacientes diagnosticados com câncer de reto no Brasil, no periodo de 1976 a 1980 , apresentaram idade média e idade mediana de 57 e 60 anos, respectiva mente, entre os de sexo masculino, e 58 e 60 anos, entre os de sexo feminino.

Para cidades brasileiras como Recife e São Paulo, em função da existência de Registros de Câncer com base populacional, é possivel conhecer a incidência de câncer de reto por idade e sexo (Tabela 6). 69, 85, 86 A Figura 4 evidencia 0 alto coeficiente de in 
MEDIA NNUAL DE INCIDENCIA DE CANCER DE RE'HO POR 100.000 IIAHTHAIIISE SEGUNDO IDNDE E SEXO PAIU RECIFE, SXO PNULO E CONNECHICU'T

\begin{tabular}{|c|c|c|c|c|c|c|}
\hline \multirow{3}{*}{$\begin{array}{l}\text { (iliurOS El'́́lRIOS } \\
\text { (nNOS) }\end{array}$} & \multicolumn{2}{|c|}{ RECIFE } & \multirow{2}{*}{\multicolumn{2}{|c|}{$\begin{array}{c}\text { SXO PNULO } \\
1973 \\
\end{array}$}} & \multicolumn{2}{|c|}{ 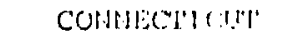 } \\
\hline & \multicolumn{2}{|c|}{$1908 \wedge 1971$} & & & \multicolumn{2}{|c|}{$1973 \times 1971$} \\
\hline & $M$ & $F$ & $M$ & $F^{\prime}$ & $M$ & j: \\
\hline $10 \longmapsto 15$ & - & - & 0,3 & - & - & - \\
\hline $15 \longmapsto 20$ & - & - & 0.3 & - & - & - \\
\hline $20 \longmapsto 25$ & 0,4 & 0,7 & 0,3 & 0,6 & 0,2 & - \\
\hline $25 \longmapsto 30$ & 0,5 & 0,4 & 0.6 & 0.5 & 0,2 & - \\
\hline $30 \longmapsto 35$ & 1,3 & 0,6 & 1,5 & 2,7 & 0,8 & 1.0 \\
\hline $35 \longmapsto 40$ & 0,8 & 5,2 & 2,3 & 3.1 & 1,7 & 2,3 \\
\hline $40 \longmapsto 45$ & 4.0 & 5,3 & 1,0 & 5,6 & 3.4 & 4,8 \\
\hline $45 \longmapsto 50$ & 3,8 & 14,6 & 7,3 & 9,4 & 14,4 & 8,2 \\
\hline $50 \longmapsto 55$ & 4,9 & 18,7 & 10,9 & 15,9 & 25,1 & 19,6 \\
\hline $55 \longmapsto 60$. & 4,9 & 22,0 & 16,1 & 18,9 & 46.4 & 30,2 \\
\hline $60 \longmapsto-65$ & 9.1 & 31.9 & 32,4 & $21 ; 0$ & 83,9 & 43,7 \\
\hline $65 \longmapsto 70$ & 21.6 & 29.1 & 34.0 & 32.8 & 117.7 & 71.2 \\
\hline $70 \longmapsto 75$ & 15,4 & 41,9 & 84.4 & 31,0 & 141,9 & 78.6 \\
\hline $751-80$ & 13,5 & 33,0 & $63,3^{\star}$ & $40,0^{\star}$ & 181,2 & 98,1 \\
\hline $80 \longmapsto 85$ & 32,9 & 48.7 & & & 198,4 & 141.6 \\
\hline $85 \cdot e+$ & - & 64.7 & & & 155,3 & 164,7 \\
\hline
\end{tabular}

85. 86

Fonte: Cancer Incidence in five Continents

* Refcre-se a 75 anos e+ 

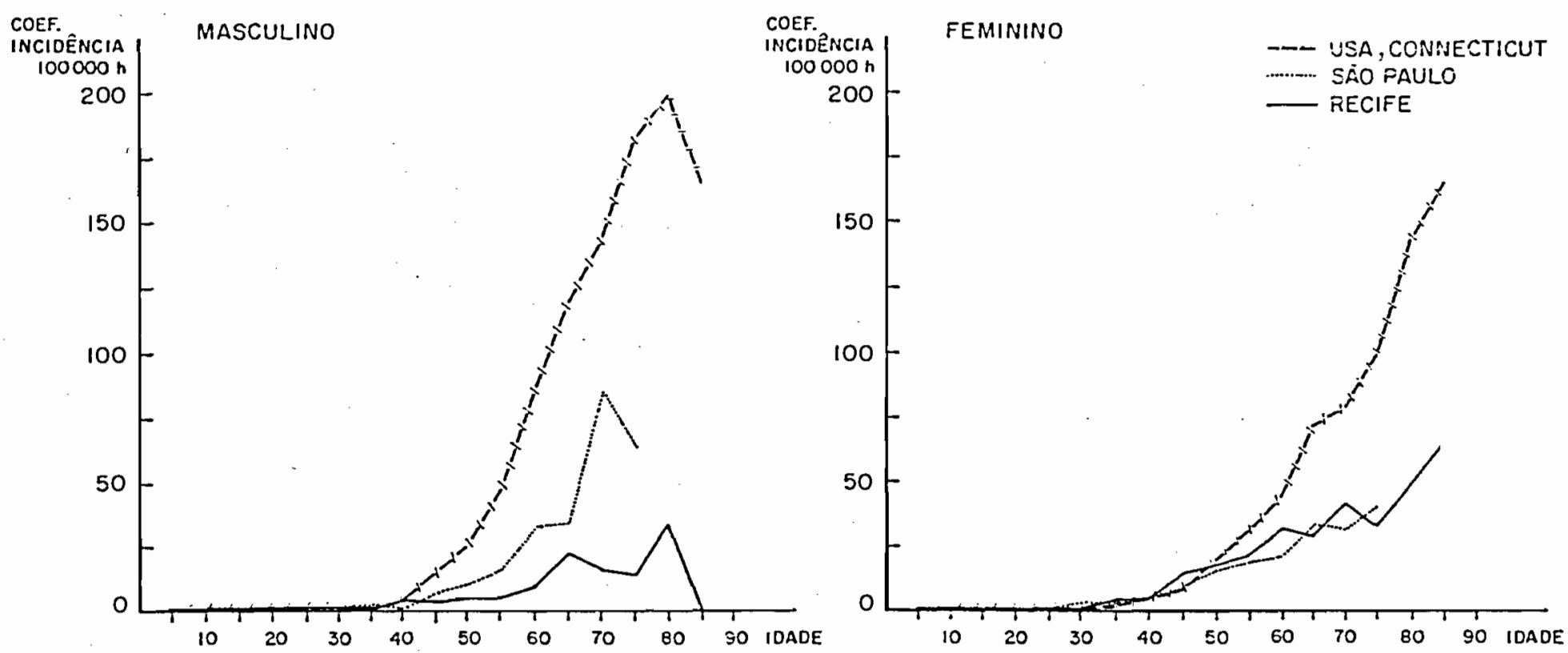

FONTE : CANCER INCIDENCE IN FIVE CONTINENTS - 65,86

FIGURA 4 - COEFICIENTE DE INCIOÊNCIA DE CÃNCER DE RETO POR 100.000 HABITANTES POR IOADE E SEXO PARA RECIFE (1968-1971), SÃO PAULO (1973)

E CONNECTICUT (1973-1977) 
cidência de câncer de reto segundo sexo e idade, para connecticut, em comparação com a incidência observada nas áreas brasileiras. Com parativamente, São Paulo apresenta incidência maior do que a de Recife com variações de incidência na distribuição etária e, principalmente, no sexo masculino.

Quanto a mortalidade, no Município de de São Paulo, - coeficiente de mortalidade por câncer de reto, em 1982, foi de 1,79 por 100.000 habitantes masculinos e 2,04 por 100.000 habitantes do sexo feminino. A mortalidade proporcional, em relação ao total de óbitos por câncer, foi para os homens igual a $0,7 \%$ e igual a $1,1 \%$ para as mulheres. 31

Vários estudos tem sido elaborados, enfocando aspec tos epidemiológicos e etiológicos, fundamentalmente do câncer de có lon $e$, em menor proporção do câncer de reto. $3,8,12,13,14,15$, $33,35,55,58,59,82,91$ E tida como válida a hipótese de que o aparecimento do câncer de cólon e de reto esteja relacionado tanto a fatores intrínsecos ao próprio indivíduo, quanto a fatores extrín secos, isto é, encontráveis no meio ambiente ao qual se expõe. Por um lado, existem populações que carregam problemas genéticos, tais como as doenças poliadenomatosas e déficits imunitários. Por outro lado, ao nível do intestino, podem se desenvolver quer lesões benig mas, que num segundo estágio podem degenerar, quer tumores malígnos, provocados por substâncias mutagênicas, ou pela ação do meio ambiente. 8, 91 Em decorrência da exposição múltipla à poluição do ar, da água e do meio ambiente de trabalho, bem como em consequência de opcão individual por dieta alimentar, o meio ambiente tem sị do responsabilizado por $80 \%$ da incidência de câncer. 43 
sim chamadas doenças da civilização ocidental.1, 82 HIGGINSON et al 42, 43 associaram a incidência de câncer de intestino grosso ao desenvolvimento econômico de uma região ou país, ressaltando ainda que este tipo de câncer está mais intimamente relacionado ao hábito alimentar. Da mesma forma, ADENIS et al $(1979)^{l}$ relataram que a fal ta ou excesso de alguns alimentos, fatores que podem levar ao câncer, estão associados ao modo de vida dos individuos.

A alimentação pode modificar a incidência desses cân ceres de duas maneiras: a) pelo aumento do número de carcinógenos diretos e, b) por uma influência indireta do regime alimentar (papel de co-fator ou de promotor) sobre as possibilidades de ação desses carcinógenos. 36,43

Duas teorias principais são propostas para explicar a influência de determinados fatores alimentares sobre o câncer de cólon e de reto.

A primeira é de WYNDER e SHIGEMATSU $(1967)^{89}$ que incrimina essencialmente uma alimentação desequilibrada em gorduras, quantitativa e qualitativamente, com um aumento anormal dos ácidos graxos saturados e dos ácidos biliares endógenos, cuja secreção é particularmente estimulada pela ingestão de proteína ou gordura de origem animal e que são convertidos pela flora intestinal em carcinógeno ou co-carcinógeno.

A segunda é de BURKITT $(1971)^{13}$ que trata do consumo de hidratos de carbono com excessivo refino sob as mais diversas for mas, com diminuição das fibras alimentares. Esta diminuição de fibras aumenta o tempo de trânsito intestinal, favorece a constipação, diminui o volume dos sais, com uma modificação da flora, em particuu 
lar, um acréscimo anormal da flora anaeróbica, com transformação dos sais biliares. Esta teoria foi formulada com base em observação das populações primitivas africanas que consomem principalmente alimen tos vegetais, excretam uma massa fecal volumosa e praticamente não têm cânceres intestinais. Isto resultaria, por um lado, em um efeito protetor, pela diluição dos carcinógenos eventualmente presentes no intestino $e$, por outro lado, na aceleração do trânsito, com consequente diminuição do tempo de contato das fezes com as mucosas in testinais. 14,82

Estudos do tipo caso-controle, realizados em diversos paises, procuram identificar possiveis fatores de risco relacionados ao câncer de cólon e de reto com ênfase nos fatores alimen tares. $6,23,34,39,40,42,47,49,67,71,78,89,90$ contudo, ainda não se tem, de modo conclusivo, a identificação dos principais fatores que agem na carcinogênese do cólon e do reto.

As duas teorias mencionadas tem sido enfocadas fundamentalmente para o câncer de cólon, com conclusões divergentes en tre autores. Para o câncer de reto tem-se pesquisado todos os possí veis fatores de risco que se estuda para o cólon, porém, o único que foi identificado como possivel fator de risco é o consumo de cerveja, em áreas de alto consumo, contudo, sem apresentar conclusões concordantes entre todos os estudos. $6,7,42,76,78,81,89$, 90

Na revisão bibliográfica feita não se encontrou trabalho do tipo caso-controle exclusivo para câncer de reto. Justifica-se o presente estudo, na medida em que se tenta encontrar fatores de risco que poderiam, em nosso meio, atuar no processo de aparecimento do câncer de reto. 


\section{2- OBJETIVO}

o objetivo do présente trabalho é estudar associaçāo entre câncer do reto e possíveis fatores de risco: consumo de bebidas alcoólicas, hábito de fumar, consumo de certos alimentos, condições sócio-demográficas, hábito intestinal. 
3- HIPÓTESES DE TRABALHO

Com base na bibliografia, foram formuladas as seguintes hipóteses de associação entre as variáveis definidas e o câncer de reto:

3.1- A ingestão de cerveja constitui fator de risco em relação ao câncer de reto.

3.2- A dieta alimentar composta de baixo consumo de verduras e de frutas e de alto consumo de alimentos ricos em gordura animal, constitui fator de risco em relação ao câncer de reto. 
4- MATERIAL E MÉTODO

Os dados do presente trabalho foram coletados para o "Estudo Epidemiológico de Câncer de Esôfago e de Reto no Município de São Paulo", pesquisa desenvolvida pelo Departamento de Epidemiolo gia da Faculdade de Saúde Pública, através do Registro de Câncer de São Paulo realizada com suporte financeiro parcial do Louisiana State University Medical Center e do United States National Cancer Institute, "Grant" Wol.

\section{1- SELEÇÃO DOS CASOS E DOS CONTROLES}

\section{Caso:}

Paciente atendido ambulatorialmente, ou internado em hospital do Município de são Paulo, portador de Câncer primário de reto, com comprovação histológica. Foram considerados os 100 primeiros casos novos, ou recém diagnosticados, ou em início de tratamento radioterápico, conhecidos no período entre lo de setembro de 1978 a 17 de março de 1981 .

\section{Controle:}

I- Paciente atendido ambulatorialmente, ou internado preferencialmen te no mesmo hospital do.caso, sem patologia de câncer de reto, parea do com o caso, segundo sexo e idade (quinquênio etário igual, acima ou abaixo da idade do caso).

II- Paciente atendido ambulatorialmente, ou internado preferencialmente no mesmo hospital do caso, sem patologia de câncer de laringe, 
da boca, do esôfago, do pulmão, pareado com caso de câncer de esôfago, segundo sexo e idade (quinquênio etário igual, acima ou abaixo da idade do caso).

Os controles pareados, sob forma I, em conjunto com os casos, constituem a denominada "amostra pareada"; os controles de esôfago (forma II), em conjunto com os controles pareados de reto (forma I) e os casos de câncer de reto constituem a "amostra global". Esta, quando trabalhada sob forma de estrato, é a "amostra estratifi cada" .

Foram enviadas cartas aos diretores dos principais hospitais do Município de são Paulo que atendem os pacientes portado res de câncer, solicitando-lhes a colaboração para que entrevistadores médicos pudessem realizar as entrevistas com os pacientes. Após - recebimento da anuência da colaboração solicitada, estruturou-se um mecanismo de identificação dos casos internados ou atendidos ambulatorialmente. Em alguns hospitais funcionou o sistema de notifica ção imediata aos coordenadores da pesquisa; em outros, os entrevista dores passavam semanalmente para verificar a existência de novos ca sos.

Localizado o paciente no hospital, realizava-se a entrevista o mais rápido possível. Após entrevistar o caso, imediatamente elegia-se o controle respectivo procedendo-se o rodízio nas clínicas, para a realização da entrevista, no mesmo hospital. Em algumas situações, houve dificuldade para se identificar um controle específico no mesmo hospital do caso, adotando-se, como alternativa, a seleção em outro hospital.

A distribuição dos casos e controles segundo hospitais do Município de São Paulo é mostrada na Tabela 7. 
DISTRIBUIÇÃO DAS ENTREVISTAS FEITAS SEGUNDO HOSPITAL E TIPO DE PARTICIPAÇAO NO ESTUDO

PERIODO 01/09/1978 a 17/03/1981

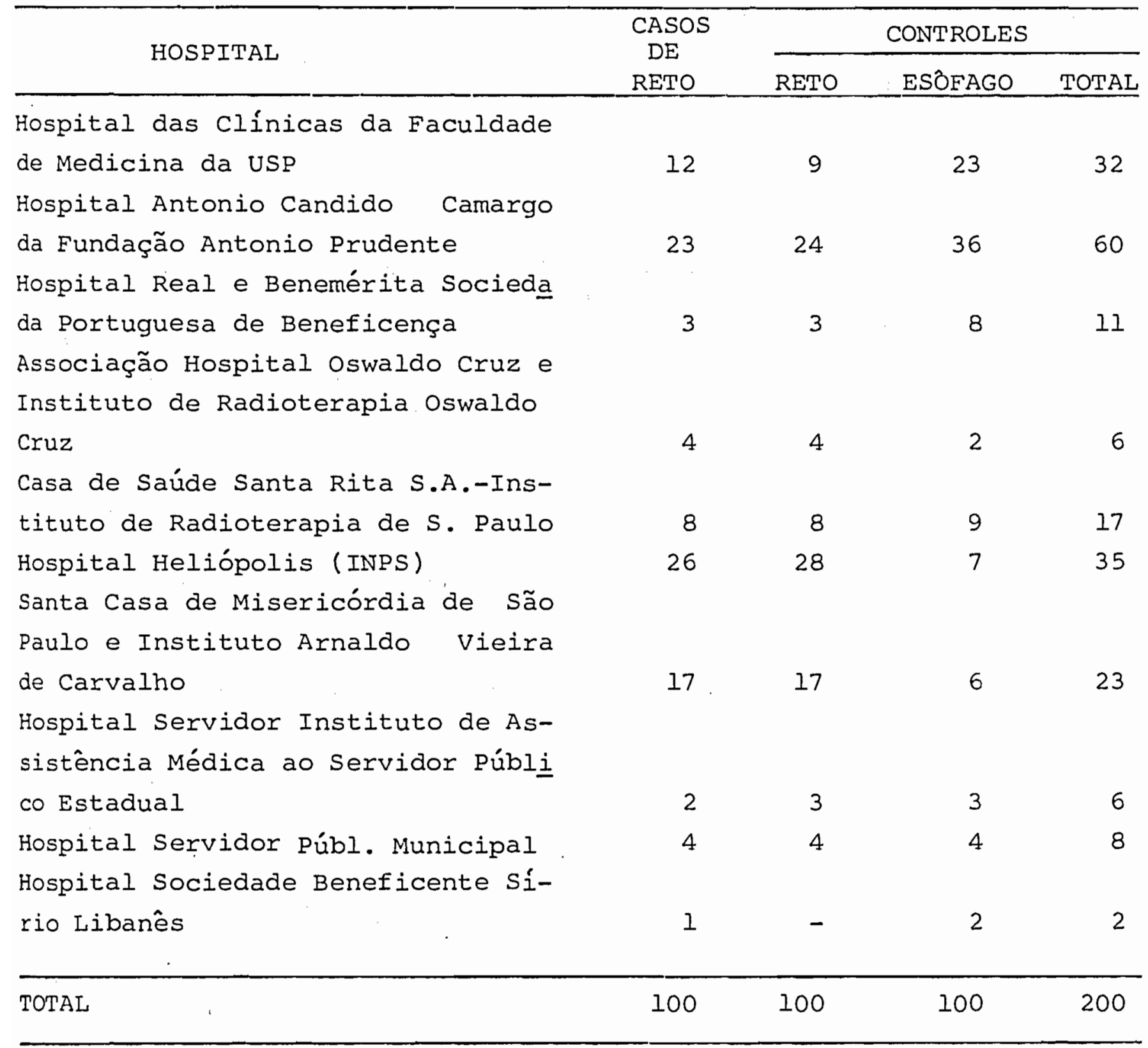


Após a análise dos formulários foram excluídos 8 casos de câncer de reto que apresentavam resultados anátomo-patológicos que poderiam levar a dúvida quanto ao seu comportamento epidemio lógico (Tabela 8).

T A B E L A

CLASSIFICAÇAO HISTOLÓGICA DOS TUMORES EXCLUIDOS DO ESTUDO

\begin{tabular}{|c|c|c|}
\hline $\begin{array}{l}\text { CLASS IFI } \\
\text { CAÇףO } \\
(\text { CID-O) }\end{array}$ & 19 & ESPECIFICAÇÃO \\
\hline 8010 & - & $\begin{array}{l}\text { carcinoma SOE - o material não permitiu esta- } \\
\text { belecer característica da neoplasia }\end{array}$ \\
\hline 8041 & - & carcinoma de cálulas pequenas \\
\hline 8070 & - & carcinoma epidermoide, SOE \\
\hline 8124 & - & carcinoma cloacogênico \\
\hline 8140 & - & adenoma, SOE - reto sigmóide \\
\hline 8261 & - & adenoma viloso de reto \\
\hline 8890 & - & leiomiossarcoma \\
\hline 9990 & - & sem exame microscópico \\
\hline
\end{tabular}


São objeto de análise, portanto, 92 casos de câncer de reto, classificados histologicamente como adenocarcinoma, em suas modalidades, conforme a Tabela 9.

T A B E I A

TIPOS DE TUMORES QUE FIZERAM PARTE DO PRESENTE ESTUDO, SEGUNDO CLASSIFICAÇÃO HISTOLÓGICA

\begin{tabular}{llr}
\hline CLASSIFICAÇAO (CID - 0)19 & $\begin{array}{r}\text { No DE } \\
\text { CASOS }\end{array}$ \\
8140 & adenocarcinoma, SOE & 77 \\
8211 & adenocarcinoma tubular & 1 \\
8260 & adenocarcinoma papilar, sOE & 5 \\
8481 & adenocarcinoma produtor & 6 \\
8480 & de mucina & 3 \\
\hline TOTAL & adenocarcinoma mucinoso & 92 \\
\hline
\end{tabular}


Os casos de reto foram considerados com base no diag nóstico hospitalar, identificado por meio da Classificação Internacional de Doenças. 63 Apenas 7 casos foram classificados como tumor malígno da porção reto-sigmóide (Tabela 10).

T A B E L A 10

CASOS DE CANCER DE RETO SEGUNDO CLASSIFICAÇÃO

DO DIAGNÓSTICO HOSPITALAR

\begin{tabular}{llc}
$\begin{array}{l}\text { CÓDIGO } \\
\text { CID 63 }\end{array}$ & $\begin{array}{c}\text { No DE } \\
\text { CASOS }\end{array}$ \\
\hline 154.0 & $\begin{array}{c}\text { tumor maligno da porção } \\
\text { reto-sigmóide }\end{array}$ & 7 \\
154.1 & tumor malígno do reto & 85 \\
\hline TOTAL & & 92 \\
\hline
\end{tabular}


Os casos foram considerados ainda em termos da locali zação exata do tumor, em relação à distância do ânus ou da linha pẹ tínea (Tabela 11).

T A B E L A 11

NÚMERO DE CASOS DE CÂNCER DE RETO, SEGUNDO LOCALIZAÇÃO EXATA DO TUMOR, EM TERMOS DE DISTÂNCIA DO ANUS OU DA LINHA PECTINEA

\begin{tabular}{lcccc}
\hline LOCALIZAÇÃo & \multicolumn{2}{c}{ DISTANCIA } & NO DE \\
\hline reto baixo & Do ANUS & DA LINHA PECTINEA & CASOS \\
reto médio & $0-5 \mathrm{~cm}$ & $0-4 \mathrm{~cm}$ & 18 \\
reto alto & $6-10 \mathrm{~cm}$ & $5-9 \mathrm{~cm}$ & 20 \\
especificado apenas reto & $11-15 \mathrm{~cm}$ & $10-14 \mathrm{~cm}$ & 14 \\
\hline
\end{tabular}

Há problemas nas diferentes definições de reto e de cólon. Alguns adotam como limite superior do reto a distância de 19 $\mathrm{cm}$ do ânus, outros a de $13 \mathrm{~cm}$. Outros ainda acham que o câncer na me tade superior do reto, isto é, aquele situado a $8 \mathrm{~cm}$ do ânus, está epidemiologicamente relacionado com o câncer de cólon. ${ }^{2}$

Não existe uma definição única, padronizada em termos de consideração da localização do tumor no reto. No estudo caso-controle de câncer de intestino grosso de japoneses no Japão, os autores consideraram reto baixo aquele com menos de $9 \mathrm{~cm}$ de distância do 
ânus. 39 Praticamente os mesmos autores, ao analisarem os dados refe rentes de japoneses de três Prefeituras no Japão, adotaram como critério de reto baixo, o tumor localizado abaixo de $6 \mathrm{~cm}$ de distância do ânus. ${ }^{40}$ Num estudo epidemiológico de câncer de cólon e de reto, desenvolvido na Argentina, 4 considerou-se reto baixo quando o polo inferior do tumor ou todo ele podia ser apalpado por meio do toque retal.

No presente estudo, embora no delineamento inicial tenham sido constituídos 3 tipos de localização, considera-se como reto baixo aquele que dista até $10 \mathrm{~cm}$ (inclusive) do ânus, incorporando, portanto, os que originalmente foram considerados como reto médio, totalizando 38 casos de reto baixo (Tabela 11).

Dos 92 casos de câncer de reto entrevistados, 50 são do sexo feminino e 42 do sexo masculino. As variáveis sexo e idade (quinquênio etário igual, acima ou abaixo daquele observado para o caso) foram usadas no pareamento dos controles, forçando, portanto, a concordância desses atributos entre os casos e os controles, que constituem a amostra pareada (Tabela 12). Estas duas variáveis foram utilizadas para a constituição de estratos, em quatro grupos: 1- feminino, menor ou igual a 60 anos; 2- feminino, maior do que 60 anos; 3- masculino, menor ou igual a 60 anos e 4-masculino, maior do que 60 anos.

Os controles pareados e os controles globais (controles de casos de câncer de reto e os controles de câncer de esôfago, em conjunto), tem a distribuição dos seus diagnósticos apresentada na Tabela 13. Observam-se proporções elevadas de pacientes com neoplasias (exceto os dos órgãos digestivos e do peritônio), em decorrência do tipo de hospital utilizado. 
T A B E L A 12

NÚMERO E PORCENTAGEM DE CASOS DE CANCER DE RETO E

DE CONTROLES, SEGUNDO GRUPOS ETRRIOS E SEXO

SAO PAULO, 01/09/78 a 17/03/81

\begin{tabular}{|c|c|c|c|c|c|c|c|}
\hline \multirow{2}{*}{\multicolumn{2}{|c|}{$\begin{array}{c}\text { GRUPOS ETKRIOS } \\
\text { (ANOS) } \\
\end{array}$}} & \multicolumn{2}{|c|}{ CASO } & \multicolumn{2}{|c|}{$\begin{array}{l}\text { COIJTROLE } \\
\text { PAREADO }\end{array}$} & \multicolumn{2}{|c|}{$\begin{array}{l}\text { CONTROLE } \\
\text { GLOBAL }\end{array}$} \\
\hline & & \multirow{2}{*}{$\frac{\text { № }}{-}$} & \multirow{2}{*}{$\%$} & \multirow{2}{*}{$\frac{\text { N2 }}{-}$} & \multirow[t]{2}{*}{$\%$} & \multirow{3}{*}{$\frac{N 2}{1}$} & \multirow{2}{*}{$\frac{\%}{0.5}$} \\
\hline Feninino & $201-25$ & & & & & & \\
\hline & $251 ـ 30$ & - & - & - & & & \\
\hline & $30 \longleftarrow 35$ & 2 & 2,2 & 4 & 4,3 & 4 & 2,0 \\
\hline & $351-40$ & 2 & 2,2 & - & & 2 & 1,0 \\
\hline & $40 \longmapsto 45$ & 2 & 2,2 & 4. & 4,3 & 4 & 2,0 \\
\hline & $451-50$ & 8 & 8.7 & 5 & 5,4 & 9 & 4,5 \\
\hline & $50 \longmapsto 55$ & 5 & 5,4 & 8 & 8,8 & 12 & 6,0 \\
\hline & $55 \longmapsto 60$ & 10 & 10,8 & 7 & 7.6 & 9 & 4,5 \\
\hline & $60 \longmapsto 65$ & 3 & 3,3 & 8 & 8,7 & 14 & 7,0 \\
\hline & $65 \longmapsto 70$ & 8 & 8,7 & 4 & 4,3 & 7 & 3,5 \\
\hline & $70 \longmapsto 75$ & 9 & 9,7 & 6 & 6.5 & 9 & 4,5 \\
\hline & $75 \longmapsto 80$ & - & & 3 & 3.3 & 4 & 2,0 \\
\hline & $80 \longmapsto$ & 1 & 1,1 & 1 & 1.1 & 2 & 1.0 \\
\hline & TOTAL & 50 & 54,3 & 50 & 54,3 & 77 & 38,5 \\
\hline & IDADE MÉDIA & 57. & & 57, & & 57. & \\
\hline & DESVIO PADRAOO & 11. & & 12 , & & 12,6 & \\
\hline & IDADE MEDIANA & 58, & & 58. & & $58, c$ & \\
\hline MASCULINC & & & & & & 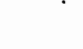 & \\
\hline & $20 \longmapsto 25$ & 1 & 1.1 & 1 & 1,1 & 1 & 0.5 \\
\hline & $25 \longmapsto 30$ & 1 & 1.1 & 1 & 1,1 & 1 & 0.5 \\
\hline & $30 \longmapsto 35$ & 1 & 1,1 & 1 . & 1,1 & 2 & 1,0 \\
\hline & $35 \longmapsto 40$ & 1 & 1,1 & 1 & 1,1 & 1 & 0,5 \\
\hline & $40 \longmapsto 45$ & - & - & 2 & 2,2 & 6 & 3.0 \\
\hline & $45 \longmapsto 50$ & 3 & 3.3 & 1 & 1,1 & 16 & 8.0 \\
\hline & $50 \longmapsto 55$ & 7 & 7,6 & 10 & 10.8 & 24 & 12,0 \\
\hline & $55 \longmapsto 60$ & 6 & 6,5 & 2 & 2,2 & 19 & 9.5 \\
\hline & $60 \longmapsto 65$ & 8 & 8,7 & 8 & 8,7 & 18 & 9.0 \\
\hline & $65 \longmapsto 70$ & 5 & 5,4 & 6 & 6,5 & 17 & 8,5 \\
\hline & $70 \longmapsto 75$ & 1 & 1,1 & 1 & 1,1 & 6 & 3.0 \\
\hline & $75 \longmapsto 80$ & 6 & 6.5 & 6 & 6.5 & 10 & 5.0 \\
\hline & $80 \longmapsto$ & 2 & 2,2 & 1 & 1,1 & 1 & 0.5 \\
\hline & $85 \longmapsto 90$ & - & & 1 & 1,1 & 1 & 0.5 \\
\hline & TOTAL & 42 & 45,7 & 42 & 45,7 & 123 & 61,5 \\
\hline & IDADE MEDIA & 59, & & 59, & & 57.8 & \\
\hline & DESVIO PADRKO & 14 , & & 14, & & 11,6 & \\
\hline & IDNDE MEDINIA & 60. & & 60. & & 57.0 & \\
\hline TOT & GERAL & 92 & 100,0 & 92 & 100,0 & 200 & 100,0 \\
\hline IDAL & MÉdIA & 58, & & 58, & & 57.4 & \\
\hline DES & PADRAO & 12. & & 13. & & 12,0 & \\
\hline IDAL & MEDIANA & 58. & & 58, & & $57, c$ & \\
\hline
\end{tabular}


NÚMERO E PORCENTAGEM DE CONTROJES PAREADOS E GLOBAIS SEGUNDO GRUPOS DE DIAGNÓSTICOS APRESENTADOS E SEXO

SRO PAULO, 01/09/78 a 17/03/81

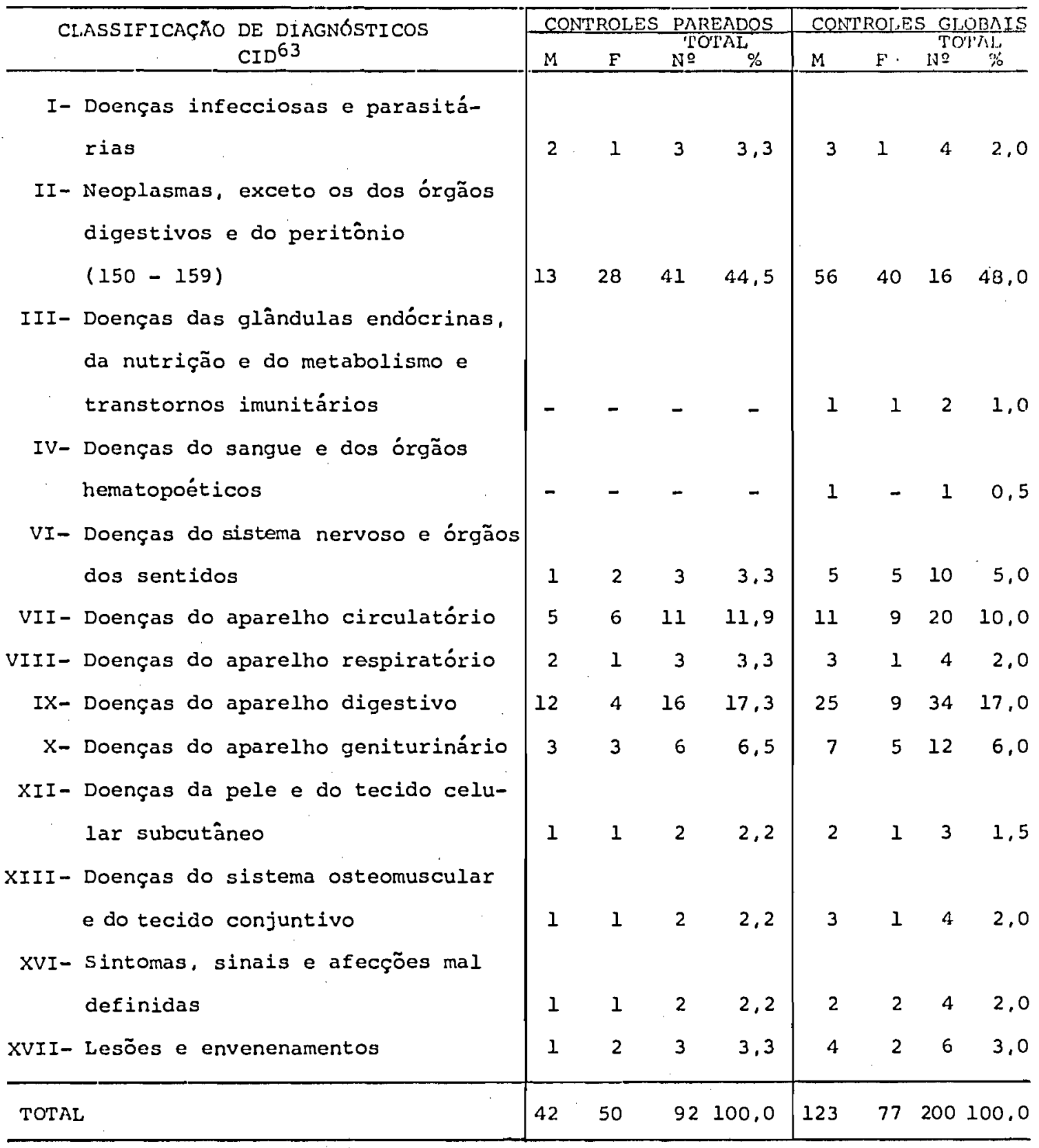

$M=$ Masculino

$F=$ Feminino 


\section{2- INSTRUMENTO DE COLETA DE DADOS}

Um formulário (Anexo) previamente testado, foi aplicado por médico entrevistador aos pacientes identificados. O for mulário era composto de elementos de identificação, de variáveis sócio-demográficas e de aspectos relevantes aos possiveis fatores de risco e variáveis de confusão: hábito de fumar, uso de laxantes, con sumo de bebidas e de alimentos, entre outros. A parte clínica, especialmente a localização exata do tumor e achados histológicos, foi obtida mediante utilização do prontuário.

As questões referentes à dieta foram formuladas visan do detectar a frequência de consumo habitual dos alimentos e tipos de preparo, entendido como hábito alimentar "costumeiro" aquele antes do aparecimento dos sintomas da doença.

\section{3- DESCRIÇÃO DAS VARIAVEIS DE ESTUDO}

\section{- Local de nascimento do entrevistado}

- Naturalidade da mãe

- Naturalidade do pai

- Residência atual do entrevistado

Estas variáveis foram igualmente categorizadas por: Município de são Paulo, Estado de São Paulo (exclusive o Município), Região Sudeste (exclusive São Paulo), Região Norte e Região CentroOeste, Região Nordeste, Região Sul, Países das Américas e Europa, Países asiáticos. 


\section{- Zona de Nascimento:}

Urbana

Rural

- Predominância Total de Zona de Residência:

Definida quando da comparação entre o número de anos vivị dos em zona urbana e zona rural em todas as mudanças de residência.

- Escolaridade

Informada pelo grau de instrução atingido, independentemente se completou ou não:

Analfabeto

Primário

Ginasial

Colegial, Técnico, Normal

Superior

- Hábito de Fumar

Considerando-se os três principais tipos de fumo e as quantidades diárias de cigarros consumidos habitualmente, num gradiente: não fumante, de hábito moderado e de hábito intenso, inclusi ve os de quantidade ignorada.
- CIGARRO SEM FIITRO
- CIGARRO COM FILTRO
- CIGARRO DE PALHA
- Não fuma
- Não fuma
- Não fuma
- I a 20 cigarros
- 1 a 20 cigarros
- 1 a 9 cigarros
- 21 e + cigarros
- 21 e + cigarros
- 10 e + cigarros 


\section{- Quantidade Total de Fumo}

É a combinação dos três tipos de cigarros e das respectị vas quantidades:

Não fuma qualquer dos tipos

Fuma pelo ${ }^{3}$ menos um dos tipos moderadamente

Fuma pelo menos um dos tipos intensamente

\section{- Consumo de Bebidas}

As respostas obtidas foram categorizadas pelo número de doses e de frequência no tempo.

- $\underline{\text { Pinga }}$

- Não bebe

- 1 a 4 doses por semana; fim de semana

- 1 a 4 doses diárias ou mais, inclusive os de quantidade ignorada dose $=30 \mathrm{ml}$
- Cerveja

- Não bebe

- 2 copos por semana; - 1 copo por se1 garrafa por semana; mana; fim de fim de semana; de vez semana; raraem quando

- 1/2 a 3 garrafas ou - 1 a 4 copos ou mais por dia, e os + por dia, e de quantidade igno- os de quantidą rada
- Vinho

- Não bebe mente de ignorada

\section{- Quantidade Total de Bebida:}

Combinação dos três tipos de consumo de bebidas e das

quantidades respectivas

Não bebe

Bebe pouco - bebe pelo menos um dos tipos moderadamente Bebe muito - bebe pelo menos um dos tipos intensamente 


\section{- Consumo de Alimentos:}

Dada a complexidade para a estruturação das opções de consumo alimentar e do tipo de preparo para cada um dos alimentos referidos pelos entrevistados, estabeleceu-se, após análise das respostas apresentadas, categorias em un gradiente, a fim de se per mitir a análise.

Adotou-se como critério que os alimentos individuais ou em grupo mencionados, quando consumidos 3 vezes ou mais por sema na, seriam considerados como de consumo intenso, em relação com o de consumo moderado e o não consumo:

- Carne Bovina Fresca - Carne Bovina Salgada - Carne Bovina Embutida

- Não come

- 1 a 2 vezes por semana moderado,

I vez por mês, e

os de quantidade

ignorada

- e vezes ou + por

semana
- Não come - Não come

- Come qualquer quan - Come qualquer quanti tidade dade 
- Carne Suina Fresca - Carne Suína Salgada

- Não come

- 1 a 2 vezes por semana, 1 vez por mês, e os de quan tidade ignorada

- 3 vezes ou + por semana
- Carne Suína Embutida

- Não come

- Come qualquer quanti dade

\section{- Quantidade Total de Carne Bovina Fresca e}

\section{Carne Suína Fresca}

Não come

Come pelo menos um dos tipos de modo moderado

Come pelo menos um dos tipos de modo intenso

- Aves

- Não come

- 1 a 2 vezes por semana; I vez por mês e os de quantidade ignorada

- 3 vezes ou + por semana
- Peixe Natural

- Não come

- 1 a 2 vezes por semana;

1 vez por mês e os de quantidade ignorada

- 3 vezes ou + por semana
- Peixe Enlatado

- Não come

- 1 a 2 vezes por semana;

1 vez por mês e os de quanti dade ignorada

- 3 vezes ou + por semana 
- Lezгe

- Não bebe

- Bebe ocasionalmente, 1 a 2 vezes por sema na

- 3 vezes ou + por semana

- Frutas

- Não come

- Come ocasionalmente, 1 a 2 vezes por semana, ignorada a periodicidade

- 3 vezes ou + por semana

- Cereais

- NJão come

- Come ocasionalmente, 1 a 2 vezes por semą na, ignorada a perio dicidade

- 3 vezes ou + por semana
- Queijo

- Não come

- Ovos

- Não come

- Come ocasionalmente, - Come ocasionalmente, 1 a 2 vezes por semana

- 3 vezes ou + por semana

- Verduras

- Não come

- Come ocasionalmente, - Come ocasionalmente, 1 a 2 vezes por semana, ignorada a periodicidade

- 3 vezes ou + por semana
1 a 2 vezes por semana

- 3 vezes ou + por semana

- Leguminosas

- Não come

1 a 2 vezes por semana, iganorada a periodicidade

- 3 vezes ou + por semana 
- Raizes e Tubérculos

- Não come

- Come ocasionalmente;

1 a 2 vezes por semana; ignorada a periodicidade

- 3 vezes ou + por semana

- Açucar

(doces, sobremesas)

- Não come

- Ingere ocasionalmente;

1 a 2 vezes por semana; ignorada a periodocidade

- 3 vezes por semana

\section{- Pimenta do Reino}

- Não usa

- Ocasionalmente, 1 a 2 vezes por semana; ignorada a periodicidade

- 3 vezes ou + por semana
- Legumes

- Não come

- Come ocasionalmente; 1 a 2 vezes por sema na; ignorada a perioㅇ dicidade

- 3 vezes ou + por semana

- Gordura (ou óleo)

- Não usa

- Vegetal (margarina. óleo) vegetal + animal ou só animal
- Farinha de Mandioca

- Não come

- Ingere ocasio nalmente; 1 a 2 vezes por semana; ignorada a periodicidade

- 3 vezes ou + por semana

- Pimenta Vermelha Ardida

(malagueta)

- Não usa

- Usa ocasional mente; 1 a 2 vezes por semana; ignorada a periodicidade

- 3 vezes por semana

- Molhos em Geral (catchup, mostarda)

- Não usa

- Usa qualquer quantidade 
- Outros Condimentos

(Orégano, Colorau)

- Não usa

- Usa qualquer quantidade

- Quantidade Total de Temperos

(pimenta malagueta, do reino, molhos em geral, outros condimentos, conservas)

- Não usa

- Usa pelo menos um dos tipos

- Frequência de Evacuação

Relacionada antes do paciente adoecer

Menos de 1 vez por dia

1 vez por dia

2 vezes por dia

3 vezes por dia

\section{- Consistência das Fezes}

Referidas imediatamente antes de adoecer

Pétreas

Duras

Firmes

Amolecidas

Diarréicas

- Prisão de Ventre, no Passado

Medido em número de dias que ficava sem evacuar Não ficava

1 dia

2 dias

3 dias

4 dias

5 dias

6 dias

7 dias

8 dias
- Conservas

(Pickes)

- Não usa

- Usa qualquer quantidade 


\section{- Tipo de Laxante Utilizado}

Após identificação dos componentes dos tipos de laxantes informados com o nome comercial:

- Não usou

- Laxantes de volume, amolecedores fecais

- Laxantes irritantes ou estimulantes

- Presença de Câncer na Família

Apenas com relação aos parentes mais próximos: mãe, pai, irmão e filho

Não

Sim

\section{- Hemorróidas}

Relacionada ao tempo de ocorrência:

Não teve

Teve, 1 a 4 anos atrás

Teve, 5 e mais anos atrás

- Papiloma

Indagado sobre localização e tempo de ocorrência:

Não teve

Teve, reto 1 a 4 anos

Teve, reto 5 e t anos

Teve, outro local 1 a 4 anos

Teve, outro local 5 e + anos 


\section{4- ANALISE ESTATISTICA}

As comparações dos casos com os controles, em reláção às variáveis que podem estar ligadas à etiologia do câncer de reto, foram feitas para os três tipos de amostras consideradas:

1 - Amostra pareada - os controles foram pareados aos casos por idade e sexo, totalizando 92 pares;

2 - Amostra global - os casos de reto foram comparados com todos os controles entrevistados (os de câncer de reto e os de câncer de esôfago). Totalizam 92 casos e 200 controles sem levar em conta a estratificação ou pareamento;

3 - Amostra estratificada - os componentes da amostra global ou seja, os 92 casos e os 200 controles, foram estratificados por idade e sexo, Constituindo 4 estratos, a saber:

a- Feminino menor ou igual a 60 anos; b- Feminino maior do que 60 anos; C- Masculino menor ou igual a 60 anos e d- Masculino maior do que 60 anos. A idade de 60 anos foi adotada por corresponder à idade mediana observada entre os casos.

Cada variável foi inicialmente analisada em separado, considerando-se os sexos em conjunto e em separado, sem estabelecer sua interrelação com as demais.

As estimativas dos Riscos Relativos (RR) por ponto e respectivos testes de significância foram calculados para cada tipo de amostra, considerando-se os contrastes dicotômicos entre ter o fator ou a característica presente em relação a não'ter o fator ou ' a característica presente. Utilizou-se procedimento de máxima verossimi lhança condicional (LUBIN (1981) 57, SCHLESSELMAN (1982) 79 BRESLOW Day $(1980)^{10}$ ) para a amostra estratificada (Programa PECAN III) e o 
procedimento clássico, para as amostras pareada e global 10, 57,60, $61,79$.

As variáveis que nas três amostras apresentaram Riscos Relativos com significância estatística ao nível de $5 \%$ foram des tacadas para o aprofundamentos da análise, utilizando-se técnica mul tivariada 10, 57, 79 para se detectar a força de associação em presença de outras variáveis.

Os Riscos Relativos foram obtidos por meio do modelo de regressão linear logística no qual um número de variáveis pode ser levado em consideração simultaneamente, controlando-se o efeito de possiveis variáveis de confusão. A utilização deste modelo logístico, por meio da estratificação dos controles e dos casos por idade e sexo, permite reter o pareamento e o ajuste para variáveis que não foram controladas no estudo. Fez-se os respectivos testes de hipóteses a um nivel de $5 \% 10,57,79$.

As estimativas de intervalo de confiança para os riscos relativos de câncer de reto foram calculadas a partir do $\mathrm{x}^{2}$ sintético de MANTEL-HAENSZEL (1959) ${ }^{60}$ pela técnica de MIETTINEN (1969) 66 apenas para os fatores de riscos considerados significantes ao final da análise. Completou-se a análise com teste de hipóteses de gradien te (tendência), usando metodologia proposta por MANTEL (1963) 61, como extensão da de MANTEL-HAENSZEL (1959) 60 .

Uma vez detectada a significância estatística de variáveis relacionadas com os casos de reto, analisou-se o comportamen to destas em relação aos casos de reto baixo (tumor localizado a menos de $10 \mathrm{~cm}$ de distância do ânus), adotando-se os mesmos critérios de análise estatística que os aplicados na totalidade dos casos de 
cäncer de reto.

A relação do consumo de bebidas e câncer de reto também foi estudada por meio de análise multivariada, em que foram consideradas como variáveis de confusão aquelas que apresentaram significância estatística ao nível de 5\% nas três amostras, acrescidas da variável FUMO TOTAL (hábito de fumar qualquer um dos tipos de cigarro, em conjunto ou em separado).

\section{5- APRESENTAÇAO DOS RESULTADOS}

Os resultados são apresentados mediante tabelas, com a distribuição de casos e de controles nas amostra pareada e global. Para a amostra estratificada (constituída de 4 estratos) são apresentados os resultados encontrados em termos de valores dos Riscos Relativos (RR) e seu nível de significância descritivo ( $p)$, constituindo um resumo dos achados referentes aos três tipos de amostra. 


\section{1- CARACTERIZAÇÃO SÓCIO-DEMOGRÁFICA DOS INDIVIDUOS AMOSTRADOS}

A distribuição por local de nascimento apresenta variações entre os casos e controles (Tabela 14). Predominam os nascidos no Estado de São Paulo; há diferenças nas proporções de nascidos no Nordeste e no Exterior. Entre os casos, 10,9\% são nordestinos e 18,5\% são estrangeiros, ao passo que, entre os controles, pareados, ou "globais", estas proporções são de $31,5 \%$ e $6,5 \%$ e $25,5 \%$ e $11,0 \%$ respectivamente.

Ao se analisar o local de nascimento em duas categorias apenas: "ser do Nordeste" e "não ser do Nordeste" (Tabela 15), verifica-se que os casos de câncer de reto são oriundos em menor prô porção do Nordeste, diferindo dos grupos controles. Os resultados são significantes com nível descritivo (p) inferior a 0.01 , quer se considere o grupo controle pareado, quer o global, ou o estratificado (Tabela 15). Assim, o fato de ser oriundo de outras localidacies que não o Nordeste, está associado a maior risco de ter câncer de re to.

Quando se analisa discriminadamente, por sexo, não se observa significância estatística para o sexo masculino em quaisquer das amostras. Para o sexo feminino encontram-se riscos relativos (RR) de $3,22(0,01<p<0,05)$ para o grupo controle pareado e 4,17 $(0,01<\mathrm{p}<0,05)$ para o grupo global. 
Na Tabela 16, vê-se que $30,4 \%$ das mães dos pacientes com câncer de reto nasceram no Estado de São Paulo, 13,0\% no Nordes te e $33,7 \%$ no Exterior, enquanto que entre os controles pareados, $26,0 \%$ são do Estado de São Paulo, $31,5 \%$ do Nordeste e $21,8 \%$ do Exterior. Para os controles globais, embora a proporção de nascidos no Estado de são Paulo seja idêntica àquela dos pareados $(26,0 \%)$, obser va-se que a proporção de nascidas no Exterior é de $28,5 \%$ e de $25,5 \%$ de oriundas do Nordeste.

Com relação à naturalidade dos pais, pela Tabela 17 observa-se semelhante distribuição àquela encontrada para as mães. Entre os casos há apenas $9,8 \%$ de pais nascidos no Nordeste, enquanto que $30,4 \%$ dos pais dos controles pareados e $24,5 \%$ dos controles globais são aí nascidos.

Quando se considera a naturalidade conjunta de pai e de mãe dos indivíduos amostrados, reforçam-se os achados anteriores. Entre os casos, apenas $9,8 \%$ de pai e de mãe são nordestinos, ao passo que entre os controles pareados encontram-se $30,4 \%$ e $24,0 \%$ entre os controles globais. Para ambos os grupos, o risco relativo referente a ter os pais nascidos em regiões diferentes do Nordeste foi da ordem de 3,00, ambos estatisticamente significantes, com nível descritivo de 0,01 (Tabela 18).

Procedendo-se à análise segundo sexo, encontra-se sig nificância estatística apenas para o sexo feminino, com riscos relativos de $3,70(0,01<\mathrm{p}<0,05)$ para amostra pareada e 5,00 $(\mathrm{p}<0,01)$ para a amostra global. 
ção na zona urbana do que na zona rural e, quando se compara com os grupos controles, verifica-se que os riscos relativos de exposição a este fator são estatisticamente significantes, com o nível descritivo menor do que 0,05 (Tabela 19). Ao se efetuar a análise específica por sexo não se detecta associação significante ao nível de 0,05.

A história migratória dos indivíduos amostrados, desde o local de nascimento até o presente local de residência, captada em termos do maior tempo de residência em zona rural ou zona urbana, não evidencia diferença entre casos e controles (Tabela 20).

Os indivíduos amostrados têm baixo grau de instrução. Apenas $19,6 \%$ dos casos, 10,9\% controles pareados e 11,5\% dos controles estratificados apresentam grau de instrução correspondente ao ní vel ginasial e mais. A proporção de analfabetos é maior nos grupos controles em comparação com aquela observada entre os casos.

Os contrastes entre ter instrução correspondente ao primário e mais, em comparação com os analfabetos, evidenciam riscos relativos superiores a 1 , porém sem significância estatística (Tabela 21).

\section{2- CONSUMO HABITUAL DE ALIMENTOS}

Considerado em termos da frequência mencionada pelos entrevistados, o consumo de alimentos foi categorizado em: não come, come moderadamente ( 1 a 2 vezes por semana, 1 vez por mês, de vez em quando, ocasionalmente) e come intensamente ( 3 vezes e mais por semana) ou, simplesmente, de maneira dicotômica, come/não come. 
Os resultados são apresentados em grandes grupos de alimentos, relacionados às hipóteses existentes, para posterior análise comparativa com outros estudos.

\subsection{1- CARNES EM GERAL, AVES, PEIXES E OVOS}

As tabelas de números 22 a 26 mostram que não existem diferenças entre os pacientes com câncer de reto e seus respectivos controles nos três tipos de amostra, com relação ao consumo de carne bovina fresca, carne suína fresca, aves, peixes e ovos. Os riscos re lativos calculados para cada alimento individual, nas respectivas amostras, não apresentaram significância estatística ao nível de 5\%.

Dentre os alimentos deste grupo, carne bovina fresca e ovos foram os mencionados como consumidos com maior frequência ( 3 vezes e mais por semana), tanto pelos pacientes de câncer de reto, quanto pelos respectivos grupos controles. O consumo de carne salgada (independentemente de ser bovina ou suína), o de embutidos de modo geral e o de peixe enlatado, foram analisados sem que se encontrassem diferenças entre casos e controles.

A partir da constituição da variável CARNE, sintetizando o hábito de consumo das carnes em geral, vê-se que 3 dos pacientes de câncer de reto, 6 dos controles pareados e 10 dos controles globais não consomem qualquer tipo de carne, o que sugere que o consumo de carne não constitui fator de risco para câncer de reto (tabela 27). 
Em decorrência do interesse em estudar o consumo de carnes em geral e gordura animal, examinou-se os tipos de gordura usados no preparo das refeições. Novamente não se encontrou diferença entre os pacientes de câncer de reto e controles no uso corrente de óleo ou gordura de orígem vegetal ou animal (Tabela 28).

\subsection{2- PRODUTOS LACTEOS}

o consumo de leite in natura, ou em pó, parece não in fluenciar o câncer de reto, uma vez que não se encontram diferenças entre casos e controles (Tabela 29). Queijo, entretanto, apresenta proporções de consumo bem diferenciadas entre casos e controles. Dos casos de câncer de reto $78,3 \%$ comem queijo moderada ou intensamente, enquanto que $55,4 \%$ dos controles pareados e $57,5 \%$ dos controles globais estão nesta categoria (Tabela 30 ).

Nas três amostras, os Riscos Relativos referentes aos contrastes: comer/não comer queijo, são estatisticamente significantes ao nivel de 1\%. Analisando o consumo de queijo nas amostras discriminadas por sexo, verifica-se que os Riscos Relativos são signifí cantes ao nível de $5 \%$ em todas elas.

\begin{tabular}{lcccc}
\hline $\begin{array}{l}\text { TIPO DE } \\
\text { AMOSTRA }\end{array}$ & SEXO & $\begin{array}{c}\text { RISCO } \\
\text { RELATIVO }\end{array}$ & $\mathrm{x}^{2}$ & $\begin{array}{c}\text { NIVEL } \\
\text { DESCRITIVO }\end{array}$ \\
\hline Pareada & feminino & 3,20 & 4,76 & $0,01<\mathrm{p}<0,05$ \\
& masculino & 4,33 & 5,06 & $0,01<\mathrm{p}<0,05$ \\
Global & feminino & 2,80 & 5,57 & $0,01<\mathrm{p}<0,05$ \\
& masculino & 2,60 & 4,60 & $0,01<\mathrm{p}<0,05$
\end{tabular}


A análise do gradiente de consumo de queijo na amostra global reforça os achados anteriores. Assim, a Tabela 30 sugere que comer queijo de modo intenso ( 3 vezes ou mais por semana) leva a um risco 5 vezes maior em relação aos que não comem, quanto à possibilidade de ter câncer de reto.

\subsection{3- VERDURAS, LEGUMES, LEGUMINOSAS E FRUTAS}

o consumo de verduras, legumes, leguminosas e frutas é de especial interesse na medida em que constitui a principal fonte de celulose e de fibras para o organismo. Quer para os casos, quer para os grupos controles, predomina o consumo de alface, tomate, cou ve e cenoura, dentre as hortaliças ingeridas mais frequentemente.

Pelas Tabelas 31 e 32 observa-se que para as verduras e para as leguminosas (feijão, ervilha, lentilha, grão de bico) não se encontram diferenças estatisticamente significantes entre casos e grupos controles. Para legumes (Tabela 33) e frutas (Tabela 34), con tudo, observam-se na amostra global Riscos Relativos superiores a l, estatisticamente significantes ao nível de $5 \%$. Porém, ao se testar a relação dose-resposta, verifica-se que não existe um gradiente no Risco Relativo acompanhando o aumento de consumo destes alimentos.

A análise conjunta do consumo de frutas e de verduras também não evidencia diferenças entre casos e grupos controles (Tabe la 35$)$. 


\subsection{4- CEREAIS, TUBÉRCULOS E DOCES}

Os hidratos de carbono são oriundos, em grande propor ção, da ingestão de cereais, raízes, tubérculos e doces.

o risco de câncer de reto, entretanto, não está associado ao consumo de alimentos deste grupo, tais como: arroz, pão, ma carrão, batata, mandioca, doces em compotas, açúcar para adoçar, entre outros (Tabelas 36 a 39 ).

Embora o consumo de raizes e tubérculos (Tabela 38) e de doces, (Tabela 39) em duas das 3 amostras analisadas tenha apresentado Riscos Relativos estatisticamente significantes a $5 \%$, 0 teste de gradiente não encontra significação estatística.

\subsection{5- CONDIMENTOS E TEMPEROS}

O consumo de pimenta do reino (Tabela 40) e o de pimenta tipo malagueta ardida (Tabela 4l) não estão associados ao câncer de reto.

Com relação ao orégano e colorau, observa-se que, nos três tipos de amostra, encontra-se associação significante ao nível de 5\% (Tabela 42). A análise de todos os temperos em conjunto, em termos de comer/não comer, incluindo nesta síntese o consumo de moIhos, pickles, mencionados pelos indivíduos amostrados, não dá indicações como fator de risco de câncer de reto (tabela 43). 
5.3- CARACTERISTICAS DO HABITO INTESTINAL

A frequîencia de evacuação informada em termos de menos l vez ao dia e de $l$ ou mais vezes ao dia, não representa fator de risco para câncer de reto. Cerca de $90 \%$ dos pacientes com câncer de reto referem evacuar una ou mais vezes ao dia, proporção semelhan te à observada para os controles. Apenas para a amostra estratificada verificou-se un Risco Relativo significante ao nivel de 5\% (Tabela 44 ).

Com relação à consistência das fezes (Tabela 45), verifica-se que $11 \%$ dos casos mencionaram tê-las de consistência diar réica e igual proporção de amolecidas, diferindo das proporções apre sentadas pelos controles pareados $(9,8 \%$ amolecidas, $0 \%$ de diarréicas) e pelos controles globais $(7,5 \%$ de amolecidas e 0,5\% de diarréi cas ).

Antes de adoecer, os pacientes com câncer de reto e os controles mencionaram que não sofriam de prisão de ventre, o que se constata também em termos de alta proporção daqueles que não usam laxante: $66,3 \%$ dos casos, $67,4 \%$ dos controles pareados e $73,5 \%$ dos controles globais (Tabela 46 ).

\section{4- OUTRAS CARACTERISTICAS}

A indagação sobre a existência de familiares próximos (pai, mãe e irmãos) com câncer não evidenciou diferenças entre casos e controles (Tabela 47). 
Tanto para a amostra pareada, quanto para a global, verifica-se que ter hemorróida constitui possível fator de risco pa ra câncer de reto (Tabela 48). Enquanto que entre os controles pareados e globais esta proporção oscila de 12 a 15\%, entre os pacien tes com câncer de reto, verifica-se que 33\% tiveram hemorróida.

A existência de papiloma foi mencionada em 3 dos casos de câncer de reto e nenhuma vez entre os controles.

\section{5- TABAGISMO}

os indivíduos amostrados não têm o hábito acentuado de fumar, quer se considere o cigarro sem filtro, quer o com filtro, quer o de palha. Pelos dados da Tabela 49 , vê-se que $77,2 \%$ dos casos de câncer de reto não fumam e nem fumaram cigarro sem filtro durante sua vida, assim como $76,1 \%$ dos controles pareados e $65,0 \%$ dos controles globais. Os contrastes entre os que fumam qualquer quantidade de cigarro sem filtro diariamente, em comparação com os que não fumam, nos três tipos de amostra, não evidenciam riscos relativos com significância estatística.

Com relação a fumar cigarro com filtro, observa-se que $79,3 \%$ dos indivíduos portadores de câncer de reto não fumam. Es ta proporção é maior do que a verificada para os controles pareados $(60,5 \%)$ e para os controles globais $(70,0 \%)$, conforme os dados da Tabela 50. Também não se constata que fumar cigarro com filtro, independente da quantidade de cigarros diários, seja fator de risco para o câncer de reto, já que os riscos relativos não são estatísti camente significantes. 
Fumar cigarro de palha não constitui hábito preponderante entre os indivíduos amostrados. Durante toda a história de tabagismo pesquisada, $84,7 \%$ dós casos de câncer de reto, $80,4 \%$ dos con troles pareados e $80,5 \%$ dos controles globais não fumaram cigarros de palha (Tabela 51). Os riscos relativos observados não apresentaram significância estatística. Por meio da criação da variável "FuMo TOTAL", que significa a análise conjunta do hábito de fumar os 3 tipos de cigarros, verifica-se que, dentre os indivíduos amostrados, $52,1 \%$ dos casos, $45,7 \%$ dos controles pareados e $40,0 \%$ dos controles globais nunca fumaram ou não fumam quaisquer dos 3 tipos de cigarros analisados. Dentre os casos, 10,9\% fumam pelo menos um dos tipos de cigarros intensamente, ocorrendo o mesmo com $9,8 \%$ dos controles pareados e $14,5 \%$ dos controles globais. Os riscos relativos não são estatisticamente significantes ao nível de 5\% (Tabela 52 ).

\section{6- CONSUMO DE BEBIDAS ALCOÓLICAS}

Foi considerado o hábito de ingestão de três tipos de bebidas: pinga, cerveja e vinho.

A proporção dos que não bebem pinga é semelhante entre os casos e os controles, oscilando de 60 a $69 \%$ (Tabela 53), a proporção dos que bebem intensamente (pelo menos uma dose diária) é superior à dos que bebem moderadamente, quer se considere os casos de câncer de reto, quer se considere os dois grupos controles. A maior diferença situa-se na distribuição dos controles globais, onde $31,0 \%$ bebem intensamente e $9,5 \%$ bebem moderadamente. Os riscos relativos calculados não têm significância estatística. 
Com relação à cerveja, verifica-se que a proporção dos que não a bebem é ainda maior do que a daqueles que não bebem pinga; oscila de 83 a $86 \%$ entre os indivíduos amostrados (Tabela 54). A proporção dos que bebem moderadamente é ligeiramente superior à dos que bebem moderadamente entre os dois grupos controles e, idên tica entre os casos. Os riscos relativos não apresentam significância estatística.

O consumo de vinho apresenta-se diferenciado entre os casos e os controles. A proporção dos indivíduos que não bebem vinho é de $76,0 \%$ entre os casos, $91,3 \%$ entre os controles pareados e $87,0 \%$ entre os controles globais (Tabela 55). Dentre os casos, $12,0 \%$ bebem vinho intensamente (pelo menos 1 copo diário), enquanto que entre os controles pareados e entre os controles globais foram observadas pro porções de $5,4 \%$ e $8,0 \%$ respectivamente.

Os riscos são estatísticamente significantes com o ní vel descritivo de 0,01 para a amostra pareada e 0,05 para a amostra global. A análise dos riscos relativos em termos das alternativas de consumo, no entanto, não evidencia gradiente. Ao se discriminar por sexo, verifica-se significância estatística apenas para o sexo mascu lino na amostra pareada $(R R=5,000,01<p<0,05)$. 


\section{7- ANALISE MULTIVARIADA}

5.7.1- ANALISE MULTIVARIADA PARA NPAMA, QUEIJO, OREGANO E CO LORAU

Ao se proceder à análise do grau de associação entre as variáveis individuais e o câncer de reto, detectou-se que 4 das variáveis estudadas apresentaram riscos relativos com significância estatística ao nível de 5\% nas três amostras, a saber: as variáveis demográficas local de nascimento do caso (não Nordeste X Nordeste), local de nascimento do pai e da mãe, variável que foi denominada de NPAMA (não Nordeste $X$ Nordeste) e as variáveis alimentares consumo de orégano e de colorau (come X não come) e de queijo (não come, come moderadamente, come intensamente). Dado que a variável "local de nascimento do paciente portador de câncer de reto" e "local de nascị mento dos pais" refletem a mesma realidade social, considerou-se ape nas a naturalidade dos pais no modelo de regressão, por ter apresentado RR mais intenso para câncer de reto.

Por meio da análise multivariada das 3 variáveis, utị zando-se a amostra estratificada por idade e sexo, em que se ajusta - efeito de uma ou mais variáveis sobre outra, verifica-se que o queijo, em todas as combinações possíveis, mantém-se com RR praticamente sem alteração e significante ao nível de 1\% ( Tabela 56), indi cando que a naturalidade dos pais e o hábito de consumo de orégano e colorau não modificam a associação entre consumo de queijo e câncer de reto. 
conjugado com queijo, apresentou-se estatisticamente significante ao nível de $1 \%$, altera sua força de associação como fator de proteção ao câncer de reto quando analisado em conjunto com NPAMA e QUEIJO.

A naturalidade dos pais (NPAMA) que individualmente apresentara-se associada com câncer de reto ao nível descritivo de 0,01, deixa de ter significância estatística na análise das 3 variáveis em conjunto.

A Tabela 57 apresenta a distribuição dos casos e controles com relação ao consumo de queijo, controlado por NPAMA e ORÉGANO. Com exceção da tabela de consumo de queijo, controlado por "ser do Nordeste" e "não comer orégano e colorau, todas as demais apresen tam RR num gradiente crescente, demonstrando uma possível relação dose- resposta.

A análise de gradiente, considerando-se conjuntamente as alternativas, mostra que não comer queijo $\mathrm{x}$ comer moderadamente tem um $R R$ de 1,37, enquanto que não comer queijo $x$ comer intensamente apresenta RR igual a 4,72. O $\mathrm{x}^{2}$ Mantel para análise de gradiente apresenta-se significante ao nível de $1 \%$.

Analisando-se o consumo de queijo em termos dicotómicos: não come $X$ come, nas 4 alternativas de contrôle de NPAMA e ORÉGANO, (sem considerar idade e sexo), encontrou-se RR de valor igual a 2,46 e $\mathrm{x}^{2}$ de Mantel - Haenszel igual a 9,27, estatisticamente significante a 1\%. Com valores bem aproximados, por meio do programa PE CAN III57, evidencia-se a mesma relação $\left(R R=2,63\right.$ e $\left.X^{2}=10,18\right) . A$ utilização da metodologia de Mantel-Haenszel permite que se visualize concretamente os resultados apresentados, permitindo uma identifi cação mais direta dos níveis de relacionamento das variáveis de con- 
trole e as de confusão.

o consumo de orégano, relacionado ao câncer de reto, apresentou associação significante ao nível descritivo de 0,05 quando da análise conjunta das três variáveis, controladas por idade e sexo (Tabela 56). Contudo, ao se proceder a análise do consumo de orégano e câncer de reto, controlado por NPAMA e QUEIJO, porém sem controle de idade e sexo, por meio da metodologia de Mantel-Haenszel. a significância estatística deixa de existir ('Tabela 58). Os dados da Tabela 58 mostram que os resultados dos RR correspondentes às com binações das variáveis em consideração apresentam-se em sentidos opostos. Para os indivíduos que têm os pais não nascidos no NORDESTE e que comem queijo, comer orégano apresenta-se como fator de agressão ao câncer de reto, enquanto que para as 3 outras combinações se apresenta como fator de proteção, porém sem significância estatística.

\subsection{2- ANALISE MULTIVARIADA PARA RETO BAIXO}

Tratou-se de estudar a relação das variáveis que aprẹ sentaram significância estatística com o câncer de reto global, no segmento específico do reto baixo. Assim, excluindo-se os casos correspondentes à área problemática de classificação, correspondente ao reto-sigmóide, e aqueles cuja localização era generalizada, ou especificado apenas reto, tinha-se um total de 38 casos a serem analisados.

Observa-se pela Tabela 59 um comportamento vulnerável das variáveis NPAMA, QUEIJO e ORÉGANO, relacionadas ao câncer de reto. Orégano, que ao ser analisado com queijo apresentava-se com ní- 
vel significante de 5\%, deixa de ter este tipo de relação, quando ana lisado só com NPAMA, ou também em conjunto com QUEIJO. A variável local de nascimento dos pais (NPAMA), que na análise do reto global não apresentava significância estatística, é a única que se mantém ao nível de 5\%, ao se proceder a análise conjunta das 3 variáveis. A Tabela 60 mostra a confirmação destes achados, em que pese o número reduzido de casos.

\subsection{3- ANÁLISE MULTIVARIADA PARA BEBIDAS - ANÁLISE PARA CERVE JA}

A possível associação entre câncer de reto e ingestão de bebidas, direcionada principalmente para cerveja, foi conduzida pa ra cada bebida, de forma a permitir um contrôle sobre a ingestão das outras. Assim, optou-se por estudar a associação entre um tipo de bebida e câncer entre aqueles que não tinham história de ingestão das outras, controlando-se as variáveis NPAMA, QUEIJO, ORÉGANO e FUMO TOTAL, esta última, devido à conhecida associação entre ingestão de bebida alcoólica e hábito de fumar, além de idade e sexo.

A Tabela 61 mostra que nenhum dos tipos de bebidas con siderado: cerveja, vinho e pinga, quando tem analisados seus efeitos sobre o câncer de reto, controlados por NPAMA, QUEIJO, ORÉGANO e FUMO TOTAL, apresenta associação significativa. Observa-se que a significância estatística que existia, quando da análise individual do consu mo de vinho com o câncer de reto, deixa de existir e que apenas o con sumo de queijo conserva risco relativo significativo ao nível descritivo de $1 \%$. 
A Tabela 62, específica de história de consumo de cer veja e câncer de reto, dentre os que não bebem pinga e/ou vinho, mos tra a não existência de uma associação significativa. A cerveja, em particular, dá um resultado oposto à hipótese formulada com base na literatura, que a apresenta como um possível fator de risco para o câncer de reto. 
TA B E L A 14

NÚMERO E PORCENTAGEM DE CASOS DE CANCER DE RETO E CONTROLES SEGUNDO LOCAL DE NASCIMENTO

\begin{tabular}{|c|c|c|c|c|c|c|}
\hline \multirow[t]{2}{*}{ LOCAL DE NASCIMENTO } & \multicolumn{2}{|c|}{ CASO } & \multicolumn{2}{|c|}{$\begin{array}{l}\text { CONTROLE } \\
\text { PAREADO }\end{array}$} & \multicolumn{2}{|c|}{$\begin{array}{l}\text { CONTROLE } \\
\text { GLOBAL }\end{array}$} \\
\hline & № & $\%$ & № & $\%$ & № & $\%$ \\
\hline Município de são Paulo & 19 & 20,6 & 10 & 10.9 & 24 & 12,0 \\
\hline Estado de são Paulo (excl.Município) & 28 & 30,4 & 29 & 31,5 & 69 & 34.5 \\
\hline Região Sudeste (exclusive S.Paulo) & 14 & 15,2 & 14 & 15.2 & 27 & 13,5 \\
\hline Região Norte e Centro-Oeste & - & - & 1 & 1,1 & 1 & 0.5 \\
\hline Região Nordeste & 10 & 10.9 & 29 & 31.5 & 51 & 25.5 \\
\hline Região Sul & 3 & 3,3 & 2 & 2,2 & 5 & 2.5 \\
\hline Paíscs das Américas e da Europa & 14 & 15,2 & 5 & 5,4 & 18 & 9,0 \\
\hline Países Asiáticos & 3 & 3,3 & 1 & 1,1 & 4 & $2, \mathrm{c}$ \\
\hline Brasil s/ identificar estado & 1 & 1,1 & - & - & - & - \\
\hline Ignorado & - & - & 1 & 1,1 & 1 & 0,5 \\
\hline I'OTAL & 92 & 100,0 & 92 & 100,0 & 200 & 100,0 \\
\hline
\end{tabular}




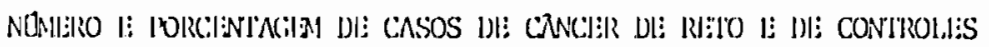
SEGUNDO LOCAL DE NASCIMEN'1'O

MMOSTRA PAREADA

\begin{tabular}{|c|c|c|c|c|}
\hline \multirow{2}{*}{ CONIIIOLL } & \multicolumn{2}{|c|}{ CASO } & \multicolumn{2}{|c|}{ IOINAL. } \\
\hline & NOLELSII: & $\begin{array}{l}\text { NTO } \\
\text { NORULSIT: }\end{array}$ & № & $\%$ \\
\hline NORDL:SI'li & 1 & 28 & 29 & 31,5 \\
\hline \multicolumn{5}{|l|}{ NTO } \\
\hline NU|य)l:STli: & 9 & 54 & 63 & 68,5 \\
\hline \multirow{2}{*}{ TOIN } & 10 & 82 & 92 & 100,0 \\
\hline & 10.9 & 89,1 & 100,0 & \\
\hline
\end{tabular}

AMOSTRA GLOBAL

\begin{tabular}{|c|c|c|c|c|}
\hline \multirow{2}{*}{$\begin{array}{l}\text { LOCAL DE } \\
\text { NASCIMENTO }\end{array}$} & \multicolumn{2}{|c|}{ CASO } & \multicolumn{2}{|c|}{ CONIROLE } \\
\hline & № & $q$ & Nọ & $:$ \\
\hline NOIULLSIL & 10 & 10,9 & 51 & 25,5 \\
\hline \multicolumn{5}{|l|}{ NXO } \\
\hline NOIயULSI': & 82 & 89.1 & 149 & 74,5 \\
\hline TOINL & 92 & 100,0 & 200 & 100,0 \\
\hline
\end{tabular}

RISCO RELATIVO (RR), QUI-QUADRADO $\left(X^{2}\right)$ E NAVEL DE SIG NIFICANCIA DESCRITIVO $(p)$, SEGUNDO TIPO DE AMOSTRA

\begin{tabular}{lccc}
\hline TIPO DE MMOSTRA & RR & $\mathrm{x}^{2}$ & $\mathrm{p}$ \\
\hline PAREADA & 3,11 & 8,76 & $<0,01$ \\
GLOBNL & 2,81 & 7,30 & $<0,01$ \\
ESTRNTIFICADA & 2,94 & 8,18 & $<0,01$ \\
\hline
\end{tabular}


NÚMERO E PORCENTAGEM DE CASOS DE CÂNCER DE RETO E DE CONTROLES SEGUNDO LOCAL DE NASCIMENTO DA MAE

\begin{tabular}{|c|c|c|c|c|c|c|}
\hline \multirow[t]{2}{*}{ LOCAL DE NASCIMENTO DA MXE } & \multicolumn{2}{|c|}{ CAso } & \multicolumn{2}{|c|}{$\begin{array}{r}\text { CONTROLE } \\
\text { PARE } \triangle D O \\
\end{array}$} & \multicolumn{2}{|c|}{$\begin{array}{c}\text { CONTROLE } \\
\text { GLOB } \wedge L\end{array}$} \\
\hline & Nㅡㅇ & $\%$ & Nㅡㅇ & $\%$ & № & $\%$ \\
\hline $\begin{array}{l}\text { Municipio de São Paulo } \\
\text { Estado de São Paulo (exclusive Municí }\end{array}$ & 6 & 6,5 & 5 & 5,4 & 10 & 5.0 \\
\hline pio & 22 & 23,9 & 19 & 20,6 & 42 & 21,0 \\
\hline Região Sudeste (exclusive São Paulo) & 15 & 16,3 & 12 & 13,0 & 28 & 14.0 \\
\hline Região Norte e Centro-Oeste & - & - & 1 & 1,1 & 1 & 0.5 \\
\hline Região Nordeste & 12 & 13,0 & 29 & 31,5 & 51 & 25,5 \\
\hline Rogião Sul & 2 & 2,2 & 1 & 1,1 & 3 & 1,5 \\
\hline Países das Mméricas e da Europa & 27 & 29.3 & 18 & 19,6 & 52 & 26,0 \\
\hline Países $n s i a ́ t i c o s$ & 4 & 4,4 & 2 & 2,2 & 5 & 2,5 \\
\hline Brasil, serl identificar Estado & 2 & 2.2 & 2 & 2,2 & 4 & 2,0 \\
\hline Ignorado & 2 & 2.2 & 3 & 3,3 & 4 & 2,0 \\
\hline TOTAL & 92 & 100,0 & 92 & 100,0 & 200 & 100,0 \\
\hline
\end{tabular}


NÚMERO E PORCENTAGEM DE CASOS DE ChNCER DE RETO E DE CONTROLES SEGUNDO LOCAL DE NASCIMENTO DO PAI

\begin{tabular}{|c|c|c|c|c|c|c|}
\hline \multirow{2}{*}{ LOCAL DE NASCIMENTO DO PAI } & \multicolumn{2}{|c|}{ CASO } & \multicolumn{2}{|c|}{$\begin{array}{c}\text { CONTROLE } \\
\text { PAREADO } \\
\end{array}$} & \multicolumn{2}{|c|}{$\begin{array}{l}\text { CON'IROLE } \\
\text { GLOBNL }\end{array}$} \\
\hline & № & $\%$ & № & $\%$ & N2 & $\%$ \\
\hline Município de São Paulo & 4 & 4,3 & 4 & 4,3 & 8 & 4.0 \\
\hline Estado de são Paulo (exclusive Municí & & & & & & \\
\hline pio & 24 & 26,2 & 15 & 16,3 & 39 & 19.5 \\
\hline Região Sudeste (exclusive S.Paulo) & 13 & 14,1 & 15 & 16,3 & 32 & 16.0 \\
\hline Região Norte e Centro-Oeste & - & - & 1 & 1,1 & 1 & 0.5 \\
\hline Poydizo nordeste. & 9 & 9.8 & 28 & 30.4 & $4: 3$ & $2.1 . r$ \\
\hline Regizus Sul & 3 & 3,3 & - & - & 2 & 1,0 \\
\hline Faises das Américas e da Europa & 30 & 32,6 & 23 & 25.0 & 583 & 29,0 \\
\hline Países Asiáticos & 4 & 4,3 & 2 & 2,2 & $\epsilon$ & 3.0 \\
\hline Brasil, scm identificar Estado & 1 & 1,1 & 2 & 2,2 & 2 & 1,0 \\
\hline Ignorado & 4 & 4.3 & 2 & 2,2 & 3 & 1,5 \\
\hline TO'TAL & 92 & 100,0 & 92 & 100,0 & 200 & 100,0 \\
\hline
\end{tabular}


$\Gamma \wedge B \mathrm{BL} \wedge \quad 18$

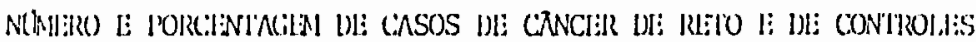

SEGUNDO LOCNL DE NASCIMENTO DO PAI E DA MXE

\begin{tabular}{|c|c|c|c|c|}
\hline \multirow{2}{*}{ (onllould: } & \multicolumn{2}{|c|}{ CASI } & \multicolumn{2}{|c|}{ IOINI. } \\
\hline & NANH:S"ll & $\begin{array}{l}N \pi() \\
N(0)(1) !: S[1:\end{array}$ & No & $\%$ \\
\hline NOHL:SII: & 1 & 27 & 28 & 30,4 \\
\hline $\mathrm{N}(\mathrm{NO}$ & 8 & 56 & 64 & 69.6 \\
\hline \multicolumn{5}{|l|}{ NoR!H:SII: } \\
\hline \multirow[t]{2}{*}{ ToIN. } & 9 & 83 & 92 & 100.0 \\
\hline & 9,8 & 90,2 & 100,0 & \\
\hline
\end{tabular}

\begin{tabular}{|c|c|c|c|c|}
\hline \multirow{2}{*}{$\begin{array}{l}\text { LOCAL } \\
\text { DE } \\
\text { NASCIMENT'O }\end{array}$} & \multicolumn{2}{|c|}{ CAso } & \multicolumn{2}{|c|}{ (INTISOIS: } \\
\hline & Nọ & $\because$ & Nọ & $"$ \\
\hline NORDI:SI!: & 9 & 9.8 & 48 & 24.0 \\
\hline Nito & 83 & 90,2 & 152 & $76,0)$ \\
\hline NOLULSSI' & & & & \\
\hline IUIN. & 92 & 100,0 & 200 & 100.0 \\
\hline
\end{tabular}

RISCO RELATIVO (RR), QUI-QUADRADO $\left(\mathrm{x}^{2}\right)$ E NFVEL IJE, STE NIFICANCIA DESCRITIVO (p), SEGUNDO TIPO DE AMOSTRA

\begin{tabular}{lccc}
\hline TIPO DE AMOSTR & RR & $\mathrm{x}^{2}$ & $\mathrm{p}$ \\
\hline PARE $\Lambda D A$ & 3.38 & 9.26 & $<0.01$ \\
GLOB $\Lambda \mathrm{L}$ & 2.91 & 7.23 & $<0.01$ \\
ESTRATIFICAD & 3,03 & 8,06 & $<0.01$ \\
\hline
\end{tabular}




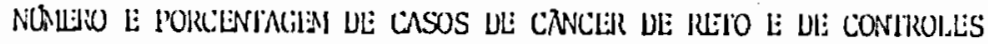
SI:CINIXO ZONA DE NASCIMENTO

\begin{tabular}{|c|c|c|c|c|}
\hline \multirow{2}{*}{ LWTKOH,I: } & \multicolumn{2}{|c|}{$(A S)$} & \multicolumn{2}{|c|}{ TOIAI. } \\
\hline & RURAL & URBANO & Nọ & $:$ \\
\hline RURL & 20 & 27 & 47 & 51,1 \\
\hline URRANO & 14 & 31 & 45 & 48.9 \\
\hline \multirow{2}{*}{$\| N]_{N L}$} & 34 & 58 & 92 & 100,0 \\
\hline & 37,0 & 63,0 & 100,0 & \\
\hline
\end{tabular}

\begin{tabular}{|c|c|c|c|c|}
\hline \multirow{2}{*}{$\begin{array}{l}\text { ZONA } \\
\text { DE } \\
\text { NASCIMENTO }\end{array}$} & \multicolumn{2}{|c|}{ (ASO) } & \multicolumn{2}{|c|}{ (G)ditus.1: } \\
\hline & Nọ & 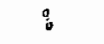 & No & i \\
\hline RURAL & 34 & 37,0 & 104 & 52,0 \\
\hline URBANO & 58 & 63,0 & 96 & 48,0 \\
\hline 'IUI'NL & 92 & 100,0 & 200 & 100,0 \\
\hline
\end{tabular}

RISCO RELATIVO (RR), QUI-QUADRADO $\left(x^{2}\right)$ E NFVEL DE SIGNIFICANCIA DESCRITIVO ( $p$ ), SEGUNDO TIPO DE AMOSTRA

\begin{tabular}{lccr}
\hline TIPO DE AMOSTRA & RR & $\mathrm{x}^{2}$ & $\mathrm{p}$ \\
\hline PARE $A D A$ & 1,93 & 3,51 & $>0,05$ \\
GLOBAL & 1,85 & 5.13 & $0.01<\mathrm{p}<0,05$ \\
ESTRATIFICADA & 1.72 & 4.45 & $0.01<\mathrm{p}<0.05$ \\
\hline
\end{tabular}


$\because \wedge B$ I: $1 \wedge \underline{20}$

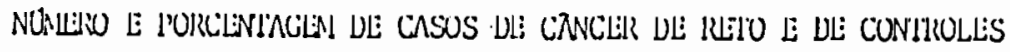
SEGUNDO PREDOMINARAIA DE TEMPO DE RESIDÊNCIA POR ZONA

\begin{tabular}{|c|c|c|c|c|}
\hline \multirow{2}{*}{ CUNIIIULE } & \multicolumn{2}{|c|}{ CAso } & \multicolumn{2}{|c|}{ TOINI, } \\
\hline & RURAL & URBANA & NO & : \\
\hline RURAL & 2 & 12 & 14 & 156,0 \\
\hline URBANA & 13 & 63 & 76 & 84,4 \\
\hline \multirow{2}{*}{ TOIN } & 15 & 75 & $90^{*}$ & 100,0 \\
\hline & 16,7 & 83,3 & 100, & \\
\hline
\end{tabular}

'Exclusive 2 com igual tempo de residencia en zona urbana e zona rural

\begin{tabular}{|c|c|c|c|c|}
\hline \multirow{2}{*}{$\begin{array}{l}\text { PRED. } \\
\text { RESIDÊNCIA }\end{array}$} & \multicolumn{2}{|c|}{ CAso } & \multicolumn{2}{|c|}{ contruld: } \\
\hline & No & $q$ & N? & $:$ \\
\hline RURAL & 15 & 16,7 & 43 & 21.7 \\
\hline URBANA & 75 & 83,3 & 155 & 78,3 \\
\hline IUI'N & $90^{*}$ & 100,0 & $198^{*}$ & 100,0 \\
\hline
\end{tabular}

RISCO RELATIVO (RRl, QUI-QUADRADO $\left(x^{2}\right)$ E NIVEL DE SIGNIFICANCIA DESCRITIVO $(p)$, SEGUNDO TIPO DE AMOSTRA

\begin{tabular}{lccc}
\hline TIPO DE MMOSTRA & $\mathrm{RR}$ & $\mathrm{x}^{2}$ & $\mathrm{p}$ \\
\hline PAREADN & 0,92 & 0,00 & $>0.05$ \\
GLOBAL & 1,39 & 0,69 & $>0,05$ \\
ESTRATIFICADA & 1,01 & 0,00 & $>0.05$ \\
\hline
\end{tabular}


Tค \& เ $\llcorner\wedge \quad 21$

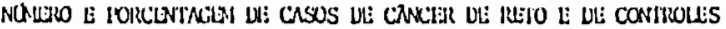

SECUNDÓ GRNU DE INSTRUÇKO

\begin{tabular}{|c|c|c|c|c|c|}
\hline \multirow{2}{*}{ curvikot.li } & \multicolumn{3}{|c|}{ crso } & \multicolumn{2}{|c|}{ IUINL } \\
\hline & $\begin{array}{l}\text { AWILL:A- } \\
\text { IN:IO }\end{array}$ & I'RINRKIO & GINSIO & NQ & 1 \\
\hline $\begin{array}{l}\text { ANLLIN- } \\
\text { MI:1O }\end{array}$ & 27 & 14 & B & 49 & 53.2 \\
\hline I'RIMURIO & 10 & 17 & 6 & 33 & 35,9 \\
\hline $\begin{array}{l}\text { GiNRSIO } \\
\text { l: }\end{array}$ & 1 & 5 & 4 & 10 & 10,9 \\
\hline TOINL & 38 & 36 & 18 & 92 & 100,0 \\
\hline 1 & 41.3 & 39.1 & 19,6 & 100,0 & \\
\hline
\end{tabular}

\begin{tabular}{|c|c|c|c|c|}
\hline \multirow{2}{*}{$\begin{array}{l}\text { GRAU } \\
\text { DE } \\
\text { INSTRUÇKo }\end{array}$} & \multicolumn{2}{|c|}{ caso } & \multicolumn{2}{|c|}{ CONTIROI } \\
\hline & NQ & 1 & NQ & $:$ \\
\hline \multicolumn{5}{|l|}{ NNN.IA- } \\
\hline แIะเO & 38 & 41,3 & 104 & 52.0 \\
\hline I'Ruкuto & 36 & 39,1 & 73 & 36.5 \\
\hline $\begin{array}{l}\text { GINRSIO } \\
\mathrm{L}+\end{array}$ & 18 & 19,6 & 23 & 11,5 \\
\hline IUIN. & 92 & 100,0 & 200 & 100,0 \\
\hline
\end{tabular}

RISCO RELATIVO ${ }^{*}(R R)$, QUI-QUADRADO $\left(x^{2}\right)$ E NFVEL DE SIG

NIFICNNCIN DESCRITIVO (p), SEGUNDO TIPO DE AMOSTRA

\begin{tabular}{lccc} 
PRIMKRIO E MAIS & \multicolumn{2}{c}{ ANALFADETO } \\
\hline TIPO DE MMOSTRA & RR & $x^{2}$ & $p$ \\
\hline PAREADA & 2,00 & 3,03 & $>0,05$ \\
GLODAL & 1,54 & 2,47 & $>0,05$ \\
ESTRATIFICADA & 1,62 & 3,46 & $>0,05$
\end{tabular}


66.

TABLLA 22

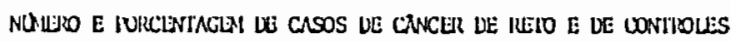
SEGUNDO CONSUMO BUBITUAL DE CARNE BOVINA FRESCA

\begin{tabular}{|c|c|c|c|c|c|}
\hline \multirow{2}{*}{ aWIRUI.L: } & \multicolumn{3}{|c|}{ CASO } & \multicolumn{2}{|c|}{ IOINL } \\
\hline & N/W (XNE: & $\begin{array}{l}\text { CWII! NBII! } \\
\text { MWWHENILE }\end{array}$ & 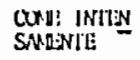 & NP & 1. \\
\hline No conn: & 2 & 4 & 5 & 11 & 12.0 \\
\hline 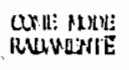 & 1 & 12 & 18 & 31 & 33.7 \\
\hline $\begin{array}{l}\text { CXYH: INTIN } \\
\text { SWHENIL: }\end{array}$ & 2 & 15 & 33 & 50 & 54,3 \\
\hline TOTNL & 5 & 31 & 56 & 92 & 100,0 \\
\hline 1 & 5.4 & 33.7 & 60,9 & 100,0 & \\
\hline
\end{tabular}

\begin{tabular}{|c|c|c|c|c|}
\hline \multirow{2}{*}{$\begin{array}{l}\text { CARNE } \\
\text { BOVINA } \\
\text { ERESCA }\end{array}$} & \multicolumn{2}{|c|}{ CASO } & \multicolumn{2}{|c|}{ CONIROLL: } \\
\hline & NQ & 1 & NQ & 1 \\
\hline Mo coXts & 5 & 5.4 & 21 & 10.5 \\
\hline $\begin{array}{l}\text { CWNL: NMIL: } \\
\text { IWLWUNIIE }\end{array}$ & 31 & 33.7 & 67 & 33.5 \\
\hline $\begin{array}{l}\text { Cunl? INIIN } \\
\text { SWHENTE }\end{array}$ & 56 & 60.9 & 312 & 56.0 \\
\hline 'IOIXI. & 92 & 100,0 & 200 & I11),.11 \\
\hline
\end{tabular}

RISCO RELATIVO (RR), QUI-QUNDRUDO $\left(x^{2}\right)$ E NFVEL DE SIGNIFICANCIA DESCRITIVO (p), SEGUNDO TIPO DE MMOSTR

\begin{tabular}{|c|c|c|c|}
\hline TIPO DE AMOSTRA & RR & $x^{2}$ & $\mathbf{p}$ \\
\hline PNRENDA & 3,00 & 2,00 & $>0,05$ \\
\hline GLOBAL & 2.04 & 1,42 & $>0.05$ \\
\hline ESTRATIFICADA & 1,13 & 0,48 & $>0,05$ \\
\hline
\end{tabular}


TヘBELA 23

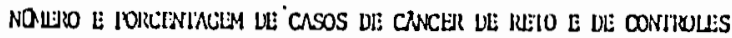

SEgUNDO CONSUMO IMAITURL DE CARNE SU1N FRESCA

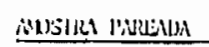

\begin{tabular}{|c|c|c|c|c|c|}
\hline \multirow{2}{*}{ IXNIRUI.E } & \multicolumn{3}{|c|}{$C \wedge S O$} & \multicolumn{2}{|c|}{ IUI'NL } \\
\hline & NNS cantE & $\begin{array}{l}\text { COMLL MUIIS } \\
\text { RUMWUNIE: }\end{array}$ & $\begin{array}{l}\text { CXND: INILN } \\
\text { SWUEIE }\end{array}$ & No & 1 \\
\hline No cun: & 22 & 18 & 6 & 46 & 50.0 \\
\hline 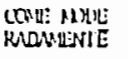 & 18 & 17 & 3 & 38 & 41,3 \\
\hline $\begin{array}{l}\text { GRU: INIIN } \\
\text { SNUENIE }\end{array}$ & 5 & 3 & - & a & B.7 \\
\hline IOTN & 45 & 38 & 9 & 92 & 100,0 \\
\hline 1 & 48,9 & 41,3 & 9,8 & 100,0 & \\
\hline
\end{tabular}

\begin{tabular}{|c|c|c|c|c|}
\hline \multirow{2}{*}{$\begin{array}{l}\text { CNRNE } \\
\text { FRESCA } \\
\text { SU1NA }\end{array}$} & \multicolumn{2}{|c|}{ cuso } & \multicolumn{2}{|c|}{ cuNTla.11.1: } \\
\hline & No & 1 & NQ & 1 \\
\hline MO CUNE & 45 & 40.9 & 92 & 46.0 \\
\hline $\begin{array}{l}\text { COAII: MUIU!: } \\
\text { RADWENIE }\end{array}$ & 38 & 41,3 & 86 & 43.0 \\
\hline $\begin{array}{l}\text { OND: INILN } \\
\text { SNUARTE }\end{array}$ & 9 & 9,8 & 22 & 11,0 \\
\hline TUIN & 92 & 100,0 & 200 & 100,0 \\
\hline
\end{tabular}

RISCO RELATIVO (RR), QUI-QUNDRADO $\left(x^{2}\right)$ E NIVEL DE SIG NIFICANCIA DESCRITIVO (p), SEGUNDO TIPO DE AMOSTRA

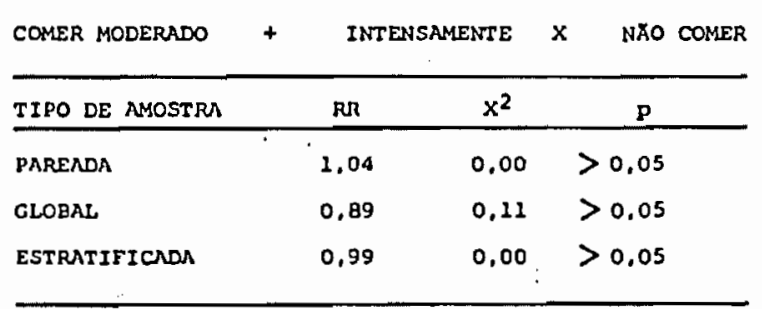




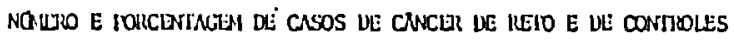
SEGUNDO CONSUMO habITUAL de AVES

\begin{tabular}{|c|c|c|c|c|c|}
\hline \multirow{2}{*}{ CONIKULL: } & \multicolumn{3}{|c|}{$C(s)$} & \multicolumn{2}{|c|}{ JUTN } \\
\hline & NXO axd: & $\begin{array}{l}\text { COML: MIII: } \\
\text { RWWHNIE }\end{array}$ & $\begin{array}{l}\text { can: INHIN } \\
\text { SNuNit: }\end{array}$ & N8 & 1 \\
\hline No Con: & 5 & 7 & 1 & 13 & 14.1 \\
\hline 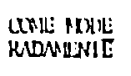 & 5 & 46 & 10 & 61 & 66,3 \\
\hline $\begin{array}{l}\text { Cunv: INTIS } \\
\text { SNDONIE }\end{array}$ & 1 & 15 & 2 & 18 & 19.6 \\
\hline TurNe ${ }^{\text {NQ }}$ & 11 & 68 & 13 & 92 & 100,0 \\
\hline 1 & 12,0 & 73.9 & 14.1 & 100,0 & \\
\hline
\end{tabular}

\begin{tabular}{|c|c|c|c|c|}
\hline \multirow{2}{*}{ AVES } & \multicolumn{2}{|c|}{ ciso } & \multicolumn{2}{|c|}{ Curliwill: } \\
\hline & NQ & 1 & NQ & 1 \\
\hline No cond: & 11 & 12,0 & 22 & 11,0 \\
\hline $\begin{array}{l}\text { CORE: MDU: } \\
\text { RNWWENIt: }\end{array}$ & 68 & 73.9 & 148 & 74,0 \\
\hline $\begin{array}{l}\text { OND: INIIN } \\
\text { SNESTEE }\end{array}$ & 13 & 14,1 & 30 & 15,0 \\
\hline TUKNL & 92 & 100,0 & 200 & 100,0 \\
\hline
\end{tabular}

RISCO RELATIVO (RR), QUI-QUADRADO $\left(x^{2}\right)$ E NAVEL DE SIG NIFICANCIA DESCRITIVO (p), SEGUNDO TIPO DE AMOSTR

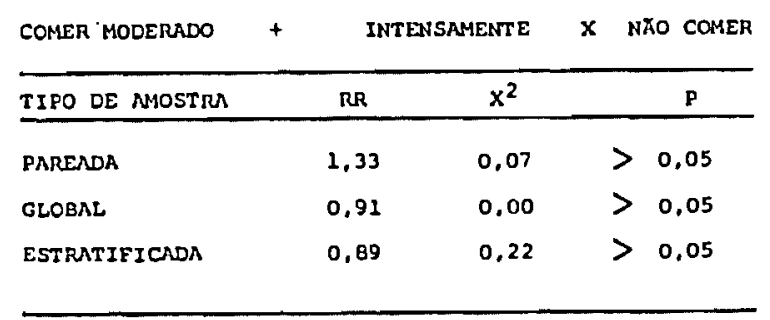


TA BELA 25

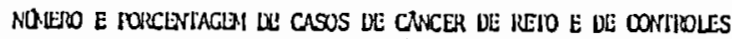
SEGUNDO CONSUMO IEABITUAL DE PEIXE

MUSIR BNUAH

\begin{tabular}{|c|c|c|c|c|c|}
\hline \multirow{2}{*}{ aWInoLE } & \multicolumn{3}{|c|}{ CASO } & \multicolumn{2}{|c|}{ TOINL } \\
\hline & NNO OANE & $\begin{array}{l}\text { COALE ADIIE } \\
\text { AWDWUNIE }\end{array}$ & $\begin{array}{l}\text { OOWE INIEN } \\
\text { SAUENIE }\end{array}$ & NP & 1 . \\
\hline NWW con: & 4 & 17 & 1 & 22 & 23,9 \\
\hline $\begin{array}{l}\text { QNE: MLULE } \\
\text { WRQWENIE }\end{array}$ & 13 & 48 & 4 & 65 & 70.7 \\
\hline $\begin{array}{l}\text { GXU: INTLEN } \\
\text { SMR:NIE }\end{array}$ & 2 & 3 & - & 5 & 5,4 \\
\hline STIN & 19 & 68 & 5 & 92 & 100,0 \\
\hline 1 & 20,7 & 73,9 & 5.4 & 100,0 & \\
\hline
\end{tabular}

MDSITU GLOBAL

\begin{tabular}{|c|c|c|c|c|}
\hline \multirow{2}{*}{ PEIXE } & \multicolumn{2}{|c|}{ CAso } & \multicolumn{2}{|c|}{ COSI10LLE } \\
\hline & NP & 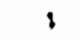 & NP & 1 \\
\hline No can: & 19 & 20.7 & 51 & 25.5 \\
\hline $\begin{array}{l}\text { CONL NDILE } \\
\text { RDNASIIE }\end{array}$ & 68 & 73,9 & 138 & 69.0 \\
\hline $\begin{array}{l}\text { COU: INTEN } \\
\text { SULWIE }\end{array}$ & 5 & 5.4 & $\cdot 11$ & 5.5 \\
\hline TOIAL. & 92 & 100,0 & 200 & 100,0 \\
\hline
\end{tabular}

RISCO RELATIVO (RR), QUI-QUNDRADO $\left(x^{2}\right)$ E NIVEL DE SIG NIFICANCIA DESCRITIVo (p), SEGUNDO TIPO DE MOSTRA

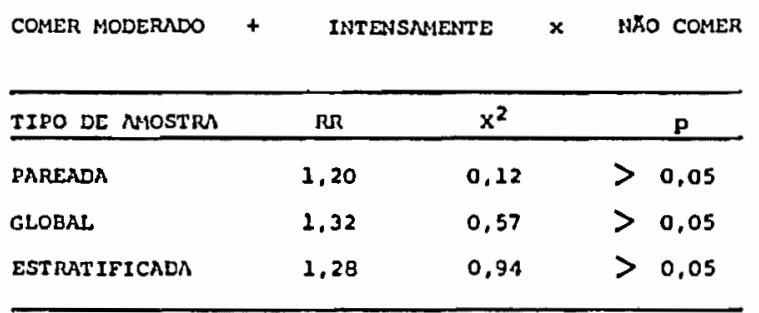




\section{TАBミ เ ^ 26}

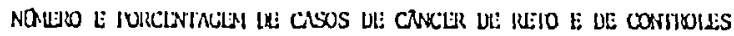
SEGUNDO CONSUMO IABITUNL DE OVOS

\begin{tabular}{|c|c|c|c|c|c|}
\hline \multirow{2}{*}{ CONITULL: } & \multicolumn{3}{|c|}{ cuso } & \multicolumn{2}{|c|}{ IOINL } \\
\hline & No wNit & $\begin{array}{l}\text { CONE: MUM: } \\
\text { RWN WNIE }\end{array}$ & $\begin{array}{l}\text { COND: INILN } \\
\text { SADENIE }\end{array}$ & NQ & 1 \\
\hline NTO CONE & 2 & 6 & 5 & 13 & 14,1 \\
\hline $\begin{array}{l}\text { COULE NDII: } \\
\text { RWANENIE }\end{array}$ & 3 & 10 & 21 & 34 & 37.0 \\
\hline $\begin{array}{l}\text { CWU: INILN } \\
\text { SWHENTE }\end{array}$ & 2 & 19 & 24 & 45 & 48.9 \\
\hline \multicolumn{5}{|l|}{ TOTAL } & 100,0 \\
\hline 1 & 7,6 & 38,0 & 54.4 & 100,0 & \\
\hline
\end{tabular}

\begin{tabular}{|c|c|c|c|c|}
\hline \multirow{2}{*}{ ovos } & \multicolumn{2}{|c|}{ croo } & \multicolumn{2}{|c|}{ (UNl(t)!l: } \\
\hline & NQ & 1 & NQ & $:$ \\
\hline No cons: & 7 & 7,6 & 23 & 11.5 \\
\hline $\begin{array}{l}\text { CONI NDIL: } \\
\text { RADWENITE }\end{array}$ & 35 & 38,0 & 74 & 37.0 \\
\hline $\begin{array}{l}\text { cuN: INILN } \\
\text { SNUNCE: }\end{array}$ & 50 & 54.4 & 103 & 51,5 \\
\hline TUINL & 92 & 100,0 & 200 & 100,0 \\
\hline
\end{tabular}

RISCO RELATIVO (RR), QUI-QUNDRADO $\left(X^{2}\right)$ E NIVEL DE SIG NIFICRNCIA DESCRITIVO (p), SEGUNDO TIFO DE NMOSTRA

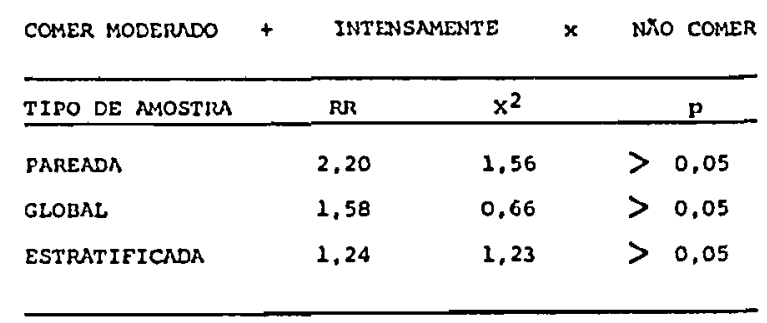




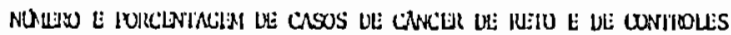
SEGUNDO CONSUMO MRDITUAL DE CARNE EM GERRL

\begin{tabular}{|c|c|c|c|c|c|}
\hline \multirow{2}{*}{ LUWIIULL: } & \multicolumn{3}{|c|}{ CASO } & \multicolumn{2}{|c|}{ IUIN } \\
\hline & NoO cond: & $\begin{array}{l}\text { CLELE MIIL } \\
\text { RUAMLNIE }\end{array}$ & $\begin{array}{l}\text { COWH: INrIN } \\
\text { SWHANRt: }\end{array}$ & NQ & 1 \\
\hline Niv cunn: & - & 2 & 4 & 6 & 6.5 \\
\hline 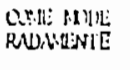 & 1 & 12 & 18 & 31 & 33,7 \\
\hline $\begin{array}{l}\text { WHII INIIN } \\
\text { SWUENIL }\end{array}$ & 2 & 14 & 39 & 55 & 59.8 \\
\hline \multirow{2}{*}{ IOIN } & 3 & 28 & 61 & 92 & 100,0 \\
\hline & 3,3 & 30,4 & 66.3 & 100,0 & \\
\hline
\end{tabular}

\begin{tabular}{|c|c|c|c|c|}
\hline \multirow{2}{*}{$\begin{array}{l}\text { CARNE } \\
\text { EM } \\
\text { GERAL }\end{array}$} & \multicolumn{2}{|c|}{ c150 } & \multicolumn{2}{|c|}{ (avilund: } \\
\hline & NP & i & No & 2 \\
\hline No cunll: & 3 & 3,3 & 10 & {$[n, 0$} \\
\hline $\begin{array}{l}\text { COML NOIL: } \\
\text { RALWyEN'E }\end{array}$ & 28 & 30.4 & 66 & 33.0 \\
\hline $\begin{array}{l}\text { CXNH: INIIN } \\
\text { SNHINII: }\end{array}$ & 61 & 66.3 & 124 & (i) 2.0 \\
\hline IOIN & 92 & 100,0 & 200 & 1110,0 \\
\hline
\end{tabular}

RISCO RELATIVO (RR), QUI-QUADRADO $\left(x^{2}\right)$ E NIVEL DE SIg NIFICANCIA DESCRITIVO (p), SEGUNDO TIFO DE AMOSTRA

\begin{tabular}{|c|c|c|c|c|}
\hline COMER MODERADO & INTE & ITE & $\mathbf{x}$ & NXO COMER \\
\hline TIPO DE AMOSTR & $\mathrm{RR}$ & $x^{2}$ & & $\mathbf{p}$ \\
\hline PARENDA & 2,00 & 0.44 & & $>0.05$ \\
\hline GLOBAL & 1,56 & 0,13 & & $>0.05$ \\
\hline ESTRATIFICADA & 1,24 & 0,90 & & $>0.05$ \\
\hline
\end{tabular}


I $\wedge$ B L L L $\wedge \underline{28}$

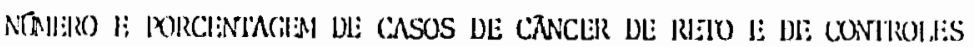

SEGUNDO CONSUMO ILAITUAL DE TIIPOS DE GORWURA

MOSIIUN PNIRENDN

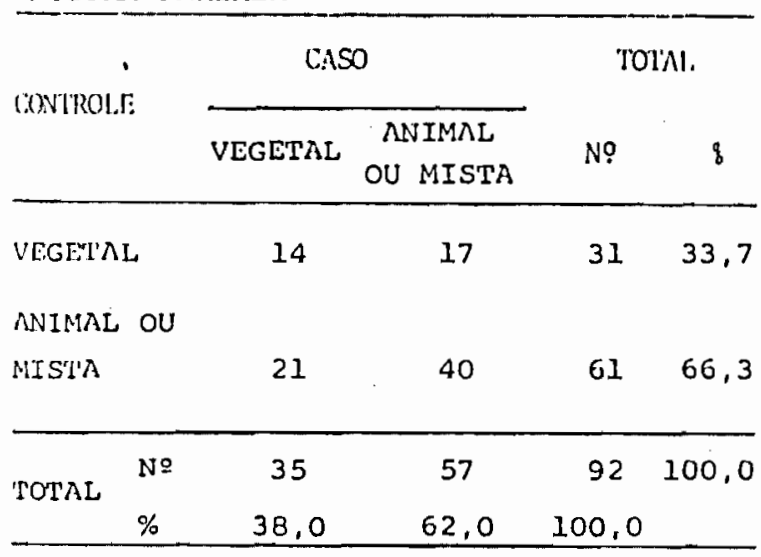

MOS'IR GLOBNL

\begin{tabular}{|c|c|c|c|c|}
\hline \multirow{2}{*}{ GORDUR $\Lambda$} & \multicolumn{2}{|c|}{$\mathrm{C} \wedge \mathrm{SO}$} & \multicolumn{2}{|c|}{ covilROLI: } \\
\hline & Nọ & $q$ & No & $\stackrel{0}{0}$ \\
\hline VEGET $\wedge \mathrm{I}$, & 35 & 38,0 & 62 & 31,0 \\
\hline \multicolumn{5}{|l|}{$\Lambda N I M \Lambda L$ OU } \\
\hline MISI' $\Lambda$ & 57 & 62,0 & 138 & 69,0 \\
\hline TOTAL & 92 & 100,0 & 200 & 100,0 \\
\hline
\end{tabular}

RISCO RELATIVO (RR), QUI-QUADRADO $\left(X^{2}\right)$ E NIVEL DE SIG NIFICRNCIA DESCRITIVO (p), SEGUNDO TIPO DE AMOSTRA

\begin{tabular}{llll}
\hline TIPO DE AMOSTRA & RR & $x^{2}$ & $\mathrm{p}$ \\
\hline PAREADA & 0.81 & 0.24 & $>0.05$ \\
GLOBAL & 0.73 & 1.11 & $>0.05$ \\
ESTRATIFICADA & 0.77 & 0.96 & $>0.05$ \\
\hline
\end{tabular}


TABELA 29

NOAERO E PORCLNTACHM DE CASOS DE CWWCFR DE REIO E DE CONTROLES SEGUNDO CONSUMO HAITUAL DE LEITE

\begin{tabular}{|c|c|c|c|c|c|}
\hline \multirow{2}{*}{ Conitert: } & \multicolumn{3}{|c|}{ caso } & \multicolumn{2}{|c|}{ TOTAL } \\
\hline & NKO BEBE & $\begin{array}{l}\text { BEBE ADDE } \\
\text { RUMENTE }\end{array}$ & $\begin{array}{l}\text { BEBE INTEN } \\
\text { SNEENTE }\end{array}$ & No & \\
\hline No BLERE & 4 & 3 & 32 & 19 & 20.7 \\
\hline $\begin{array}{l}\text { BEBEE RMUL- } \\
\text { RUWU:NTL: }\end{array}$ & - & 1 & 10 & 11 & 12,0 \\
\hline $\begin{array}{l}\text { REBE INTEN } \\
\text { SWUENTE }\end{array}$ & 11 & 2 & 49 & 62 & 67.3 \\
\hline rors. NQ & $\begin{array}{c}15 \\
16,3\end{array}$ & $\begin{array}{c}6 \\
6,5\end{array}$ & $\begin{array}{c}71 \\
77,2\end{array}$ & 100,0 & 100,0 \\
\hline
\end{tabular}

\begin{tabular}{|c|c|c|c|c|}
\hline \multirow{2}{*}{ LEITE } & \multicolumn{2}{|c|}{ CASO } & \multicolumn{2}{|c|}{ CONIROI:: } \\
\hline & NQ & 1 & N8 & \\
\hline NXO BLBBE & 15 & 16.3 & 42 & 21.0 \\
\hline $\begin{array}{l}\text { BEBE NDCE- } \\
\text { RAONLENIE }\end{array}$ & 6 & 6.5 & 17 & 8.5 \\
\hline $\begin{array}{l}\text { BEBLE INIEN } \\
\text { SMEENTE }\end{array}$ & 71 & 77,2 & 141 & 70.5 \\
\hline TOTN & 92 & 100,0 & 200 & 100,0 \\
\hline
\end{tabular}

RISCO RELATIVO (RR), QUI-QUADRADO $\left(X^{2}\right)$ E NIVEL DE SIG NIFICANCIA DESCRITIVO (p), SEGUNDO TIPO DE AMOSTRA

\begin{tabular}{lccc} 
BEBER MODERADO & INTENSAMENTE & $\times$ & NAO BEBER \\
\hline TIPO DE AMOSTRA & RR & $\mathrm{x}^{2}$ & $\mathrm{p}$ \\
\hline PAREADA & 1,36 & 0.35 & $>0,05$ \\
GLOBAL & 1,36 & 0.61 & $>0.05$ \\
ESTRATIFICADA & 1,05 & 0,19 & $>0.05$ \\
\hline
\end{tabular}




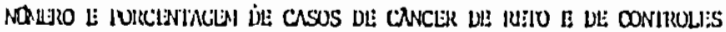
SEGUNDO CONSUMO UABITUAL DE QUEIJO

\begin{tabular}{|c|c|c|c|c|c|}
\hline \multirow{2}{*}{ CONIROLE } & \multicolumn{3}{|c|}{ CASO } & \multicolumn{2}{|c|}{ IOINAL } \\
\hline & No can & $\begin{array}{l}\text { CON: ADILE } \\
\text { RALWUENE }\end{array}$ & $\begin{array}{l}\text { COND: INILN } \\
\text { SNMUNTE }\end{array}$ & NP & 1 \\
\hline Nho cond: & 12 & 9 & 20 & 41 & 44,6 \\
\hline $\begin{array}{l}\text { OONE ADDE- } \\
\text { RUWAENTE } \\
\text { CONE INTEN }\end{array}$ & 6 & 13 & 18 & 37 & 40,2 \\
\hline SWIENIE & 2 & 4 & 8 & 14 & 15,2 \\
\hline \multirow{2}{*}{ TOTAL } & 20 & 26 & 46 & 92 & 100,0 \\
\hline & 21,7 & 28,3 & 50,0 & 100,0 & \\
\hline
\end{tabular}

AMOSTRA GLOBAL

\begin{tabular}{|c|c|c|c|c|c|}
\hline \multirow{2}{*}{ QUEIJO } & \multicolumn{2}{|c|}{ CASO } & \multicolumn{2}{|c|}{ CONIROLE } & \multirow{2}{*}{$\begin{array}{l}\text { RLSCO } \\
\text { R:LATHo }\end{array}$} \\
\hline & NQ & 9 & N? & l & \\
\hline Nho conll: & 20 & 21.7 & 85 & 42,5 & 1 \\
\hline \multicolumn{6}{|l|}{ CONE ADDE- } \\
\hline RADWLNIE & 26 & 28,3 & 76 & 38,0 & 1,45 \\
\hline \multicolumn{6}{|l|}{ CONE INIEN } \\
\hline SMENIL: & 46 & 50,0 & 39 & 19,5 & 5,01 \\
\hline TOIAL & 92 & 100,0 & 200 & 100,0 & \\
\hline
\end{tabular}

RISCO RELATIVO (RR), QUI-QUADRNDO $\left(X^{2}\right)$ E NAVEL DE SIC NIFIChNCIA DESCRITIVO $(p)$, SEGUNDO TIPO DE AMOSTAN

\begin{tabular}{lccc} 
COMER MODERADO & + INTENSMMENTE & $\mathrm{x}$ & NKO COMER \\
\hline TIPO DE AMOSTRA & $\mathrm{RR}$ & $\mathrm{x}^{2}$ & $\mathrm{p}$ \\
\hline PAREADA & 3,62 & 10,81 & $<0,01$ \\
GLOBAL & 2,66 & 10,91 & $<0,01$ \\
ESTRATIFICADA & 2,66 & 11,21 & $<0,01$ \\
\hline
\end{tabular}


TABELA 31

NANENO E RORCENINCIN DL: CASOS DE CNCER DE RETO E DE CONIROLES SEGUNDO CONSUMO ILABITUAL DE VERDURAS

\begin{tabular}{|c|c|c|c|c|c|}
\hline \multirow{2}{*}{ COW'JTULE: } & \multicolumn{3}{|c|}{ USO } & \multicolumn{2}{|c|}{ JOI'AL } \\
\hline & No cont: & $\begin{array}{l}\text { OALE HDIL: } \\
\text { RUNLNIE }\end{array}$ & $\begin{array}{l}\text { CONI: INTLN } \\
\text { SWHENTE }\end{array}$ & N8 & 1. \\
\hline NW cande & 1 & 2 & 5 & 日 & 8,7 \\
\hline 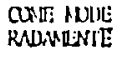 & 3 & 5 & 12 & 20 & 21.7 \\
\hline $\begin{array}{l}\text { OWU: INIEN } \\
\text { SNUNILE }\end{array}$ & 6 & 13 & 45 & 64 & 69.6 \\
\hline \multirow{2}{*}{ IUINL } & 10 & 20 & 62 & 92 & 100,0 \\
\hline & 10.9 & 21.7 & 67,4 & 100,0 & \\
\hline
\end{tabular}

\begin{tabular}{|c|c|c|c|c|}
\hline \multirow{2}{*}{ VERDURAS } & \multicolumn{2}{|c|}{ caso } & \multicolumn{2}{|c|}{ WNIIUI.I: } \\
\hline & NQ & 1 & N8 & : \\
\hline NRO CONit: & 10 & 10,9 & 31 & 15,5 \\
\hline $\begin{array}{l}\text { CONLE MDIL: } \\
\text { RNLWDENIEE }\end{array}$ & 20 & 21.7 & 40 & 20.0 \\
\hline $\begin{array}{l}\text { CON: INILN } \\
\text { SNHWNLE }\end{array}$ & 62 & 67,4 & 129 & 64.5 \\
\hline TUIN, & 92 & 100,0 & 200 & 100,0 \\
\hline
\end{tabular}

RISCO RELATIVO (RR), QUI-QUADRADO ( $X^{2}$ ) E NIVEL DE SIG NIFICANCIA DESCRITIVO (p), SEGUNDO TIPO DE AMOSTRA

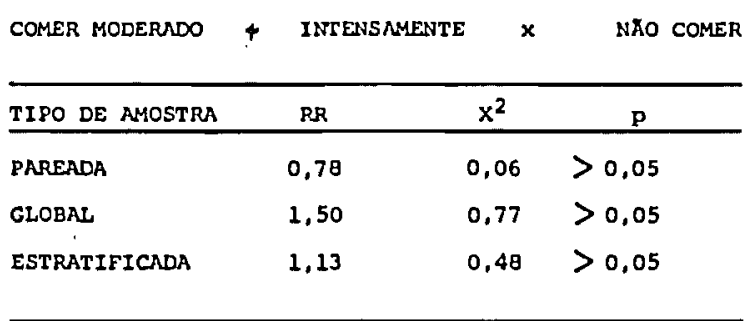


TABELA 32

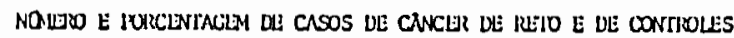
SEGUNDO CONSUMO IAagITUAL DE LEGUMINOSAS

MUSIM INLEN

\begin{tabular}{|c|c|c|c|c|c|}
\hline \multirow{2}{*}{ OONIIELE } & \multicolumn{3}{|c|}{$\operatorname{crso}$} & \multicolumn{2}{|c|}{ TOTN } \\
\hline & NTo COA: & $\begin{array}{l}\text { CONE ADIDE } \\
\text { RAWENTE }\end{array}$ & $\begin{array}{l}\text { OWM: INIEN } \\
\text { SALENIE }\end{array}$ & NQ & 1. \\
\hline MO can: & - & - & 1 & 1 & 1,1 \\
\hline $\begin{array}{l}\text { CYU: MLU: } \\
\text { RNUNENIE }\end{array}$ & - & - & 6 & 6 & 6,5 \\
\hline $\begin{array}{l}\text { Con: INILN } \\
\text { SWHiNIE }\end{array}$ & 2 & 15 & 68 & B5 & 81,5 \\
\hline \multicolumn{2}{|l|}{ TUIN } & 15. & 75 & 92 & 100,0 \\
\hline 1 & 2,2 & 16,3 & 81,5 & 100,0 & \\
\hline
\end{tabular}

\begin{tabular}{|c|c|c|c|c|}
\hline \multirow{2}{*}{ LEGUMINOSAS } & \multicolumn{2}{|c|}{$\cos 0$} & \multicolumn{2}{|c|}{ CONIIOLE } \\
\hline & NQ & 1 & No & 1 \\
\hline NKO COAE & 2 & 2,2 & 3 & 1.5 \\
\hline $\begin{array}{l}\text { CONL: HUD } \\
\text { MONWENIE' }\end{array}$ & 15 & 16,3 & 19 & 9.5 \\
\hline $\begin{array}{l}\text { CONAI INTEN } \\
\text { SNENTE }\end{array}$ & 75 & 81,5 & 178 & 89.0 \\
\hline TOINL & 92 & 100,0 & 200 & 100,0 \\
\hline
\end{tabular}

RISCO RELATIVO (RR), QUI-QUADRADO $\left(x^{2}\right)$ E NIVEL DE SIG NIFICANCIA DESCRITIVO ( $p$ ), SEGLNDO TIPO DE AMOSTRA

\begin{tabular}{lccc} 
COMER MODERADO & INTENSAMENTE & $\mathrm{x}$ & NKO COMER \\
\hline TIPO DE MMOSTRA & RR & $\mathrm{x}^{2}$ & $\mathrm{p}$ \\
\hline PAREADA & 0.50 & 0,00 & $>0.05$ \\
GLOBAL & 0,68 & 0.00 & $>0.05$ \\
ESTRATIFICADA & 0,66 & 1,90 & $>0.05$
\end{tabular}


TABBLA 33

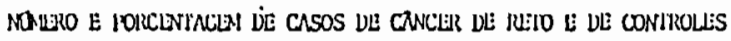
SEGUNDO CONSUMO HATITUAL DE LEGUMES

\begin{tabular}{|c|c|c|c|c|c|}
\hline \multirow{2}{*}{ CANITLLEE } & \multicolumn{3}{|c|}{ crso } & \multicolumn{2}{|c|}{ IOTNL } \\
\hline & No CONEB & $\begin{array}{l}\text { CONE ADDE } \\
\text { RUWWNIE }\end{array}$ & $\begin{array}{l}\text { CONE: INILN } \\
\text { SMLENIL }\end{array}$ & NQ & 1 \\
\hline$N$ NO OXE & 2 & 1 & 9 & 12 & 13,0 \\
\hline \multicolumn{5}{|l|}{ COND: NUDE- } & 18,5 \\
\hline \multicolumn{6}{|l|}{ CONE INTEN } \\
\hline SUINRE & 9 & 14 & 40 & 63 & 68,5 \\
\hline \multirow[t]{2}{*}{ TOTAL } & 12 & 20 & 60 & 92 & 100,0 \\
\hline & 13,0 & 21.7 & 65,3 & 100.0 & \\
\hline
\end{tabular}

\begin{tabular}{|c|c|c|c|c|c|}
\hline \multirow{2}{*}{ LEGUMES } & \multicolumn{2}{|c|}{$\operatorname{crso}$} & \multicolumn{2}{|c|}{ CONIROLE } & \multirow{2}{*}{$\begin{array}{l}\text { MUSCO } \\
\text { HaATIVO }\end{array}$} \\
\hline & NP & 1 & NQ & 1 & \\
\hline NAO CONE & 12 & 13.0 & 51 & 25,5 & 1 \\
\hline \multicolumn{6}{|l|}{ CONE ADDE- } \\
\hline RADWLNIE & 20 & 21,7 & 29 & 14,5 & 2.93 \\
\hline \multicolumn{6}{|l|}{ CONE INIEN } \\
\hline SNEWTE & 60 & 65,3 & 120 & 60.0 & 2,12 \\
\hline JOINL & 92 & 100,0 & 200 & 100,0 & \\
\hline
\end{tabular}

RISCO RELATIVÓ (RR), QUI-QUADRADO, $\left(x^{2}\right)$ E NIVEL DE SIG NIFICANCIA DESCRITIVO (p), SEGUNDO TIPO DE AMOSTRA

\begin{tabular}{|c|c|c|c|c|}
\hline COMER MODERADO & \multicolumn{2}{|c|}{ INTENSAMENTE } & $\mathbf{x}$ & NXO COMER \\
\hline TIPO DE MOSTRA & $\mathrm{RR}$ & $x^{2}$ & & $\mathbf{p}$ \\
\hline PAREADA & 1.00 & 0.05 & & $>0,05$ \\
\hline GLOBAL & 2,28 & 5.07 & 0,0 & $<\mathrm{p}<0,05$ \\
\hline ESTRATIFICAOA & 1.26 & 1.93 & & $>0.05$ \\
\hline
\end{tabular}


TABELA 34

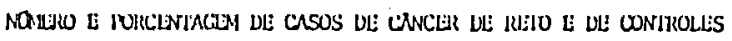
SEGUNDO CONSLMO HABITUAL DE FRUTAS

\begin{tabular}{|c|c|c|c|c|c|}
\hline \multirow{2}{*}{ curitiule: } & \multicolumn{3}{|c|}{ caso } & \multicolumn{2}{|c|}{ TOTAL } \\
\hline & Mo call: & $\begin{array}{l}\text { CON: ADIJL } \\
\text { RADWIENIE }\end{array}$ & $\begin{array}{l}\text { COM: INILN } \\
\text { SNEENIE }\end{array}$ & NQ & 1 \\
\hline No cand & - & 1 & 3 & 4 & 4,4 \\
\hline $\begin{array}{l}\text { CONE ADUL- } \\
\text { MAWWENTE }\end{array}$ & 2 & 7 & 27 & 25 & 27.1 \\
\hline $\begin{array}{l}\text { CONE INרEN } \\
\text { SNUENIE }\end{array}$ & 3 & 22 & 38 & 63 & 68,5 \\
\hline IOTN NP & $\begin{array}{c}4 \\
4.4\end{array}$ & $\begin{array}{c}30 \\
32,6\end{array}$ & $\begin{array}{c}58 \\
63,0\end{array}$ & $\begin{array}{l}92 \\
100,0\end{array}$ & 100,0 \\
\hline
\end{tabular}

\begin{tabular}{|c|c|c|c|c|c|}
\hline \multirow{2}{*}{ FRUTAS } & \multicolumn{2}{|c|}{ CASO } & \multicolumn{2}{|c|}{ CONIROLL: } & \multirow{2}{*}{$\begin{array}{l}\text { IISSO } \\
\text { IU:AIIVO }\end{array}$} \\
\hline & NP & 1 & NQ & 1 & \\
\hline NTO CO.U: & 4 & 4,4 & 26 & 13,0 & 1 \\
\hline \multicolumn{6}{|l|}{ OONE MDUL:- } \\
\hline RAOWLNIE & 30 & 32,6 & 43 & 21.5 & 4.53 \\
\hline \multicolumn{6}{|l|}{ CONI' INIEN } \\
\hline SNEENTE & 58 & 63.0 & 131 & 65,5 & 2,88 \\
\hline TOTAL & 92 & 100,0 & 200 & 100,0 & \\
\hline
\end{tabular}

RISCO RELATIVO (RR), QUI-QUADRADO ( $X^{2}$ ) E NIVEL DE SIG NIFICANCIA DESCRITIVO (p), SEGUNDO TIPO DE AMOSTRA

\begin{tabular}{lccr} 
COMER MODERNDO & INTENSAMENTE & $X$ & NKO COMER \\
\hline IIPO DE MNOSTRA & RR & $X^{2}$ & \multicolumn{1}{c}{$P$} \\
\hline PAREADA & 1,00 & 0.12 & $>0.05$ \\
GLOBAL & 3.29 & 4.22 & $0.01<p<0.05$ \\
ESTRATIFICADA & 1,20 & 0.22 & $>0.05$ \\
\hline
\end{tabular}


TABELA 35

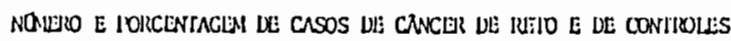
SEGUNDO CONSUMO ILABITUAL DE VERDURAS E FRUTAS

\begin{tabular}{|c|c|c|c|c|c|}
\hline \multirow{2}{*}{ corriull: } & \multicolumn{3}{|c|}{ inso } & \multicolumn{2}{|c|}{ IOTNL } \\
\hline & NTU COAL & 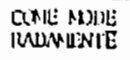 & $\begin{array}{l}\text { COXLE INILN } \\
\text { SNUENILE }\end{array}$ & No & 1 \\
\hline No cat: & - & - & 2 & 2 & 2,2 \\
\hline $\begin{array}{l}\text { CORE RIUU: } \\
\text { RWWUENE }\end{array}$ & - & 4 & 7 & 11 & 12,0 \\
\hline $\begin{array}{l}\text { OWD: INILN } \\
\text { SNGPGIE }\end{array}$ & 2 & 12 & 65 & 79 & 85,8 \\
\hline \multirow{2}{*}{ IOTNL } & 2 & 16 & 74 & 92 & 100,0 \\
\hline & 2,2 & 17.4 & 80,4 & 100,0 & \\
\hline
\end{tabular}

\begin{tabular}{|c|c|c|c|c|}
\hline \multirow{2}{*}{$\begin{array}{l}\text { VERDURAS } \\
\text { FRUTAS }\end{array}$} & \multicolumn{2}{|c|}{ ciso } & \multicolumn{2}{|c|}{ CUNTIRULE: } \\
\hline & No & 1 & N9 & 1 \\
\hline NHO CONE & 2 & 2.2 & 14 & 7.0 \\
\hline $\begin{array}{l}\text { Conit: NDDL: } \\
\text { RWWW-1ENI'E }\end{array}$ & 16 & 17.4 & 22 & 11,0 \\
\hline $\begin{array}{l}\text { COA: INILN } \\
\text { SNALNTE }\end{array}$ & 74 & 80,4 & 164 & 82,0 \\
\hline TOIN & 92 & 100,0 & 200 & 100,0 \\
\hline
\end{tabular}

RISCO RELATIVǪ (RR), QUI-QUADRADO $\left(X^{2}\right)$ E NIVEL DE SIG NIFICANCIA DISCRITIVO ( $p$ ), SEGUNDO TIPO DE AMOSTR

\begin{tabular}{lccc} 
COME MODERNDO + & INTENSAMENTE & $\boldsymbol{x}$ & NAO COME \\
\hline TIPO DE AMOSTR & $\mathrm{RR}$ & $\mathrm{x}^{2}$ & $\mathrm{p}$ \\
\hline PAREADA & 1,00 & 0,25 & $>0,05$ \\
GLOBAL & 3,32 & 1,98 & $>0,05$ \\
ESTRATIFICADA & 1,04 & 0,03 & $>0,05$ \\
\hline
\end{tabular}


TABELA 36

NQNERO E PORCENTAGRN DE CASOS DE CNACER DE RETD E DE CONTROLES SEGUNDO CONSUMO HAITUAL DE FARINIA DE MMNDIOCA

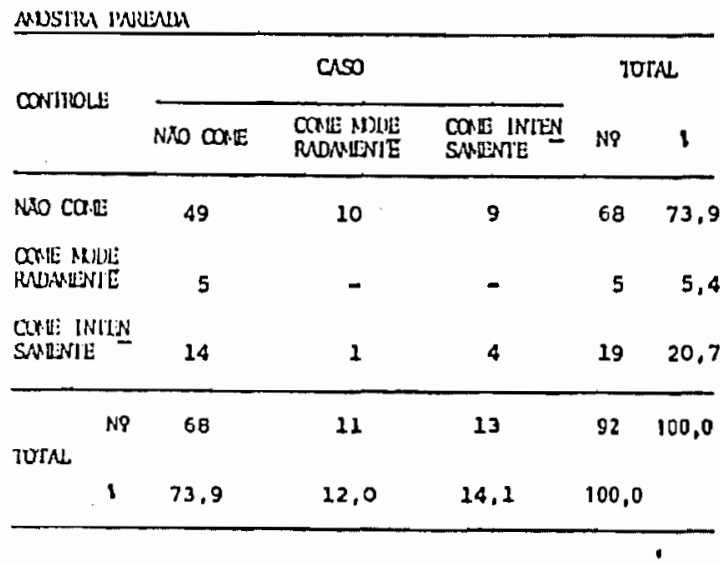

\begin{tabular}{|c|c|c|c|c|}
\hline \multirow{2}{*}{$\begin{array}{l}\text { EARINILA } \\
\text { DE } \\
\text { MANDIOCA }\end{array}$} & \multicolumn{2}{|c|}{ CASO } & \multicolumn{2}{|c|}{ CONIILLE } \\
\hline & N9 & 1 & N9 & 1 \\
\hline NO CONE & 68 & 73.9 & 160 & 80,0 \\
\hline $\begin{array}{l}\text { COUL NDDE } \\
\text { HAWNDENIE }\end{array}$ & 11 & 12,0 & 5 & 2,5 \\
\hline $\begin{array}{l}\text { CONL: INTIEN } \\
\text { SWUENLE }\end{array}$ & 13 & 14,1 & 35 & 17,5 \\
\hline TOTAL & 92 & 100,0 & 200 & 100,0 \\
\hline
\end{tabular}

RISCO RELATIVO (RR), QUI-QUADRADO $\left(x^{2}\right)$ E NAVEL DE SIG NIFICANCIA DESCRITIVO (p), SEGUNDO TIPO DE MMOSTRA

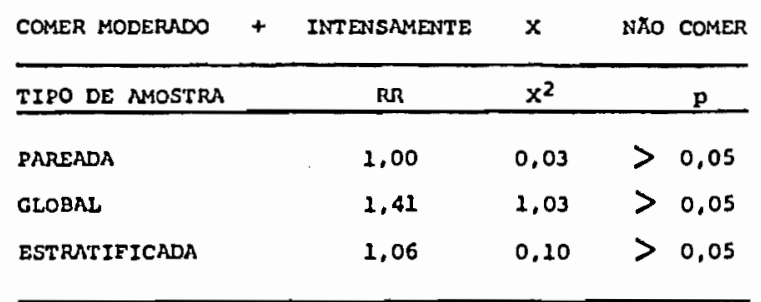


T A B L L A, 37

NOEW E POICENINGE DE CASOS DE CNCEH DE REIO E DE CONITOLES SEGUNDO CONSUMO HABITUAL DE CEREAIS

\begin{tabular}{|c|c|c|c|c|c|}
\hline \multirow{2}{*}{ CONTROLE } & \multicolumn{3}{|c|}{ CASO } & \multicolumn{2}{|c|}{ TOIAL } \\
\hline & NXO 00 VE & $\begin{array}{l}\text { CONL AUNE } \\
\text { RADNENTE }\end{array}$ & $\begin{array}{l}\text { OONL INIEN } \\
\text { SARDETE }\end{array}$ & Ne & 1 \\
\hline No CaE & - & - & - & - & - \\
\hline $\begin{array}{l}\text { AXE: ADUE: } \\
\text { ROPWENIE }\end{array}$ & - & - & 1 & 1 & 1,1 \\
\hline $\begin{array}{l}\text { CUND: INTIN } \\
\text { SNUENIE }\end{array}$ & - & 3 & 88 & 91 & 98,9 \\
\hline \multirow[t]{2}{*}{ TOTAL } & - & 3 & 89 & 92 & 100,0 \\
\hline & - & 3,3 & 96.7 & 100,0 & \\
\hline
\end{tabular}

\begin{tabular}{|c|c|c|c|c|}
\hline \multirow{2}{*}{ CEREAIS } & \multicolumn{2}{|c|}{ CASO } & \multicolumn{2}{|c|}{ CONIIULE } \\
\hline & NP & 1 & No & 1 \\
\hline No CONE & - & - & 2 & 1.0 \\
\hline $\begin{array}{l}\text { CONE ADOE: } \\
\text { RADAMENTE }\end{array}$ & 3 & 3,3 & 1 & 0.5 \\
\hline $\begin{array}{l}\text { CONH INILN } \\
\text { SALENTE }\end{array}$ & 89 & 97.9 & 197 & 98.5 \\
\hline TOIAL & 92 & 100,0 & 200 & 100,0 \\
\hline
\end{tabular}

RISCO RELATIVO (RR), QUI-QUNDRADO $\left(X^{2}\right)$ E NAVEL DE SIG NIFICANCIA DESCRITIVO $(p)$, SEGUNDO TIPO DE AMOSTRA

\begin{tabular}{lccc} 
COMER MODERRDO & + INTENSAMENTE & $x$ & NXO COMER \\
\hline TIPO DE AMOSTRA & RR & $x^{2}$ & $p$ \\
\hline PAREADA & 0,00 & 0,00 & $>0,05$ \\
GLOBAL & INDETERMINADO & 0,00 & $>0,05$ \\
ESTRATIFICADA & 0,82 & 0,0 & $>0,05$ \\
\hline
\end{tabular}

$184 \div 0$ 
TA B L LA

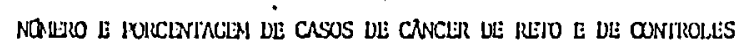
SEGUNDO CONSUMO IIATITUAL DE RAfZES E TUBÉRCULOS

\section{MOSTIR PAREADA}

\begin{tabular}{|c|c|c|c|c|c|}
\hline \multirow{2}{*}{ COWIRULL: } & \multicolumn{3}{|c|}{ CASO } & \multicolumn{2}{|c|}{ IOTAL } \\
\hline & NO COE & $\begin{array}{l}\text { CONE ADUUE } \\
\text { RADWENIE }\end{array}$ & $\begin{array}{l}\text { CONL: INTLN } \\
\text { SNLENIE }\end{array}$ & NP & I \\
\hline
\end{tabular}

\begin{tabular}{lccccc} 
NO COND: & - & 3 & 7 & 10 & 10,9 \\
$\begin{array}{l}\text { COAE NDUL- } \\
\text { RADANENIE }\end{array}$ & - & 25 & 11 & 36 & 39,1 \\
$\begin{array}{l}\text { CONLE INIEN } \\
\text { SALENIE }\end{array}$ & 1 & 18 & 27 & 46 & 50,0 \\
\hline NOTAL NQ & 1 & 46 & 45 & 92 & 100,0 \\
1 & 1.1 & 50,0 & 48,9 & 100,0 & \\
\hline
\end{tabular}

\section{AMOSTRA GLODAL}

\begin{tabular}{|c|c|c|c|c|c|}
\hline \multirow{2}{*}{$\begin{array}{l}\text { RAfZES } \\
\text { E } \\
\text { TUBÉRCULO }\end{array}$} & \multicolumn{2}{|c|}{ caso } & \multicolumn{2}{|c|}{ CANIKOLL: } & \multirow{2}{*}{$\begin{array}{l}\text { RISLO } \\
\text { RE:AIIVO }\end{array}$} \\
\hline & No & 1 & No & 1 & \\
\hline NAO COUE & 1 & 1,1 & 20 & 10,0 & 1 \\
\hline \multicolumn{6}{|l|}{ CONE ADUL } \\
\hline RALWENTE & 46 & 50,0 & 74 & 37,0 & 12,43 \\
\hline \multicolumn{6}{|l|}{ CONE INTEN } \\
\hline SANENTL & 45 & 48,9 & 106 & 53,0 & 8.49 \\
\hline TOTAL & 92 & 100,0 & 200 & 100,0 & \\
\hline
\end{tabular}

RISCO RELATIVO (RR), QUI-QUADRADO $\left(x^{2}\right)$ E NFVEL DE SIG NIFIChNCIA DESCRITIVO.(p), SECUNDO TIPO DE AMOSTRA

\begin{tabular}{lccc} 
COMER MODERADO & + INTENSAMENTE & $\boldsymbol{x}$ & NAO COMER \\
\hline TIPO DE AMOSTRA & $\mathrm{RR}$ & $\mathrm{x}^{2}$ & $\mathrm{P}$ \\
\hline PAREACA & 10,00 & 5,82 & $0,01<\mathrm{p}<0,05$ \\
GLOBAL & 10,11 & 6,22 & $0,01<\mathrm{p}<0,05$ \\
ESTRATIEICNOA & 1,14 & 0,44 & $>0,05$
\end{tabular}




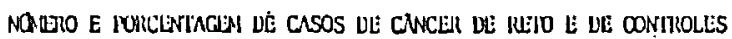
SEGUNDO CONSUMO HABITUAL DE DOCES

\begin{tabular}{|c|c|c|c|c|c|}
\hline \multirow{2}{*}{ (ONITWLLE } & \multicolumn{3}{|c|}{ CAsO } & \multicolumn{2}{|c|}{ TOINL } \\
\hline & NO CUIL & $\begin{array}{l}\text { CXYS ADIUE } \\
\text { RUWDINE }\end{array}$ & $\begin{array}{l}\text { COND! INTLN } \\
\text { SNAUNIE }\end{array}$ & N9 & 1 \\
\hline NO COAE & 22 & 13 & 18 & 53 & 57,6 \\
\hline 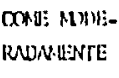 & 9 & 9 & 5 & 23 & 25,0 \\
\hline $\begin{array}{l}\text { CON: INIIN } \\
\text { SWAEIIE }\end{array}$ & B & 5 & 3 & 16 & 17.4 \\
\hline IUINS. NQ & $\begin{array}{c}39 \\
42,4\end{array}$ & $\begin{array}{c}27 \\
29,3\end{array}$ & $\begin{array}{c}26 \\
28,3\end{array}$ & $\begin{array}{c}92 \\
100,0\end{array}$ & 100,0 \\
\hline
\end{tabular}

\begin{tabular}{|c|c|c|c|c|c|}
\hline \multirow{2}{*}{ DOCES } & \multicolumn{2}{|c|}{$C \wedge O O$} & \multicolumn{2}{|c|}{ CarItrolle } & \multirow{2}{*}{$\begin{array}{l}\text { MISOO } \\
\text { MELATIO }\end{array}$} \\
\hline & NP & 1 & NQ & 1 & \\
\hline NTO COAL & 39 & 42.4 & 117 & 58,5 & 1 \\
\hline \multicolumn{6}{|l|}{ CONE: NNUE- } \\
\hline RULWENIIS & 27 & 29,3 & 42 & 21,0 & 3.95 \\
\hline \multicolumn{6}{|l|}{ CONA INILN } \\
\hline SNLENTL & 26 & 28,3 & 41 & 20,5 & 3,68 \\
\hline מנIAL & 92 & 100,0 & 200 & 100,0 & \\
\hline
\end{tabular}

RISCO RELATIVO (RR), QUI-QUADRRDO $\left(X^{2}\right)$ E NFVEL DE SIg NIFICHNCIA DESCRITIVO $(p)$, SEGUNDO TIPO DE AMOSTR

\begin{tabular}{lcccr} 
COMER MODERAD & + & INTENSAMENTE & $x$ & NAO COMER \\
\hline TIPO DE NMOSTRA & RR & X2 & p \\
\hline ENREADA & 1,82 & 3,52 & \\
GLOBAL & 1,92 & 5,94 & $0,01<\mathrm{p}<0,05$ \\
ESTRATIFICADA & 1,43 & 5,38 & $0,01<\mathrm{p}<0,05$
\end{tabular}




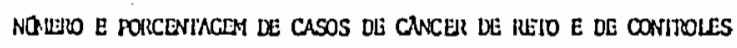
SEGUNDO CONSUMO ILABITUAL DE PIMENTA DO REINO

MUSIRI NULEN

\begin{tabular}{|c|c|c|c|c|c|}
\hline \multirow{2}{*}{ DONIIUI: } & \multicolumn{3}{|c|}{$C A S O$} & \multicolumn{2}{|c|}{ TOTAL } \\
\hline & NOO OXI: & $\begin{array}{l}\text { CONL ADIIR } \\
\text { RANLENSE }\end{array}$ & $\begin{array}{l}\text { COR: INTEN } \\
\text { SNU:NII }\end{array}$ & NQ & 1 \\
\hline No CULE & 60 & - & - & 60 & 65,2 \\
\hline $\begin{array}{l}\text { COR: NDUE } \\
\text { RADWUENIE }\end{array}$ & - & 13 & - & 13 & 14,1 \\
\hline $\begin{array}{l}\text { CONU: INILEN } \\
\text { SNDPVIt: }\end{array}$ & - & - & 19 & 19 & 20,7 \\
\hline NQ & 60 & 13 & 19 & 92 & 100,0 \\
\hline \multicolumn{6}{|l|}{ TUIN. } \\
\hline 1 & 65,2 & 14,1 & 20,7 & 100,0 & \\
\hline
\end{tabular}

\begin{tabular}{|c|c|c|c|c|}
\hline \multirow{2}{*}{$\begin{array}{c}\text { PIMENTA } \\
\text { DO } \\
\text { REINO }\end{array}$} & \multicolumn{2}{|c|}{ caso } & \multicolumn{2}{|c|}{ CONITIII: } \\
\hline & NP & 1 & NQ & 1 \\
\hline NTo cont: & 60 & 65,2 & 131 & 65.5 \\
\hline $\begin{array}{l}\text { CONE NDIUE } \\
\text { WWWENIT }\end{array}$ & 13 & 14,1 & 15 & 7.5 \\
\hline $\begin{array}{l}\text { COWE INILN } \\
\text { SNENIE }\end{array}$ & 19 & 20.7 & 54 & 27,0 \\
\hline TOTAL & 92 & 100,0 & 200 & 100,0 \\
\hline
\end{tabular}

RISCO RELATIVO (RR), QUI-OUADRADO $\left(x^{2}\right)$ E NIVEL DE SIG NIFICANCIA DESCRITIVO (p), SEGUNDO TIFO DE AMOSTRA

\begin{tabular}{|c|c|c|c|c|}
\hline COMER MODERNDO & + & INTENSAMENTE & $x$ & NRO COMER \\
\hline TIPO DE MMOSTRA & & $R R$ & $x^{2}$ & p \\
\hline PAREADA & & INDETERMINADO & - & - \\
\hline GLOBAL & & 1,01 & 0,01 & $>0.05$ \\
\hline ESTRATIFICADA & & 0,92 & 0.34 & $>0,05$ \\
\hline
\end{tabular}

$0 \div 0$ 
$T A B E L \wedge 41$

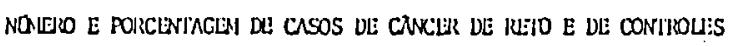
SEGUNDO CONSUMO HABITUAL DE PIMENTA VERMELHA ARDIDA

MDSIIU WNERM

\begin{tabular}{|c|c|c|c|c|c|}
\hline \multirow{2}{*}{ OUNTIOLE } & \multicolumn{3}{|c|}{ CASO } & \multicolumn{2}{|c|}{ TOI'AL } \\
\hline & NTo cury: & $\begin{array}{l}\text { CONIE MDIIS } \\
\text { RONENIENIE }\end{array}$ & $\begin{array}{l}\text { CON: INTIN } \\
\text { SADENIE }\end{array}$ & NQ & 1 \\
\hline MO CONE & 53 & 6 & 13 & 72 & 78,3 \\
\hline $\begin{array}{l}\text { ONEE AOUE } \\
\text { RADNEENTE }\end{array}$ & 2 & - & 1 & 3 & 3.3 \\
\hline $\begin{array}{l}\text { COND: INTEN } \\
\text { SANENIE }\end{array}$ & 13 & 1 & 3 & 17 & 18,5 \\
\hline NQ & 68 & 7 & 17 & 92 & 100,0 \\
\hline \multicolumn{6}{|l|}{ 3OIAL } \\
\hline 1 & 73.9 & 7,6 & 18,5 & 100,0 & \\
\hline
\end{tabular}

MUSIR GLOBAL

\begin{tabular}{|c|c|c|c|c|}
\hline \multirow{2}{*}{$\begin{array}{l}\text { PIMENTA } \\
\text { VERMELHA } \\
\text { ARDIDA }\end{array}$} & \multicolumn{2}{|c|}{ crso } & \multicolumn{2}{|c|}{ CONIJWLE } \\
\hline & NQ & 1 & NQ & : \\
\hline No CONA & 68 & 73,9 & 246 & 73,0 \\
\hline $\begin{array}{l}\text { CONL: ADUE } \\
\text { RADWENIE }\end{array}$ & 7 & 7.6 & 10 & 5.0 \\
\hline $\begin{array}{l}\text { CONL: INILN } \\
\text { SNLENIE }\end{array}$ & 17 & 18,5 & 44 & 22,0 \\
\hline JOTAL & 92 & 100,0 & 200 & 100,0 \\
\hline
\end{tabular}

RISCO RELATIVO (RR), QUI-QUADRADO $\left(X^{2}\right)$ E NFVEL DE SIG NIFICANCIA DESCRITIVO (p), SEGUNDO TIPO DE AMOSTRA

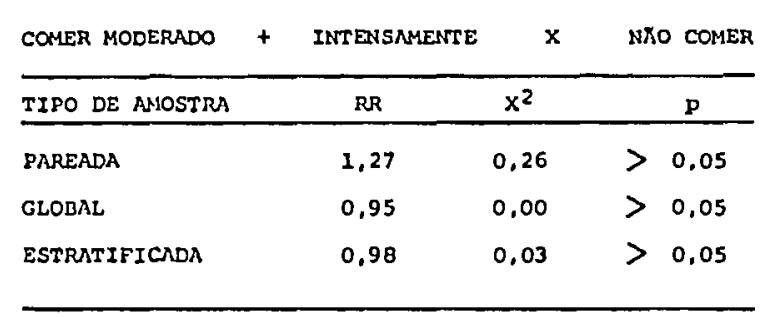


I $\triangle \mathrm{B}$ E L $\wedge \quad 42$

NÚMERO E PORCEN'SGEM DE CASOS DE CANCER LE REHO l: LE:

CONIROLES SEGUNDO CONSUMO IINBIIUNL DE ORĹCANNO E COLOMTU

WUSIU ГNRENDN

\begin{tabular}{|c|c|c|c|c|}
\hline \multirow{2}{*}{ CUNTROLLE } & \multicolumn{2}{|c|}{ c^so } & \multicolumn{2}{|c|}{ 'T'ז' } \\
\hline & WTO COME & COME & № & $\%$ \\
\hline NTO CONE & 32 & 6 & 38 & 41,3 \\
\hline $\cos 1 \mathrm{E}$ & 40 & 14 & 54 & 58,7 \\
\hline \multirow{2}{*}{ TOIAL } & 72 & 20 & 92 & 100.0 \\
\hline & 78,3 & 21,7 & 100. & \\
\hline
\end{tabular}

MMOSI'IX CLOHNL

\begin{tabular}{|c|c|c|c|c|}
\hline & \multicolumn{2}{|c|}{ cnso } & \multicolumn{2}{|c|}{ CONITROLF; } \\
\hline & No & $\%$ & No & 㐬 \\
\hline NXO COME & 72 & 78,3 & 129 & $6 n, 5$ \\
\hline COME & 20 & 21,7 & 71 & 35.5 \\
\hline 'I'OTAL & 92 & 100,0 & 200 & 100,0 \\
\hline
\end{tabular}

RISCO RELATIVO (RR), QUI-QUADRADO $\left(\mathrm{X}^{2}\right)$ E NfVEL DE SIGNIFICANCIA DESCRITIVO (p), SEGUNDO TIPO DE AMOSTRA

\begin{tabular}{|c|c|c|c|}
\hline I'IPO DE MNOS'TRA & RR & $x^{2}$ & $\underline{p}$ \\
\hline PNREADA & 0.15 & 23,67 & $<0,01$ \\
\hline GLOBAL & 0,50 & 4,94 & $0,01<\mathrm{p}<0,05$ \\
\hline ESTRALIFICADA & 0,44 & 7.29 & $<0,01$ \\
\hline
\end{tabular}


T A B E L A

NÚMERO E PORCENTAGEM DE CASOS DE CAANCER DE RETO E DE

CONTROLES SEGUNDO CONSUMO HABITUAL DE TODOS OS TEMPEROS

\begin{tabular}{|c|c|c|c|c|}
\hline \multirow{2}{*}{ CONTROLE } & \multicolumn{2}{|c|}{ CASO } & \multicolumn{2}{|c|}{ TOTAL } \\
\hline & NXO COME & COME & NN & $\%$ \\
\hline NXO COME & 12 & 14 & 26 & 28,3 \\
\hline COME & 26 & 40 & 66 & 71,7 \\
\hline \multirow[t]{2}{*}{ TOTAL } & 38 & 54 & 92 & 100,0 \\
\hline & 41,3 & 58,7 & 100, & \\
\hline
\end{tabular}

\begin{tabular}{|c|c|c|c|c|}
\hline \multirow{2}{*}{ TEMPEROS } & \multicolumn{2}{|c|}{ CASO } & \multicolumn{2}{|c|}{ CONTROLE } \\
\hline & No & $\%$ & No & $\%$ \\
\hline NAO COME & 38 & 41,3 & 72 & 36,0 \\
\hline COME & 54 & 58,7 & 128 & 64.0 \\
\hline TOYAL & 92 & 100,0 & 200 & 100,0 \\
\hline
\end{tabular}

RISCO RELATIVO (RR), QUI-QUADRADO $\left(X^{2}\right)$ E NIVEL DE SIGNIFICANCIA DESCRITIVO (p), SEGUNDO TIPO DE AMOSTRA

\begin{tabular}{llll}
\hline TIPO DE AMOSTRA & $\mathrm{RR}$ & $\mathrm{x}^{2}$ & $\mathrm{p}$ \\
\hline PAREADA & 0,54 & 3,02 & $>0.05$ \\
GLOBAL & 0,80 & 0,55 & $>0.05$ \\
ESTRATIFICADA & 0,78 & 0,88 & $>0.05$ \\
\hline
\end{tabular}


TA B ELA 44

húmero E porCentAGEM DE CASOS DE CANCER DE RESO E DE CON CONTROLES SEGUNDO FILEQUENCIA DE EVACUAÇKO

\begin{tabular}{|c|c|c|c|c|}
\hline FREQUENCIA & & $\mathrm{c} n$ & TOI & TAL \\
\hline EVACUACXO & $\begin{array}{l}\text { MENOS DE I } \\
\text { VEZ/DIA }\end{array}$ & $\begin{array}{l}1 \text { OU MAIS } \\
\text { VEZES/UIA }\end{array}$ & No & $\%$ \\
\hline \multicolumn{5}{|l|}{ MENOS DE } \\
\hline I VEZ/DIA & 1 & 12 & 23 & 14,1 \\
\hline \multicolumn{5}{|l|}{1 oU mis } \\
\hline VEZES/DIA & 8 & 71 & 79 & 85,9 \\
\hline \multicolumn{5}{|r|}{100,0} \\
\hline$\ddot{x}$ & 9.8 & 90,2 & 100.0 & \\
\hline
\end{tabular}

AMOSTRA GLOBAL

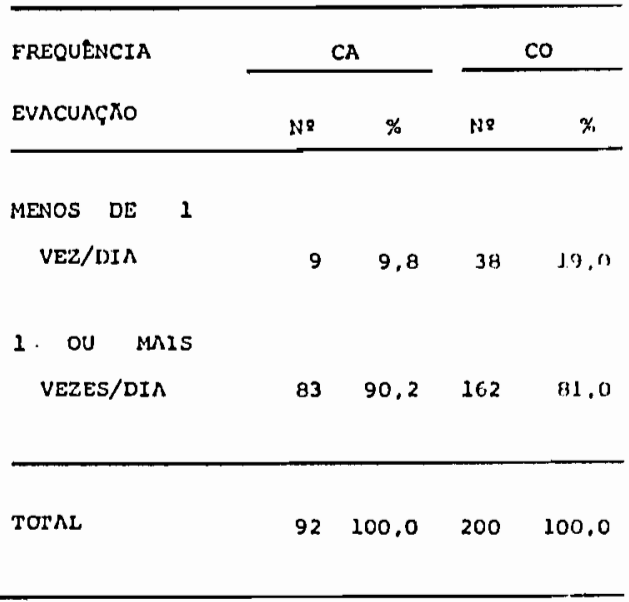

RISCO RELATIVO (RR), QUI-QUADRADO $\left(x^{2}\right)$ E NIVEL DE SIG NIFICANCIA DISCRITIVA (p), SEGUNDO TIPO DE NOSTR

\begin{tabular}{lccr}
\hline TIRO DE NIOSTRA & RR & $x^{2}$ & \multicolumn{1}{c}{ p } \\
\hline PAREADA & 1,50 & 0.45 & $>0.05$ \\
GLOBNL & 2.16 & 3.31 & $>0.05$ \\
ESTRNIIFICADA & 2.29 & 4.24 & $0.01<\mathrm{p}<0.05$ \\
\hline
\end{tabular}


T A B E I A 45

NÚMERO E PORCENTAGEM DE CASOS DE CANCER DE RETO F DE CONTROLES SEGUNDO CONSISTENCIA DAS FEZES

\begin{tabular}{l|rr|rr|rr}
\hline $\begin{array}{l}\text { CONSISTENCIA } \\
\text { DAS FEZES }\end{array}$ & \multicolumn{2}{|c|}{ CASOS } & \multicolumn{2}{c|}{$\begin{array}{l}\text { CONTROLE } \\
\text { PAREADO }\end{array}$} & \multicolumn{2}{c}{$\begin{array}{l}\text { CONTROLE } \\
\text { GLOBAL }\end{array}$} \\
\hline $1-$ PETREAS & 5 & 5,4 & 4 & 4,3 & 4 & 2,0 \\
$2-$ DURAS & 25 & 27,2 & 23 & 25,0 & 51 & 25,5 \\
3 - FIRMES & 42 & 45,6 & 56 & 60,9 & 129 & 64,5 \\
$4-$ AMOLECIDAS & 10 & 10,9 & 9 & 9,8 & 15 & 7,5 \\
$5-$ DIARREfCAS & 10 & 10,9 & - & & 1 & 0,5 \\
\hline TOTAL & 92 & 100,0 & 92 & 100,0 & 200 & 100,0 \\
\hline
\end{tabular}


NÚMERO E FORCENTAGEM DE CASOS DE CANCER DE RETO E DE CONTROLES SEGUNDO USO DE LAXANTES

\begin{tabular}{|c|c|c|c|c|}
\hline \multirow{2}{*}{ CONTROLE } & \multicolumn{2}{|c|}{ c^so } & \multicolumn{2}{|c|}{ TO'P I } \\
\hline & NAO USA & USA & No & $\%$ \\
\hline NAOO USA & 40 & 22 & 62 & 67,4 \\
\hline USA & 21 & 9 & 30 & 32,6 \\
\hline \multirow{2}{*}{ TOTAL } & 61 & 31 & 92 & 100,0 \\
\hline & 66,3 & 33,7 & 10 &, 0 \\
\hline
\end{tabular}

\begin{tabular}{|c|c|c|c|c|}
\hline \multirow{2}{*}{$\begin{array}{l}\text { USO } \\
\text { LAXANTE }\end{array}$} & \multicolumn{2}{|c|}{ cnso } & \multicolumn{2}{|c|}{ CONI'KOLL' } \\
\hline & NN & $\%$ & No & $\%$ \\
\hline NAO USA & 61 & 66,3 & 147 & 73,5 \\
\hline USA & 31 & 33,7 & 53 & 26,5 \\
\hline TO'ML & 92 & 100,0 & 200 & 100,0 \\
\hline
\end{tabular}

RISCO RELATIVO (RR), QUI-QUADRADO (X ) E NFVEL DE SIGNIFICÂNCIA DESCRITIVO (p), SEGUNDO TIPO DE AMOSTRA

\begin{tabular}{lccc}
\hline TIPO DE AMOSTRA & RR & $\mathrm{x}^{2}$ & $\mathrm{p}$ \\
\hline PAREADA & 1,05 & 0,00 & $>0,05$ \\
GLOBAL & 1,41 & 1,26 & $>0,05$ \\
ESTRATIFICADA & 1,10 & 0,37 & $>0,05$ \\
\hline
\end{tabular}


'I A B E I A 47

NÚMERO E PORCENTAGEM DE CASOS DE CANCER DE RETO E DE CONTROLES SEGUNDO EXISTENCIA DE CÂNCER NA FAMILIA

\begin{tabular}{lccccc} 
NHOSTRA PNRENDN \\
\hline
\end{tabular}

9 sem informação

\begin{tabular}{|c|c|c|c|c|}
\hline \multirow{2}{*}{$\begin{array}{l}\text { CANCER } \\
\text { FAMILIA }\end{array}$} & \multicolumn{2}{|c|}{ CASO } & \multicolumn{2}{|c|}{ CON'HROLE } \\
\hline & No & $\%$ & No & $\%$ \\
\hline NAO TER & 68 & 78,2 & 143 & 78,6 \\
\hline TER & 19 & 21,8 & 39 & 21,4 \\
\hline TO'TAL & $87^{\star}$ & 100,0 & $182^{\text {* }}$ & 100,0 \\
\hline
\end{tabular}

5 sem informação

** 18 sem informação

RISCO RELATIVO (RR), QUI-QUADRADO $\left(x^{2}\right)$ E NIVEL DE SIGNIFICANCIA DESCRITIVO $(p)$, SEGUNDO TIPO DE AMOSTRA

\begin{tabular}{lccc}
\hline TIPO DE AMOSTRA & RR & $\mathrm{x}^{2}$ & $\mathrm{p}$ \\
\hline PAREADA & 0,81 & 0,14 & $>0.05$ \\
GLOBAL & 1,02 & 0,01 & $>0.05$ \\
ESTRATIFICADA & 0,94 & 1,19 & $>0.05$ \\
\hline
\end{tabular}


I $\triangle B E$ I $\triangle \quad 48$

NÚMERO E PORCENTAGEM DE CASOS DE CANCER DE RETO E DE CONTROLES SEGUNTO TER TIDO HEMORRÓIDA

RMOSTRA PAREADA

\begin{tabular}{|c|c|c|c|c|}
\hline \multirow{2}{*}{ CONTROLE } & \multicolumn{2}{|c|}{ cnso } & \multicolumn{2}{|c|}{ TOTIS. } \\
\hline & $\begin{array}{l}\text { NAO TER } \\
\text { TIDO }\end{array}$ & $\begin{array}{l}\text { TER } \\
\text { TIDO }\end{array}$ & Ne & $\%$ \\
\hline \multicolumn{5}{|l|}{ NKO TER } \\
\hline TIDO & 52 & 25 & 77 & 83,7 \\
\hline TER TIDO & 10 & 5 & & 15,3 \\
\hline \multirow[t]{2}{*}{ TO'INL } & 62 & 30 & 92 & 100,0 \\
\hline & 67,4 & 32,6 & 100,0 & \\
\hline
\end{tabular}

AMOSTRA GLOBAL

\begin{tabular}{|c|c|c|c|c|}
\hline \multirow{2}{*}{ HEMORRÓIDA } & \multicolumn{2}{|c|}{ cnso } & \multicolumn{2}{|c|}{ CON'IROLE } \\
\hline & No & $\%$ & № & $\%$ \\
\hline \multicolumn{5}{|l|}{ NAO TER } \\
\hline TIDO & 62 & 67,4 & 175 & 87,5 \\
\hline TER TIDO & 30 & 32,6 & 25 & 12,5 \\
\hline TOTAL & 92 & 100,0 & 200 & 100.0 \\
\hline
\end{tabular}

RISCO RELATIVO (RR), QUI-QUADRADO $\left(x^{2}\right)$ E NFVEL DE SIGNIFICANCIA DESCRITIVO $(p)$, SEGUNDO TIPO DE AMOSTRA

\begin{tabular}{lrrr}
\hline TIPO DE AMOSTRA & RR & \multicolumn{1}{c}{$\mathrm{x}^{2}$} & \multicolumn{1}{c}{$\mathrm{p}$} \\
\hline PAREADA & 2,50 & 5,60 & $0,01<\mathrm{p}<0,05$ \\
GLOBAL & 3,39 & 15,38 & $<0,01$ \\
ESTRATIFICADA & 1,18 & 3,53 & $>0,05$ \\
\hline
\end{tabular}


T A B E L A $\underline{49}$

NO.IERO E PORCENTAGEM DE CASOS DE CRNCER DE RETO E DE CONIROLLS SEGUNDO HABITO DE FUMAR CIGARRO SEM FILTRO

ADSITM PALLADA

\begin{tabular}{|c|c|c|c|c|c|}
\hline \multirow{2}{*}{ CONIROLE } & \multicolumn{3}{|c|}{ CASO } & \multicolumn{2}{|c|}{ TOTAL } \\
\hline & NRO FUMA & $\begin{array}{lc}1 & A \\
\text { CIGARROS }\end{array}$ & $\begin{array}{l}21 \text { E }+ \\
\text { CIGNJROS }\end{array}$ & No & 8 \\
\hline NAO FUM & 55 & 13 & 2 & 70 & 76,1 \\
\hline \multicolumn{6}{|l|}{$1 A 20$} \\
\hline CIGARROS & 15 & 2 & 3 & 20 & 21,7 \\
\hline \multicolumn{6}{|l|}{$21 E+$} \\
\hline CIGARROS & 1 & 1 & - & 2 & 2,2 \\
\hline \multirow{2}{*}{ TOTAL } & 71 & 16 & 5 & \multirow{2}{*}{\multicolumn{2}{|c|}{$100,0^{92} 100,0$}} \\
\hline & 77,2 & 17,4 & 5,4 & & \\
\hline
\end{tabular}

AMOSIRA ESTRATIFICADA

\begin{tabular}{|c|c|c|c|c|}
\hline \multirow{2}{*}{$\begin{array}{l}\text { CIGARRO } \\
\text { SEM } \\
\text { FILTRO }\end{array}$} & \multicolumn{2}{|c|}{ CASO } & \multicolumn{2}{|c|}{ CONITOLIEE } \\
\hline & No & 8 & No & 8 \\
\hline NAO FUMA & 71 & 77,2 & 130 & 65,0 \\
\hline 1 A 20 & & & & \\
\hline CIGARROS & 16 & 17,4 & 55 & 27,5 \\
\hline $21 E+$ & & & & \\
\hline CIGARROS & 5 & 5,4 & 15 & 7,5 \\
\hline TOTAL & 92 & 100,0 & 92 & 100,0 \\
\hline
\end{tabular}

RISCO RELATIVO (RR), QUI-QUADRADO $\left(X^{2}\right)$ E NFVEL DE SIGNIFICANCIA DESCRITIVO (p), SEGUNDO TIPO DE AMOSTRA

\begin{tabular}{|c|c|c|c|}
\hline FUMAR MODERADO & INTENSAMENTE & $x$ & NAัO FUMAR \\
\hline TIPO DE AMOSTRA & $\mathrm{RR}$ & $x^{2}$ & $p$ \\
\hline PAREADA & 0,94 & 0,00 & 0,05 \\
\hline GLOBAL & 0,55 & 3,80 & 0,05 \\
\hline ESTRATIFICADA & 0,80 & 0,79 & 0,05 \\
\hline
\end{tabular}


TABELA 50

NaUERO E PORCENTACEN DE CASOS DE CANCER DL RETO E LE CONTROLES SEGUNDO HABITO DE FUMAR CIGARRO COM FILTRO

\begin{tabular}{|c|c|c|c|c|c|}
\hline \multirow[b]{2}{*}{ CONIROLE } & \multicolumn{3}{|c|}{ CASO } & \multicolumn{2}{|c|}{ TOIAL } \\
\hline & NO FUIA & $\begin{array}{l}1 \quad 20 \\
\text { CICARROS }\end{array}$ & $\begin{array}{l}21 \mathrm{E}+ \\
\text { CIGNREOS }\end{array}$ & N8 & 1 \\
\hline No mu & 51 & 11 & 2 & 64 & 69.5 \\
\hline \multicolumn{6}{|l|}{$1 \wedge 20$} \\
\hline Cicurros & 19 & 5 & 1 & 25 & 27,2 \\
\hline \multicolumn{6}{|l|}{$21 E+$} \\
\hline CICNuLOS & 3 & - & - & 3 & 3,3 \\
\hline \multirow{2}{*}{ TOIAL } & 73 & 16 & 3 & & \\
\hline & 79,3 & 17,4 & 3,3 & $\begin{array}{c}92 \\
100,0\end{array}$ & 100,0 \\
\hline
\end{tabular}

\begin{tabular}{|c|c|c|c|c|}
\hline \multirow{2}{*}{$\begin{array}{c}\text { CIGARRO } \\
\text { COM } \\
\text { EILTRO }\end{array}$} & \multicolumn{2}{|c|}{ CASO } & \multicolumn{2}{|c|}{ CONIWOLL: } \\
\hline & N8 & 1 & N8 & 1 \\
\hline Mo Iun & 73 & 79,3 & 140 & 70.0 \\
\hline \multicolumn{5}{|l|}{$1 \wedge 20$} \\
\hline cicurzos & 16 & 17,4 & 47 & 23,5 \\
\hline \multicolumn{5}{|l|}{$21 \mathrm{I}+$} \\
\hline CICNRJßOS & 3 & 3,3 & 13 & 6,5 \\
\hline LIOAL & 92 & 100,0 & 92 & 100,0 \\
\hline
\end{tabular}

RISCO RELATIVO (RR), QUI-QUADRNDO $\left(x^{2}\right)$ E NAVEL DE SIGNIFICANCIA DESCRITIVO (p), SEGUNDO TIPO DE AMOSTRA

\begin{tabular}{|c|c|c|c|}
\hline FUMAR MODERADO & INTENSAMENTE & $\mathrm{x}$ & NRo FUMAR \\
\hline TIPO DE AMOSTRA & $\mathbf{R R}$ & $x^{2}$ & $\mathbf{p}$ \\
\hline PAREADA & 0,59 & 1.83 & $>0,05$ \\
\hline GLOEAL & 0,61 & 2,34 & $>0,05$ \\
\hline ESTRATIFICADA & 0,76 & 1.14 & $>0,05$ \\
\hline
\end{tabular}


TABELA $\underline{51}$

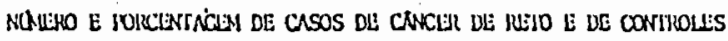
SEGUNDO HABITO DE FUMAR CIGARRO DE PALHA

\begin{tabular}{|c|c|c|c|c|c|}
\hline \multirow{2}{*}{ conrirou: } & \multicolumn{3}{|c|}{ caso } & \multicolumn{2}{|c|}{ TOTNL } \\
\hline & NXO FUNA & $\begin{array}{l}1 \text { A } \\
\text { Clcúvos }\end{array}$ & $\begin{array}{l}10 R \\
\text { CicNuos }\end{array}$ & N9 & 1 \\
\hline No rus & 66 & 5 & 3 & 74 & 80,4 \\
\hline $\begin{array}{l}1 \wedge 9 \\
\text { :kcindus }\end{array}$ & 9 & 5 & - & 14 & 15,2 \\
\hline $\begin{array}{l}10 \mathrm{l} \text { 1: } \\
\text { chiveros }\end{array}$ & 3 & 1 & - & 4 & 4,3 \\
\hline IOTN NP & 78 & 11 & 3 & 92 & 100,0 \\
\hline 1 & 84,7 & 12,0 & 3.3 & 100,0 & \\
\hline
\end{tabular}

\begin{tabular}{|c|c|c|c|c|}
\hline \multirow{2}{*}{$\begin{array}{l}\text { CIGARRO } \\
\text { DE } \\
\text { PALIA }\end{array}$} & \multicolumn{2}{|c|}{ CASO } & \multicolumn{2}{|c|}{ CONIROLL: } \\
\hline & NP & 1 & NP & 1 \\
\hline NRO RUMA & 78 & 84.7 & 161 & 80.5 \\
\hline \multicolumn{5}{|l|}{$1 \wedge 9$} \\
\hline Clivives & 11 & 12,0 & 33 & 16.5 \\
\hline \multicolumn{5}{|l|}{$10 \mathrm{E}+$} \\
\hline Cicneros & 3 & 3.3 & 6 & 3.0 \\
\hline TOTNL & 92 & 100.0 & 200 & 100.0 \\
\hline
\end{tabular}

RISCO RELATIVO (RR), QUI-QUADRADO $\left(x^{2}\right)$ E NIVEL DE SIGNIFICANCIA DESCRITIVO (p), SEGUNDO TIPO DE AMOSTRA

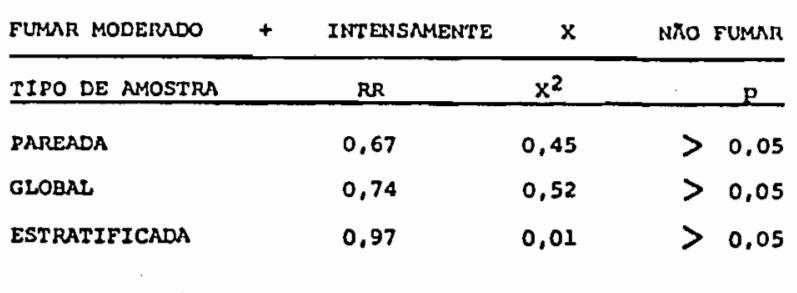


IA B L L LA 52

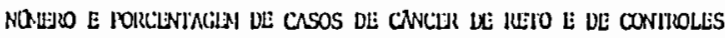
SEGUNDO FUMO TOTAL

\begin{tabular}{|c|c|c|c|c|c|}
\hline \multirow{2}{*}{ CONIROLE } & \multicolumn{3}{|c|}{ CASO } & \multicolumn{2}{|c|}{ TORN } \\
\hline & No run & $\begin{array}{l}\text { IUM ADUE } \\
\text { RWNLENE }\end{array}$ & $\begin{array}{l}\text { FUAM INILN } \\
\text { SNUENIE }\end{array}$ & $N 9$ & 1 \\
\hline wo run & 33 & 8 & 1 & 42 & 45.7 \\
\hline $\begin{array}{l}\text { FUR MLUE- } \\
\text { IWLURNIE }\end{array}$ & 11 & 21 & 9 & 41 & 44,6 \\
\hline $\begin{array}{l}\text { FR.h INILN } \\
\text { SWUNAL }\end{array}$ & 4 & 5 & - & 9 & 9,8 \\
\hline TOTN NQ & 48 & 34 & 10 & 92 & 100,0 \\
\hline 1 & 52.1 & 37,0 & 10,9 & 100.0 & \\
\hline
\end{tabular}

MMOSTRA GLOBAL

\begin{tabular}{|c|c|c|c|c|}
\hline \multirow{2}{*}{$\begin{array}{l}\text { FUMO } \\
\text { TOTAL }\end{array}$} & \multicolumn{2}{|c|}{ cAso } & \multicolumn{2}{|c|}{ CONInol, } \\
\hline & NQ & 1 & NQ & 1 \\
\hline No lum & 48 & 52,1 & 80 & 40,0 \\
\hline \multicolumn{5}{|l|}{ I:UMK ADII)- } \\
\hline RNAWNIL & 34 & 37.0 & 91 & 45.5 \\
\hline \multicolumn{5}{|l|}{ FMU JNILN } \\
\hline SNUENIL: & 10 & 10,9 & 29 & 14.5 \\
\hline TOINL & 92 & 100,0 & 200 & 100.0 \\
\hline
\end{tabular}

RISCO RELATIVO (RR), QUI-QUADRNDO $\left(X^{2}\right)$ E NIVEL DE SIGNIFICANCIA DESCRITIVO (p), SEGUNDO TIPO DE AMOSTRA

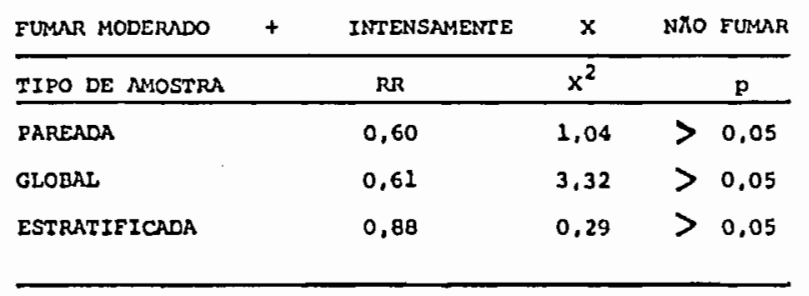


TABELA 53

NOARO E PORCENTACHA DE CASOS DL CNAEER DE REID E DE CONTROLES SEGUNDO CONSUMO inBituAL DE PINGA

\begin{tabular}{|c|c|c|c|c|c|}
\hline \multirow{2}{*}{ CUNCINLE } & \multicolumn{3}{|c|}{ caso } & \multicolumn{2}{|c|}{ TOJ'AL } \\
\hline & NOOO BEBE & $\begin{array}{l}\text { BEBE ADDL: } \\
\text { RWMUNIE }\end{array}$ & $\begin{array}{l}\text { BEBE JNTEN } \\
\text { SWENIE }\end{array}$ & NQ & 1 \\
\hline NO IBLEL & 44 & 5 & 11 & 60 & 65,2 \\
\hline $\begin{array}{l}\text { BLBE MDDI:- } \\
\text { IEHNUNIL }\end{array}$ & 7 & 2 & 1 & 10 & 10,9 \\
\hline $\begin{array}{l}\text { BEBE INTN } \\
\text { SMENIE }\end{array}$ & 12 & 3 & 7 & 22 & 23,9 \\
\hline TOTN NQ & 63 & 10 & 19 & 92 & 100,0 \\
\hline 1 & 68,5 & 10,9 & 20,6 & 100,0 & \\
\hline
\end{tabular}

\begin{tabular}{|c|c|c|c|c|}
\hline \multirow{2}{*}{ PINGA } & \multicolumn{2}{|c|}{ caso } & \multicolumn{2}{|c|}{ CONIROLE: } \\
\hline & N8 & 1 & N9 & 1 \\
\hline NKO BEBEE & 63 & 68,5 & 119 & 59,5 \\
\hline $\begin{array}{l}\text { BEIBE ADUE- } \\
\text { LWWMLVIL }\end{array}$ & 10 & 10,9 & 19 & 9.5 \\
\hline $\begin{array}{l}\text { BEBR INTEN } \\
\text { SNEATEE }\end{array}$ & 19 & 20.6 & 62 & 31.0 \\
\hline IOTAL & 92 & 100,0 & 200 & 100.0 \\
\hline
\end{tabular}

RISCO RELATIVO (RR), QUI-QUADRADO $\left(x^{2}\right)$ E NIVEL DE SIG NIFICRNCIA DESCRITIVO (p), SEGUNDO TIPO DE AMOSTRA

\begin{tabular}{|c|c|c|c|}
\hline BEBER MODERADO & INTENSAMENTE & $\mathrm{x}$ & NXO BEBER \\
\hline TIPO DE AMOSTRA & RR & $x^{2}$ & $\mathbf{p}$ \\
\hline PAREADA & 0,84 & 0,11 & 0,05 \\
\hline GLOBAL & 0.68 & 1.80 & $>0,05$ \\
\hline ESTRATIFICADA & 0.92 & 0,27 & 0,05 \\
\hline
\end{tabular}


TABBLA 54

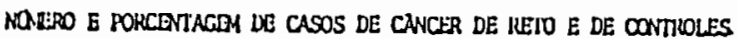
SEGUNDO CONSUMO haBtTUAL DE CERVEJa

\section{AMOSTRA PARENDA}

\begin{tabular}{|c|c|c|c|c|c|}
\hline \multirow{2}{*}{ CONTHOLA } & \multicolumn{3}{|c|}{ CASO } & \multicolumn{2}{|c|}{ TOTAL } \\
\hline & Nho Beile & $\begin{array}{l}\text { BEUB IDOC } \\
\text { RULARDNTE }\end{array}$ & $\begin{array}{l}\text { BCBE INTHN } \\
\text { SNEENTE }\end{array}$ & NQ & 1 \\
\hline NO BEBE & 69 & 6 & 4 & 79 & 05,9 \\
\hline $\begin{array}{l}\text { BEBE NDDE- } \\
\text { HANWEIE }\end{array}$ & 6 & 1 & .2 & 9 & 9.8 \\
\hline $\begin{array}{l}\text { BEBE INTEN } \\
\text { SMANTE }\end{array}$ & 1 & 1 & 2 & 4 & 4,3 \\
\hline TOTAL NQ & $\begin{array}{r}76 \\
82.6 \\
\end{array}$ & $\begin{array}{c}8 \\
0.7 \\
\end{array}$ & $\begin{array}{c}8 \\
8,7 \\
\end{array}$ & $\begin{array}{r}92 \\
100, \\
\end{array}$ & 100,0 \\
\hline
\end{tabular}

AMOSTR GLOBAL

\begin{tabular}{|c|c|c|c|c|}
\hline \multirow{2}{*}{ CERVEJA } & \multicolumn{2}{|c|}{ crso } & \multicolumn{2}{|c|}{ CONITOLE } \\
\hline & NQ & 1 & NP & 1 \\
\hline NO DEOU & 76 & 02,6 & 167 & 83.5 \\
\hline BEDH NDDE- & & & & \\
\hline IWDWENIE & B & 8.7 & 19 & 9.5 \\
\hline BEBE INTLN & & & & \\
\hline SAMENIY & $\mathbf{B}$ & 0.7 & 14 & 7,0 \\
\hline TOTAL & 92 & 100,0 & 200 & 100,0 \\
\hline
\end{tabular}

RISCO RELATIVO (RR), QUI-QUADRNDO $\left(X^{2}\right)$ E NIVEL DE SIG NIFICANCIA DESCRITIVO (p), SEGUNDO TIPO DE AMOSTRA

\begin{tabular}{lccc} 
BEBER MODERRD + INTENSMMENTE & $x$ & NKO BEBER \\
\hline TIPO DE AMOSTRA & RR & $x^{2}$ & $p$ \\
\hline PAREADA & 1,43 & 0.24 & $>0.05$ \\
GLOBAL & 1,06 & 0.00 & $>0.05$ \\
ESTRATIFICADA & 1,28 & 1,19 & $>0.05$
\end{tabular}


TABELA $\underline{55}$

MOALE E PORCENINGLM DE CASOS DE CANCER DE RUTO U DE CONIROLLS SEGUNDO CONSUMO HABITUAL DE VINIO

\begin{tabular}{|c|c|c|c|c|c|}
\hline \multirow{2}{*}{ CONInOLE } & \multicolumn{3}{|c|}{ CASO } & \multicolumn{2}{|c|}{ IOI'AL } \\
\hline & NDO BEBE & $\begin{array}{l}\text { BEABE ADUE } \\
\text { RADAUNIE }\end{array}$ & $\begin{array}{l}\text { CONEE INIEN } \\
\text { SAEENIE }\end{array}$ & NP & 1 \\
\hline NO BEBE & 65 & 9 & 10 & 84 & 91,3 \\
\hline BLEBE RDDL- & 1 & 1 & 1 & 3 & 3.3 \\
\hline \multicolumn{6}{|l|}{ BLIISE INIEN } \\
\hline SWLNTE & 4 & 1 & - & 5 & 5,4 \\
\hline \multirow{2}{*}{ IOIAL } & 70 & 11 & 11 & 92 & 100,0 \\
\hline & 76.0 & 12.0 & 12,0 & 100,0 & \\
\hline
\end{tabular}

\begin{tabular}{|c|c|c|c|c|c|}
\hline \multirow{2}{*}{ VINIIO } & \multicolumn{2}{|c|}{ CASO } & \multicolumn{2}{|c|}{ COWITROLE } & \multirow{2}{*}{$\begin{array}{l}\text { RISLO } \\
\text { MELNTIVO }\end{array}$} \\
\hline & NP & 1 & NP & 1 & \\
\hline NNO BLBBE & 70 & 76,0 & 174 & 87.0 & 1 \\
\hline \multicolumn{6}{|l|}{ BL:BE ADDL:- } \\
\hline RDNLWIIE & 11 & 12,0 & 10 & 5,0 & 2.73 \\
\hline \multicolumn{6}{|l|}{ RCBE INIEN } \\
\hline SNENTE & 11 & 12,0 & 16 & 8,0 & 1,71 \\
\hline TOIAL & 92 & 100,0 & 200 & 100.0 & \\
\hline
\end{tabular}

RISCO RELATIVO (RR), QUI-QUADRADO $\left(x^{2}\right)$ E NFVEL DE SIG NIFICANCIA DESCRITIVO (p), SEGUNDO TIPO DE AMOSTRA

\begin{tabular}{|c|c|c|c|}
\hline BEDER MODERADO & + & INTENSAMENTE & NAO BEBER \\
\hline TIPO DE AMOSTRA & RR & $x^{2}$ & $\mathbf{p}$ \\
\hline PAREADA & 3,80 & 7,04 & $<0,01$ \\
\hline GLOBAL & 2,10 & 4,70 & $0.01<\mathrm{p}<0.05$ \\
\hline ESTRATIFICADA & 1,26 & 2,07 & $>0,05$ \\
\hline
\end{tabular}


T A B E L A

RISCO RELATIVO (RR), QUI-QUADRADO $\left(\mathrm{X}^{2}\right)$, NIVEL DE SIGNIFICÅNCIA DESCRITIVO (p) RESULTANTES DA ANALISE MULTIVARIADA DE NPAMA, QUEIJO, ORÉGANO CONTROLADAS POR IDADE E SEXO

ANALISE CONJUNTA DAS 3 VARIAVEIS

\begin{tabular}{lccr}
\hline & RR & $\mathrm{x}^{2}$ & \multicolumn{1}{c}{ p } \\
NPAMA & 2,12 & 3,30 & $>0,05$ \\
QUEIJO & 2,49 & 9,14 & $<0,01$ \\
ORÉGANO & 0,48 & 5,25 & $0,01<\mathrm{p}<0,05$ \\
\hline
\end{tabular}

ANÁLISE CONJUUNTA DAS 2 VARIÁVEIS

\begin{tabular}{lccc} 
NPAMA & 2,58 & 5,61 & $0,01<\mathrm{p}<0,05$ \\
QUEIJO & 2,38 & 8,49 & $<0,01$ \\
\hline NPAMA & 2,60 & 5,66 & $0,01<\mathrm{p}<0,05$ \\
ORÉGANO & 0,52 & 4,56 & $0,01<\mathrm{p}<0,05$ \\
\hline QUEIJO & 2,74 & 11,59 & $<0,01$ \\
ORÉGANO & 0,42 & 7,71 & $<0,01$ \\
\hline
\end{tabular}

ANALISE INDIVIDUAL

\begin{tabular}{llll} 
QUEIJO & 2,66 & 11,21 & $<0,01$ \\
\hline ORÉGANO & 0,44 & 7,29 & $<0,01$ \\
\hline NPAMA & 3,03 & 8,06 & $<0,01$
\end{tabular}


CASOS DE CANCER DE RETO E CONTROLES GLOBAIS SEGUNDO CONSUMO DE QUEIJO CONTROLADO POR NPAMA E ORÉGANO E RESPECTIVOS RISCOS RELATIVOS (RR), QUI-QUADRRDOS $\left(x^{2}\right)$, NAVEL DE SIGNIFICANCIA DESCRITIVO (p)

QUEIJO CONTROLADO POR NPAMA NORDEŚTE ORÉCANO = NAOO COME

\begin{tabular}{lccr}
\hline QUEIJo & CASO & CONrROLE & RR \\
Não come & 2 & 15 & 1 \\
$\begin{array}{l}\text { Come mode } \\
\text { radamente }\end{array}$ & - & 4 & - \\
Come inten & & & \\
samente & 2 & 3 & 5.00 \\
\hline ToTnL & 4 & 22 & \\
\hline
\end{tabular}

QUEIJO CONTROOLADO POR NPAMA = NORDESTE ORÉGANO = COME

\begin{tabular}{lccr}
\hline & CASO & CONTROLE & RR \\
Náo cone & 2 & 12 & 1 \\
Como mode & & & \\
radamente & 2 & 11 & 1,09 \\
Come inten & & & \\
samente & 1 & 3 & 2,00 \\
\hline Total & 5 & 26 & \\
\hline
\end{tabular}

QUEIJO CONTROLADO POR NPAMA - NXO NORDESTE

ORÉGANO = NKO COME

\begin{tabular}{lccr}
\hline QUEIJo & CASO & CONTROLE & RR \\
Näo come & 14 & 42 & 1 \\
Cone mode & & & \\
radamente & 21 & 43 & 1,46 \\
Come 1nten & & 22 & 4,50 \\
samente & 33 & 107 & \\
\hline ToTal & 68 & & \\
\hline
\end{tabular}

QUEIJO CONTROLADO POR NPAMA - NAO NOIDESTE ORÉGANO = COME

\begin{tabular}{lccr}
\hline & CASO & CONTROLE & RR \\
Não come & 2 & 16 & 1 \\
Come mode & & & \\
radamente & 3 & 18 & 1,33 \\
Come lnten & 10 & 11 & 7,27 \\
samente & 10 & & \\
\hline ToTAL & 15 & 45 & \\
\hline
\end{tabular}

ANÁLISE DE GRADIENTE

\begin{tabular}{cccc}
\hline \multicolumn{2}{c}{ RISCOS RELATIVOS } & $\mathrm{x}^{2}$ SINTÉTICO & $p$ \\
\hline COME MODERIDAMENTE & COME INTENSAMENTE & MANTEL - HAENSZEL & \\
\hline 1,37 & 4,72 & 21,52 & $<, 01$ \\
\hline
\end{tabular}

ANALISE PAHA COMER $X$ NXO COMER

ESTINATIVA POR PONTO

ESTIMATIVA POR INTERVALO

DE CONFIANÇA (5\%)

$2,46 \quad 1,41 \longmapsto 4,30$


T A B E.L A $\underline{58}$

CASOS DE CANCER DE RETO E CONTROLES GLOBAIS SEGUNDO CONSUMO DE ORÉGANO CONTROLADO POR NPAMA E QUEIJO E RESPECTIVOS RISCOS RELATIVOS (RR), QUI-QUADRADO ( $(X)$, NIVEL DE SIGNIFICANCIA DESCRITIVO ( $p$ )

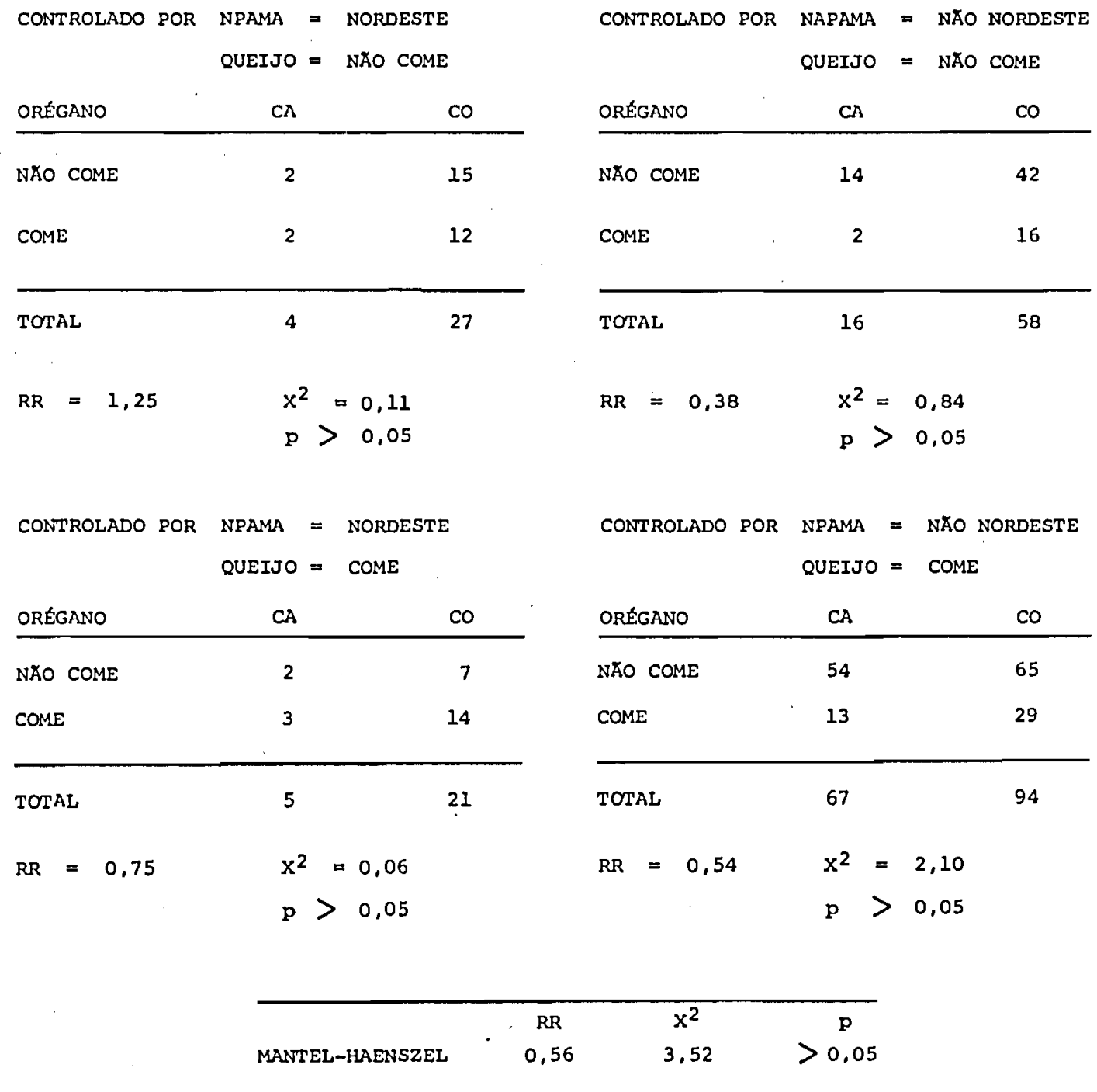


T A B E L A 59

RISCO RELATIVO (RR), QUI-QUADRADO $\left(\mathrm{X}^{2}\right)$, NIVEL DE SIGNIFICÂNCIA DESCIRI'L VO (p), RESULTANTES DA ANALISE CONJUNTA PARA RETO BAIXO DAS VARIXVEIS NPAMA, QUEIJO, ORÉGANO, CONTROLADAS POR IDADE E SEXO

ANALISE CONJUNTA DAS 3 VARIAVEIS

\begin{tabular}{lcrr}
\hline & RR & $\mathrm{x}^{2}$ & \multicolumn{1}{c}{ P } \\
NPAMA & 4,58 & 4,02 & $0,01<\mathrm{p}<0,05$ \\
QUEIJO & 1,63 & 1,51 & $>0,05$ \\
ORÉGANO & 0,48 & 2,60 & $>0,05$ \\
\hline
\end{tabular}

ANALISE CONJUNTA DAS 2 VARIAVEIS

\begin{tabular}{|c|c|c|c|}
\hline NPAMA & 5,42 & 5,06 & $0,01<\mathrm{p}<0,05$ \\
\hline QUEIJO & 1,54 & 1,21 & $>0,05$ \\
\hline NPAMA & 5,14 & 4,74 & $0,01<\mathrm{p}<0,05$ \\
\hline ORÉGANO & 0,51 & 2,32 & $>0,05$ \\
\hline QUEIJO & 1,92 & 2,79 & $>0,05$ \\
\hline ORÉGANO & 0,40 & 4,28 & $\mathrm{p}<0.05$ \\
\hline
\end{tabular}

ANALISE INDIVIDUAL

\begin{tabular}{lccc} 
QUEIJO & 1,82 & 9,44 & $<0,01$ \\
\hline ORÉGANO & 1,63 & 1,51 & $>0,05$ \\
\hline NPAMA & 5,92 & 5,67 & $0,01<0<0,05$
\end{tabular}


CASOS DE CANCER DE RETO BAIXO E CONTROLES GLOBAIS SEGUNDO CONSUMO DE QUEIJO CONTROLADO POR NPAMA E ORÉGANO E RESPECTIVOS RISCOS RELATIVOS (RR), QUI-QUADRADOS $\left(X^{2}\right)$, NIVEL DE SIGNIFICANCIA DESCRITIVO $(p)$

NPAMA $=$ NORDESTE

CONTROLADO POR ORÉGANO - NAO COME

\begin{tabular}{lcc} 
QUEIJO & $\mathrm{CA}$ & CO \\
\hline NAO COME & 1 & 15 \\
COME & - & 7 \\
\hline TOTAL & 1 & 22 \\
RR $=0,00$ & $\mathrm{x}^{2}=0,19$. \\
& $\mathrm{p}>0,05$
\end{tabular}

CONTROLADO POR NPAMA = NORDESTE

$$
\text { ORÉGANO = COME }
$$

\begin{tabular}{lll} 
QUEIJO & CA & CO \\
\hline NAO COME & 1 & 12 \\
COME & - & 14 \\
& & 26 \\
TOTAL & 1 & \\
RR $=0,00$ & $x^{2}=0,00$ \\
& $\mathrm{p}>0.05$
\end{tabular}

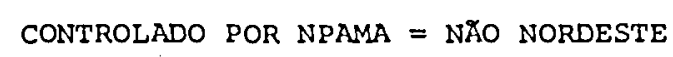

\begin{tabular}{lll} 
QUEIJO & CA & CO \\
\hline NAO COME & 8 & 42 \\
COME & 21 & 65 \\
\hline TOTAL & 29 & 107 \\
RR $=1,70$ & $\mathrm{x}^{2}=0,88$ & \\
& $\mathrm{p}>0,05$
\end{tabular}

CONTROLADO POR NPAMA $=$ NAO NORDESTE ORÉGANO = COME

\begin{tabular}{lll} 
QUEIJO & CA & CO \\
\hline NAO COME & 1 & 16 \\
COME & 6 & 29 \\
\hline TOTAL & 7 & 45 \\
RR $=3,31$ & $x^{2}=0,47$ & \\
& $p>0,05$
\end{tabular}

\begin{tabular}{lccc}
\hline & RR & $\mathrm{x}^{2}$ & $\mathrm{p}$ \\
MANTEL - HAENSZEL & 1,60 & $1,36 \quad>0,05$ \\
\hline
\end{tabular}


T A B E L A 61

RISCOS RELATIVOS (RR), QUI-QUADRADOS (X ) E NfVEIS DE SIGNIFI CANCIA DESCRITIVO (p) RESULTANTES DA ANÁLISE MULTIVARIADA DE BEBIDAS, CONTROLADAS POR IDADE E SEXO

\begin{tabular}{|c|c|c|c|}
\hline TIPOS DE ANALISES & $\mathrm{RR}$ & $x^{2}$ & $\mathrm{p}$ \\
\hline DENTRE OS QUE NAO & BEBEM CERVEJA & E PINGA & \\
\hline VINHO & 1,87 & 1,50 & $>0,05$ \\
\hline QUEIJO & 2,43 & 5,36 & $0,01<\mathrm{p}<0,05$ \\
\hline ORÉGANO & 0,51 & 2,87 & $>0,05$ \\
\hline FUMO T'O'TAL & 0,69 & 0,74 & $>0,05$ \\
\hline NPAMA & 1,96 & 1,68 & $>0,05$ \\
\hline DENTRE OS QUE NÃO & BEBEM VINHO E & PINGA & \\
\hline CERVEJA & 0,81 & 0,08 & 0,05 \\
\hline QUEIJO & 2,35 & 4,51 & $0,01<\mathrm{p}<0,05$ \\
\hline ORÉGANO & 0,46 & 3,52 & $>0,05$ \\
\hline FUMO TOTAL & 0,68 & 0,75 & $>0,05$ \\
\hline NPAMA & 1,62 & 0,85 & $>0.05$ \\
\hline
\end{tabular}

DENTRE OS QUE NÃO BEBEM CERVEJA E VINHO

$\begin{array}{lllr}\text { PINGA } & 0,92 & 0,13 & >0,05 \\ \text { QUEIJO } & 2,00 & 4,36 & 0,01<\mathrm{p}<0,05 \\ \text { ORÉGANO } & 0,56 & 2,56 & >0,05 \\ \text { FUMO TOTAL } & 0,62 & 1,37 & >0,05 \\ \text { NPAMA } & 2,12 & 2,63 & >0,05\end{array}$


NÚMERO DE CASOS DE CANCER DE RETO E DE CONTROLES GLOBAIS SEGUNDO HISTÓRIA DE BEBER CERVEJA, DENTRO OS QUE NAัO BEBEM VINHO E NAO BEBEM PINGA

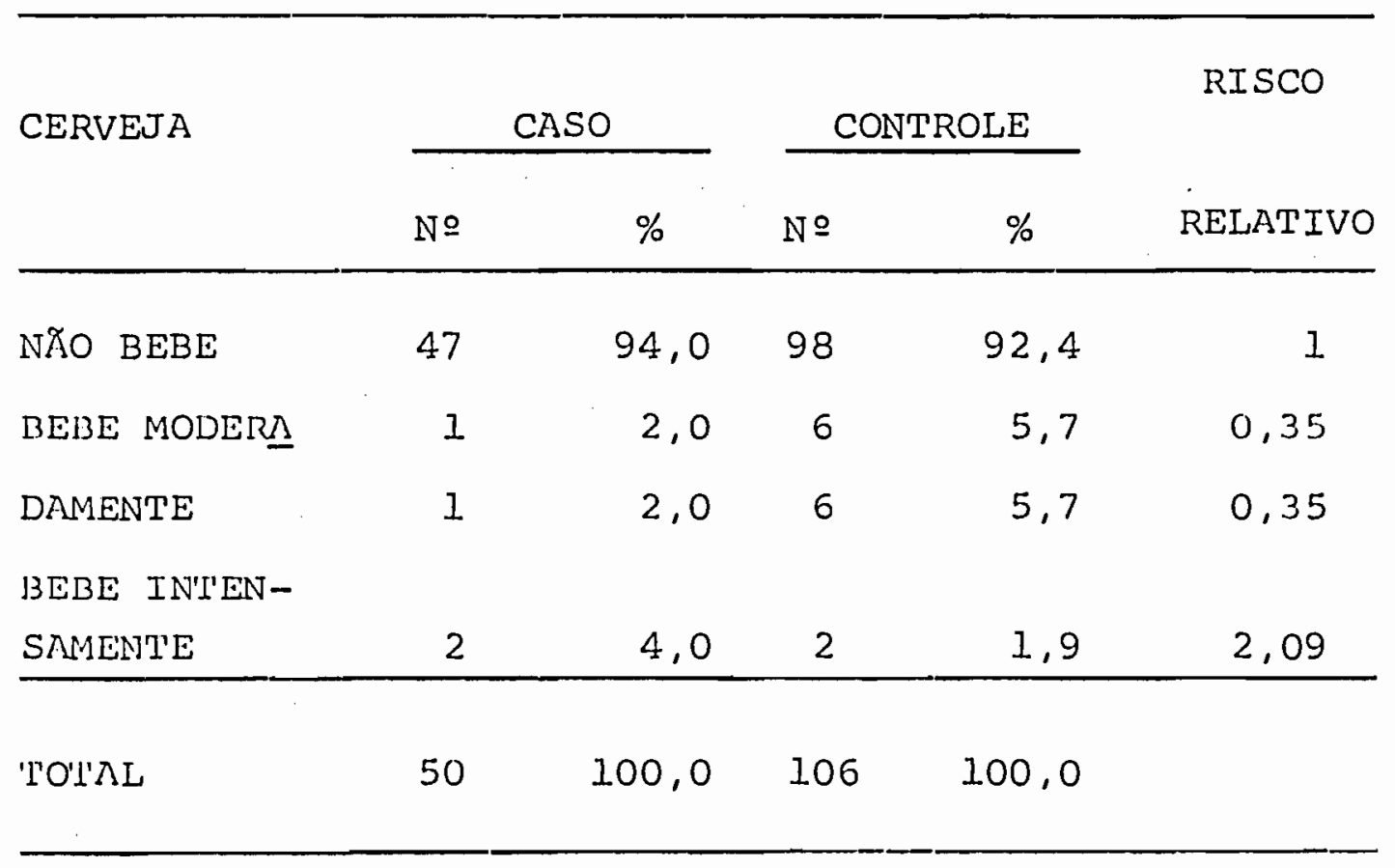

\begin{tabular}{lccc}
\hline RR & $x^{2}$ & $p$ \\
NAN'TEL-IIAENSZEL & 0,79 & $0,12>0,05$ \\
\hline
\end{tabular}


Os resultados referentes ao consumo de carnes não mos tram associação significante com o câncer de reto, quer se considere a carne bovina exclusivamente, quer o conjunto de vários tipos de carne. Assim, o presente estudo não suporta a teoria proposta por WYNDER \& SHIGEMATSU $(1967)^{89}$ sobre a ação das gorduras, que, gerando aumento da produção de ácidos biliares e esteróis neutros, por meio da atividade bacteriana, produziria componentes carcinogênicos para intestino grosso 44,45 .

Coincidem com os achados de outros estudos, como o de HIGGINSON et al (1966) 42 , nos Estados Unidos, que não encontraram rẹ lação em quaisquer dos grupos de alimentos considerados: carnes, pro dutos lácteos, vegetais, frutas e cereais; o de WYNDER et al (1969) 90 que estudaram os japoneses residentes no Japão; o de BJELKE (1971) 6 , realizado na Noruega; o de GRAHAM et al (1978) ${ }^{34}$, em Buffalo, USA; o de DALES et al (1979) ${ }^{23}$, em San Francisco, USA; o de HAENSZEL et al $(1980)^{40}$, que ao replicar o estudo anteriormente realizado entre japoneses residentes no Havai, para os japoneses residentes no Japão não encontraram associação entre câncer de intestino grosso e ingestão de carnes, e o de PICKLE et al $(1984)^{78}$, realizado em Nebraska, USA.

A associação positiva entre consumo de carnes (princi palmente de carne bovina), que constitui um dos principais alimentos ricos em gordura animal (gordura saturada), e câncer de intestino grosso, foi encontrada em alguns estudos tipo caso-controle e que sustentam a teoria referida. 
o estudo de HAENSZEL et al $(1973)^{39}$ foi o precursor da verificação da influência do meio ambiente no processo etiológico do câncer de cólon, ao constatar que os japoneses que migraram para - Havai apresentavam hábitos de consumo e riscos de câncer de cólon semelhantes aos havaianos locais. O de MARTINEZ et al (1979) 65 , em Porto Rico, o de PHILLIPS $(1975)^{77}$, que estudou os Adventistas do 7ㅇ dia, na califórnia, também salientam associação positiva para ingestão de carne de cordeiro e carnes em geral, bem como a sugestão de uma associação positiva para ingestão de alimentos ricos em gorduras saturadas. O de JAIN et aI (1980)49, no Canadá, mostrou um aumento do risco de câncer de intestino grosso, acompanhando um aumento da ingestão de gordura saturada, significativo, tanto para o cólon quan to para o reto. Estes autores salientam que, embora a ingestão de co lesterol esteja correlacionada significativamente com a ingestão de gorduras saturadas e outros nutrientes, a força de associação com câncer de cólon e de reto para o colesterol é menor do que para gorduras saturadas.

Os estudos caso-controle, desenvolvidos também no Canadá por HOWE et al $(1982)^{47}$ e MILLER et al (1983) 67 , mostram o consumo de gordura saturada como o principal fator de risco de câncer de cólon e de reto para ambos os sexos. Há indicação de que para os pacientes masculinos a carne de vaca e de vitela, ao invés das gordu ras saturadas, constituem fator de risco para o câncer de reto e, pa ra as mulheres, o consumo de carne de porco apresenta-se como de maior risco 67 .

Comparações internacionais mostram correlação entre consumo de gordura e de proteína e taxas de incidência de câncer ${ }^{26}$. Outro estudo, referente a 28 países, mostra correlação positiva entre níveis nacionais de proteína animal e mortalidade por câncer do 
intestino grosso ${ }^{35}$. Também são mostradas as diferenças na composição da flora intestinal em populações com altas e baixas taxas de câncer de cólon 48 .

Entretanto, em outro estudo coordenado pelo IARC 51 , no qual são incluídas amostras populacionais da Finlândia e Dinamarca, nenhuma tendência de câncer de cólon e de reto emerge com relação à média diária de ingestão de gordura e de proteína que foi alta nas áreas amostradas e não mostrou diferenças estatisticamente signi ficantes. A análise da correlação entre o consumo de gorduras, de proteínas e de alimentos com fibra com a taxa de mortalidade, em diferentes regiões da Grã Bretanha, no período de 1969 a 1973, também não evidenciou significância estatística ${ }^{5}$.

Frente aos resultados discrepantes assinalados nos vá rios estudos, a ação das gorduras e das proteínas e carnes encontrase ainda inconclusiva para o câncer de cólon e de reto.

Outra teoria, proposta por BURKITT $(1971)^{13}$, diz respeito à ingestão de alimentos com poucas fibras e à ação da flora in testinal, que converte o conteúdo intestinal em carcinogênio ou cocarcinogênio, dependendo do tempo do processo. o papel protetor das fibras alimentares surgiu da observação da alta incidência de cânceres de intestino grosso nos países da Europa Ocidental e dos Estados Unidos, onde a alimentação é pobre em fibras e rica em gorduras e proteínas, e de una incidência baixa nos países da Africa, onde a alimentação é particularmente rica em fibras e pobre em gorduras e proteínas 13, 14, 15 .

A base teórica para associação inversa entre o consumo de fibra e câncer de cólon está sustentada no fato de que uma die 
ta rica em fibras pode resultar num trânsito mais rápido de material pelo intestino, uma vez que aumenta os movimentos peristálticos e o bolo fecal ${ }^{22}$. Isto pode reduzir a oportunidade das bactérias existentes produzirem carcinógeno e pode reduzir o tempo do carcinógèno estar em contato com a parede do intestino grosso. A dieta rica em fibras aumenta o volume total do conteúdo fecal, fazendo com que os vários materiais carcinogênicos passem de forma mais diluida através do intestino 13,80 .

Os resultados do presente estudo também não suportam esta teoria e se assemelham aos achados de outros pesquisadores. DRASAR e IRVING (1966) 26; HIGGINSON et al )1966) 42, não conseguiram estabelecer qualquer relação entre a incidência de câncer de cólon e - conteúdo de fibras. da dieta. WARD et al (1973) 84 também não demostraram qualquer efeito protetor pela adição de fibras vegetais à alimentação de animais, aos quais se administrava substâncias carcinogênicas para o cólon.

BINGHAM et al (1979) ${ }^{5}$ não encontraram correlação entre consumo de vegetais verdes frescos e mortalidade por câncer de cólon e de reto na Grã Bretanha.

Vários estudos indicam uma relação negativa entre cân cer de cólon e o consumo de vegetais. KINLEN (1982) 53, ao indagar sobre qual ou quais componentes dos vegetais podem exercer este efei to protetor, assinala que o beta-caroteno, a mais importante pró-vitamina A no homem, é um candidato e que está presente em uma grande quantidade de vegetais.

A teoria da baixa ingestão de vegetais ou alimentos fibrosos e o câncer de cólon embora refutada pelos trabalhos anterio res é sustenta por vários outros estudos tipo caso-controle. 
Os estudos de BJELKE ${ }^{6}$ e o de MODAN et al 70,71 demostram uma frequência de consumo de fibra significante mais baixa entre pacientes com câncer. Destaca-se que no estudo realizado em Is rael 71 o componente fibra foi o único grupo onde diferenças signifí cantes entre casos e controles foram observados, apenas para câncer de cólon, porém, o estudo de Dales et al ${ }^{23}$ revelou gradiente para alimentos com fibras. Quando analisou em conjunto o consumo de gordu ras saturadas e o consumo de fibras, encontrou que significantemente mais pacientes com câncer de cólon do que controles relataram maior consumo de alimentos ricos em gorduras saturadas e baixo consumo de alimentos fibrosos.

HAENSZEL et al (1980) 40 encontraram associação negativa entre alimentos comumente consumidos pela população japonesa e câncer de intestino grosso como um todo. Ao estudarem exclusivamente a relação com câncer de reto baixo (menos de $5 \mathrm{~cm}$ do ânus) não encon traram significância estatística.

Resultados em Adventistas do 7 ㅇ dia, anteriormente re feridos também sugerem uma associação negativa entre fibras contidas nos alimentos e câncer de cólon, porém, não significativas.

O estudo de GRAHAM et al (1978) ${ }^{34}$ destaca um aumento do risco de câncer de cólon com o decréscimo de consumo de vegetais, principalmente os do gênero crucifera, que contém quantidade apreciá vel de fibra: nabo, repolho, couve de Bruxelas, brócoli, além de 19 vegetais, considerados conjuntamente, crus ou cozidos. Este estudo é compativel com a hipótese de WATTENBURG (1971) 87 que, por meio de estudos em animais, também sugere que componentes destes vegetais contém determinadas enzimas que induzem o crescimento da capacidade metabólica das hidroxilases dos hidratos de carbonos policíclicos, aumentando a taxa do metabolismo de potenciais agentes carcinogêni- 
cos. Já com relação ao câncer de reto, verificou a mesma relação, po rém, para o decréscimo de consumo de vegetais crus e de repolho.

A teoria das fibras, portanto, também apresenta discordância entre os estudos apresentados. Além disso não se tem garan tido que a dieta rica em fibra sempre diminua o tempo de trânsito ${ }^{44}$. Enquanto alguns autores mostram que as fibras apressam o tempo de trânsito intestinal, outros mostram que elas não têm efeito sobre este tempo; outros, ainda, mostram que pelas fibras o tempo de trânsito é acelerado em pessoas que originalmente apresentam tempo de trânsito moroso, ou se torna mais lento naqueles que apresentam trân sito rápido, não afetando aqueles que tem tempo de trânsito moderado 41 .

Há que se considerar, ainda, que estas teorias mencio nadas dizem respeito mais ao cólon, não sendo especificas para o reto. Assim sendo, a hipótese formulada de que o baixo consumo de verduras e de frutas e o alto consumo de gorduras constituiriam fator de risco para o câncer de reto não se confirma. 
A detecção inicial de associação significante entre câncer de reto e indivíduos nascidos em outras áreas que não as da Região Nordeste, bem como aquela evidenciada para os indivíduos que tinham seus pais nascidos nestas mesma áreas, permitiu que se imaginasse a existência de um diferencial de câncer de reto por local de nascimento.

Por meio da análise multivariada, contudo, foi possível verificar que, ao se analisar o local de nascimento dos pais dos individuos amostrados, conjuntamente com o consumo de queijo e de orégano, essa associação era espúria. Assim, no presente estudo, não se pode afirmar que ter origem nordestina confira um certo fator de "proteção" ao aparecimento de câncer de reto. Na realidade, o único fator que apresentou-se como possível fator de risco é o consumo de queijo. Este achado, no entanto não encontra semelhança com outros estudos. PICKLE et al (1984) 78 verificaram que existe uma associação positiva entre câncer de cólon e câncer de reto entre os que con sumiam produtos lácteos, porém, sem significação estatística.

É possivel que em decorrência de inúmeros testes realizados, a constatação da associação entre consumo de queijo e câncer de reto seja um artefato estatístico, embora esta associação tenha ocorrido nos três tipos de amostra considerados. Por outro lado, a análise do gradiente do risco relativo para esta variável induz a refletir sobre a possibilidade da relação aventada. O consumo de queijo poderia estar refletindo status sócio-ecônomico diferente en tre os casos e, por conseguinte, outros tipos de práticas de estilo de vida que aqui não foram consideradas.

Nenhuma das variáveis não nutricionais apresenta asso ciação significativa com câncer de reto. 
No presente trabalho constatou-se a inexistência da associação significativa entre hábito de fumar e câncer de reto. Coincidem com os resultados de outros estudos epidemiológicos, quer de coortes 25 , quer de caso-controle $38,40,42,78,89,90$ induzindo a afirmar que o hábito de fumar não constitui fator de risco para. o câncer de reto.

o hábito intestinal dos pacientes com câncer de cólon e de reto tem sido investigado com base na hipótese de que o câncer de intestino grosso possa ter alguma relação com o conteúdo fecal e com a ação da flora bacteriana. No presente estudo não há marcantes diferenças na frequência de movimentos intestinais entre os pacientes com câncer de reto e os controles.

Os pacientes com câncer de reto apresentaram fezes amolecidas e diarréicas mais frequentemente do que os controles, quer pareados, quer globais. DALES et al (1979) 23 que também encontra ram um número maior de casos de câncer de cólon e de reto com história de frequêntes diarréias ou fezes soltas, menciona que o fato de ve estar relacionado com "bias" desde que envolve sintomas da doença intestinal. PERNU (1967) 76 relacionou a diarréia com existência de lesões pré-cancerosas, tais como colite ulcerativa e polipose. Os es tudos de PICKLE et al (1984) 78, wYNDER et al ( $1967^{89}, 1969^{90}$ ) e o mais recente e especifico estudo sobre hábitos intestinais, de NAKAMURA et al, (1984) ${ }^{73}$ não apresentam diferenças significantes entre hábitos intestinais dos pacientes com câncer de cólon e de reto e os controles. Há que se destacar que o reto está normalmente vazio, exceto imediatamente antes da defecação, um ponto importante a ser con siderado na avaliação do papel que as fezes podem desempenhar na etiologia do câncer de intestino grosso ${ }^{89}$. 
lipos e câncer de reto. Apenas três pacientes com câncer de reto men cionaram possuí-los. Tampouco se verificou regular uso de laxante que poderia atuar como fator de risco no câncer de reto. Os estudos de HOWE et al (1982) 47 e MILIER et al (1983) 63 , realizados no Cana dá, e o de PICKLE et al (1984) ${ }^{78}$, realizado nos Estados unidos da América, ressaltam a importância da história de pólipos como fator de risco, tanto para câncer de cólon, quanto para o câncer de reto.

A relação entre pólipos e câncer de cólon e de reto tem sido apresentada como de alta incidência. Pessoas com pólipo ade nomatoso ou adenomas com um foco de displasia epitelial tem aumentado o risco de câncer de cólon 17, 54, 72. Alguns estudos histopatoló gicos têm evidenciado que as lesões adenomatosas do cólon são precursoras do câncer de cólon 38, 83 , outros, contudo, não reforçam es ta relação ${ }^{64}$. Existem sugestões de que em áreas de baixa incidência de câncer de cólon e de reto haja uma menor relação de dependência entre as condições de pré-existência de pólipos transformando-se em cânceres de reto do que para outros segmentos do cólon ${ }^{21}$.

Não se observou associação entre câncer de reto e hemorróida. Difere, portanto, dos resultados de PERNU (1967) 76 " que encontrou que história de hemorróida e desordens biliares eram mais frequentes nos homens com câncer de intestino grosso do que entre os controles.

Vários investigadores tem estudado a possível influên cia da hereditariedade no câncer do intestino grosso e têm concluído que câncer tem sido mais frequente entre parentes de um paciente de câncer, do que na população em geral. Estes estudos indicam um fator poligênico no desenvolvimento do câncer, embora isto exerça pequeno papel em toda a etiologia do câncer de intestino grosso ${ }^{78}$. No presente estudo não se evidenciou diferenças entre casos e controles 
quanto a existência de familiares próximos com câncer.

A associação inicial entre consumo de vinho e câncer de reto apresenta-se possivelmente como espúria, na medida em que, ao se analisar seu efeito em conjunto com as variáveis queijo, orégano e fumo total, deixa de ter significância estatistica. Um dos mecanis mo explicativos para a possivel relação entre o consumo de cerveja e - câncer de reto diz respeito ao fato de que, para alguns indivíduos, cerveja funciona como "purgante", produzindo fezes líquidas, que facilmente enchem ó reto, ao contrário das fezes normais, que são usualmente firmes e ficam retidas no cólon sigmóide até momentos antes da evacuação. Assim sendo, os bebedores de cerveja teriam maior tempo de contato das fezes com a mucosa retal 50, 56. A hipótese for mulada de que o consumo de cerveja constitui fator de risco para cân cer de reto, não é confirmada no presente estudo. Quer a nível de análise individual, quer a nível de análise multivariada, quando se procurou estabelecer a relação do hábito de cerveja dentre os que não bebiam pinga e vinho, conjugado com as outras variáveis, que apresentaram significância com câncer de reto, não se confirmou que - consumo de cerveja seja fator de risco. Também a relação positiva entre bebedores dos diversos tipos de bebidas e fumantes, observada em estudo de coorte ${ }^{46}$, não se confirma com os dados do presente estudo.

A relação entre o consumo de cerveja e câncer de reto, embora confirmada por alguns autores, tem sido contestada por ou tros. Uma intensa associação entre câncer de cólon e de reto e consu mo de cerveja surgiu quando BRESLOW e ENSTRON (1974) 9 correlacionaram a mortalidade por câncer com o consumo per capita de cigarro, be bida alcoólica, vinho e cerveja em diferentes estados dos Estados Unidos da América do Norte. Em outro estudo ENSTRON (1977) 29 achou que entre as 8 primeiras localizações de câncer rios homens, o câncer 
de reto mantém a maior correlação entre mudança de consumo per capita de cerveja e mudança de mortalidade. Acentuou que a razão homem/ mulher de mortalidade por câncer de reto está relacionada com o consumo de cerveja em diferentes estados americanos.

Dois recentes estudos que investigaram a mortalidade por câncer de reto entre os trabalhadores de cervejaria, aos quais era permitido uma quota livre do produto, mostram resultados diferen tes. Enquanto que entre trabalhadores de Dublim 24 encontrou-se um excesso de mortes por câncer de reto, nenhuma associação foi encontrada em Copenhagen 50 . Três estudos caso-controle indicaram uma associação entre beber cerveja e câncer de cólon e de reto. STocks (1958) 81, achou uma relação significante na população masculina inglesa entre câncer do intestino grosso como um todo e consumo de cer veja. WYNDER e SHIGAMATSU ${ }^{89}$ mostraram uma significante proporção de bebedores de cerveja entre os casos de câncer de reto em comparação com os controles, porém destacam que deva ser reflexo de outros fato res econômicos e sociais. PICKLE et al (1984) 78 ao analisar os padrões de consumo da cerveja comercial e "caseira" entre os grupos et nicos da área rural de Nebraska encontrou uma associação positiva entre câncer de cólon entre os individuos masculinos que bebiam cerveja comercial maior do que para câncer de reto. Para o sexo feminino mostrou uma relação com câncer de reto, porém, de menor valor.

Outros estudos como os de HIGGINSON et al, em Kansas (1966) 42, e WYNDER et al, no Japão (1969) 90, PERNU na Finlandia (1960) $76, \operatorname{BJELKE}\left(1971^{6}, 1973^{7}\right.$ ) não encontraram associação entre os diversos tipos e quantidades de bebidas (vinho, cerveja e bebidas alcoólicas) e câncer de intestino grosso como um todo ou câncer de cólon e de reto. 
Os estudos sobre dois grupos religiosos: MORMONS ${ }^{28} \mathrm{e}$ os Adventistas do 7 o dia 77 , que consomem menos cerveja que a popula ção em geral, apresentaram coeficientes de mortalidade $2 / 3$ do observado para a população em geral. É provável que outros fatores relatị vos ao estilo de vida desses grupos contribuiram para as baixas taxas de mortalidade por câncer de intestino.

De um modo geral todos os estudos revistos na literatura, que cuidam dos fatores relacionados ao câncer de intestino gros so, tratam mais especificamente dos fatores alimentares relacionados ao câncer de cólon e sendo poucos os que encontram alguma relação com o câncer de reto.

Há que se destacar que, ao se considerar exclusivamen te os casos de câncer de reto baixo, não se detectou a importância do consumo de queijo como fator associado ao câncer, fato que pode estar ligado ao menor tamanho de amostra, levando a um poder de teste reduzido. 
7- CONSIDERAÇÕES FINAIS

o presente estudo mostrou haver associação positiva entre consumo de queijo e câncer de reto. Outras variáveis estudadas não apresentaram evidência estatística como fator de risco. A ingestão de orégano e de colorau poderia ser considerada como sendo um le ve fator de proteção. A hipótese específica de associação entre ingestão de cerveja e câncer de reto não foi corroborada.

Como todo estudo epidemiológico em geral, e investiga ção caso-controle em particular, os resultados têm que ser vistos com - devido "equilíbrio". Como foram feitos múltiplos testes, não está afastada a possibilidade de que a significância encontrada para quei jo seja um artefato estatístico. Deve-se notar, no entanto, que foi o único fator investigado que manteve consistência de resultados sig nificantes nos três tipos de amostras, quer quando analisado isolada mente, quer quando controlado por outras variáveis. Há ainda a consi derar a significância do teste de gradiente.

Para o estudo do consumo de bebidas procurou-se evitar a possível confusão que adviria da interação de consumo de mais de uma bebida. Como a análise para cada bebida foi feita sempre entre os não bebedores das outras, julga-se que este problema foi contornado, estando os resultados isentos deste tipo de vício.

A não associação entre hábito de fumar e câncer de re to era esperada. Este resultado é importante, pois pode servir como indicador para a confiabilidade na condução geral do trabalho e nos seus resultados. 
8- CONCLUSÕES

8.1- Houve evidência estatística de associação positiva entre o consumo de queijo e câncer de reto. Epidemiologicamente isto pode sugerir que o consumo de queijo seja un possivel fator de risco.

8.2- Não houve evidência estatística de associação entre o consumo de cerveja e câncer de reto.

8.3- Não houve evidência estatística de associação entre os diversos tipos de alimentos consumidos (carnes e derivados, leite, ovos, peixe, verduras, legumes, leguminosas, cereais, frutas, doces, temperos) e câncer de reto.

8.4- Não houve evidência estatística entre características do hábi to intestinal e câncer de reto.

8.5- Não houve evidência estatística entre história de tabagismo e câncer de reto. 
I ADENIS, L. et al. Épidémiologie des cancers colo-rectaux. Lille Médical, 24: 649-52, 1979.

2 BERG, J.W. \& HOWELL, M.A. The geographic pathology of bowel can cer. Cancer, 34: 807-14, 1974.

3 BETTARELlo, A. et al. Etiologia do Câncer do colo e do reto. Rev. Hosp.Clin. Fac.Med.S.Paulo, 35: 77-82, 1980.

4 BIANCO, M. et al. Estudio epidemiologico colaborativo de cancer recto-colonico. Informe de su implementacion y resultados pre liminares. Bol. A.N.de Medicina, 61: 145-55, 1983.

5 BINGHAM, s. et al. Dietary fibre and regional large-bowel cancer mortality in Britain. Brit. J.Cancer, 40: 456-63, 1979.

6 BJELKE, E. Case-control study of cancer of the stomach, colon and rectum. In: Oncology, 1970: procceedings of the Tenth International Cancer Congress, Chicago, 1970. Year Book Med. Publ., 5: 320-84, 1971 apud ZARIDZE, D.G. Environmental etiology of large-bowel cancer. JNCI, 70: 389-400, 1983.

7 BJELKE, E. Epidemiological studies of cancer of the stomach, coIon and rectum. Ann Arbor Univ.Microfilms, 1-4, 1973 apud POT TER, J.D. et al. Alcohol and beer consumption in relation to cancers of bowel and lung: an extended correlation analysis. J.Chron. Dis. , 35: 833-842, 1982 . 
8 BOURNOVILLE, M. \& TRIBOULET. Notions épidémiologiques sur les cancers du colon et du rectum. Lille Médical, 25: 526-33, 1980 .

9 BRESLOW, N.E. \& ENSTROM, S.E. Geographic correlations between cancer mortality and alcohol-tobacco consumption in the United States. J.Nat.Cancer Inst., 53: 631-9, 1974.

10 BRESLOW, N.E \& DAY, N.E. Statistical methods in Cancer Research. The analysis of case-control studies. Lyon, International Agency for Research Cancer, 1980. Vol.1 (IARC Scient.Publ.32)

ll BRUMINI, R. et al. Câncer no Brasil - dados histopatológicos, 1976-80. Rio de Janeiro, Ministério da Saúde/Campanha Nacional de Combate ao Câncer, 1982.

12 BURKITT, D.P. Related disease-related cause ? Lancet, 2: 1229$31,1969$.

13 BURKITT, D.P. Epidemiology of cancer of the colon and rectum. Cancer, 28: 3-13, 1971 .

14 BURKITT, D.P. et al. Effect of dietary fibre on stools and transet-times, and its role in causation of disease. Lancet, $\underline{30}$ : $1408-12,1972$.

15 BURKITT, D.P. Epidemiology and etiology. JAMA, 231: 517-18, 1975

16 BUSSEY, H.J.R. Genetic factors. Recent Results Cancer Res. , 83: $45-58,1982$. 
17 CALKINS, W.G. Premalignant gastrointestinal lesions. Geriatrics, 19: 707-17, 1964 apud WYNDER. E.L. \& SHIGEMATSU, T. Enviromental factors of cancer of the colon and rectum. Cancer, 20:152061, 1967.

18 CANCER Facts and Figures. New York, The American Cancer Society, 1980 apud ELIAS, G. Carcinoma of the colon and rectum: epidemiology, etiology and diagnosis (Part 1) MD State Med. J., 30: $40-2,1981$.

19 CLASSIFICAÇÅ Internacional de Doenças para Oncologia. Washington, D.C., Organização Panamericana de Saúde, 1978. (Publ. Cient., 345).

20 COLE, W.H. Cancer of the colon and rectum. Surgical Clinics of North America, 52: 871-82, 1972.

21 CORREA, P. et al. Polyps of the colon and rectum in Cali, Colombia. Int. J.Cancer, 9: 86-96, 1972.

22 CUMMINGS, J.H. et al. The effect of meat protein and dietary fiber on colonic function and metabolism. II. Bacterial metaboli tes in feces and urine. Am.J.Clin.Nut., 32: 2094-2101, 1979 apud MODAN, B. et al. Low-fiber intake as an etiologic factor in cancer of the colon. J.Natl. Cancer Inst., 58: 15-18, 1975.

23 DALES, L. G. et al. A case-control study of relationships of diet and other traits to colorectal cancer in American blacks. Am. J.Epidemiol. , 109: 132-44, 1979. 
24 DEAN, g. et al. Causes of death of blue-collar workers at a Dublin brewery, 1954-1973. Brit.J.Cancer, 40: 581-89, 1979 apud KINLEN, I.J. Aetiology. Recent Results Cancer Res. 83: 11-20, 1982 .

25 DOLL, R. \& HILL, A.B. Mortality in relation to smoking:ten years observations of British doctors. Brit.Med.J., 5395:1399-1410; 5396: 1460-1467, 1964 .

26 DRASAR, L.S. \& IRWING, D. Environmental factors and cancer of the colon and breast. Brit.J.Cancer, 27: 167-172, 1973.

27 ELIAS, G. Carcinoma of the colon and rectum: epidemiology, etiology and diagnosis (Part I) MD State Med.J., March, 40-2, 1981.

28 ENSTROM, J.E. Cancer mortality among Marmons. Cancer, Philadelphia, $\underline{36}: 825,1975$.

29 ENSTROM, J.E. Colorectal cancer and beer drinking. Brit. J. Cancer, 35: 674-83, 1977 .

30 FRASER, P. \& ADEISTEIN, A.M. Colorectal cancer recent trends. Re cent Results Cancer Res., 83: 1-10, 1982.

31 FUNDAÇão Sistema Estadual de Análise de Dados Estatísticos. Óbitos gerais por causa de morte detalhada, segundo sexo e idade microficha TBAI. 005, 1982.

32 GONVERS, J.J. Early diagnosis of cancer of the colon and rectum. Schweiz, Rundschau Med. (Praxis) 68: 842-46, 1979. 
33 GONVERS, J.J. Épidémiologie et étiologie du cancer colo-rectal. Schweiz. Rundschau Med. (Praxis) 68: 864-67, 1979.

34 GRAHAM, $S$. et al. Diet in the epidemiology of cancer of the colon and rectum. J.Natl.Cancer Inst., 61: 709-14, 1978.

35 GRAHAM, s. et al. Need pursue new leads in the epidemiology of colorectal cancer. JNCI, 63: 879-81, 1979.

36 GRAHAM, S. Toward a dietary prevention of cancer. Epidemiologic Reviews, $\underline{5}: 38-49,1983$.

37 GREGOR, O. et al. Geographical distribution of stomach cancer in Czechoslovakia GUT, 10: 150-154, 1969 apud LIPIIN, N. Dietary, environmental, and hereditary factors in the development of colorectal cancer. CA - A Cancer Jour, for Clinic., 29: 219-9, 1979.

38 HAENSZEL, W. \& CORREA, P. Cancer of the colon and rectum and ade nomatous polyps a review of epidemiologic findings. Cancer, 28: 14-24, 1971 .

39 HAENSZEL, W. et al. Large-bowel cancer in Hawaiian Japanese. J. Natl Cancer Inst., 51: 1765-79, 1973.

40 HAENSZEL, W. et al. A case-control study of large bowel cancer in Japan. JNCI, 64: 17-22, 1980. 
41 HARVEY, R.F. et al. Effets of increased dietary fibre on intesti nal transit. Lancet, 1 : 1278-80, 1973 apud GRAHAM, S. et al. Need to pursue new leads in the epidemiology of colorectal cancer - guest editorial. JNCI, 63: out., 1979.

42 HIGGINSON, J. et al. Etiological factors in gastrointestinal can cer in man. J.Natl. Cancer Inst., 37: 527-45, 1966.

43 HIGGINSON, J.\& MUIR, C.S. Détermination de l'importance des fac teurs environmentaux dans le cancer humain. Rôle de l'epidemiologie. BULL. Cancer, 64: 365-84, 1977.

44 HILL, M.J. et al. Bacteria and aetiology of cancer of large bowel. Lancet, I: 95-100, 1978 .

45 HILL, M.J. Bacteria and the aetiology of colonic cancer. Cancer, 34: $815-18,1974$.

46 HIRAYAMA, T. A large-scale cohort study on the relationship between diet and selected cancers of digestive organs. In:BRUCE, W.R. et al. Gastrointestinal cancer: endogenous factors. Harbor, N.Y., Cold Spring Harbor Laboratory, 1981. p 409-29 (Ban bury Report 7) apud ZARIDZE, D.G. Environmental aetiology of large-bowel cancer - guest editorial. JNCI, 70: 389-400,1983.

47 HOWE, G.R. et al. Dietary factors in relation to the aetiology of colorectal cancer. Cancer Detect Prev. , 5: 331-34, 1982. 
48 INTERNATIONAL Agency for Research on Cancer Intestinal Microecology Group. Dietary fibre, transit-time, faecal bacteria, ste roids and colon cancer in two Scandinavian populations. Lancet, 2: 207-11, 1977.

49 JAIN, M. et al. A case-control study of diet and colo-rectal can cer. Int. J.Cancer, 26: 757-68, 1980 .

50 JENSEN, O.M. Cancer morbity and causes of death among Danish bre wery workers. Int. J.Cancer, 23: 454-63, 1979 apud KLINLEN,I. J. Aetiology. Recent Results Cancer Res., 83: 11-20, 1982.

51 JENSEN, O.M. et al. Diet, bowel function, fecal characteristics, and large bowel cancer in Denmark and Finland. Nutr. Cancer, $4: 5-19,1982$.

52 JONG, U.W. et al. The distribution of cancer within the large bo wel. Int. J.Cancer, 10: 463-77, 1972 .

53 KINLEN, L.J. Aetiology - Recent Results Cancer Res. , 83: 11-20, 1982.

54 LIPKIN, M. Dietary, environmental, and hereditary factors in the development of colorectal cancer. Cancer Jour, Clinic., 29: $291-9,1979$.

55 LOWENFELS, A.B. Etiological aspects of cancer of the gastrointes tinal tract. Surg.Gynecol.Obstet., 137: 291-9, 1973.

56 LOWENFELS, A.B. Beer and rectal cancer. Lancet, 26: 201, 1980. 
57 LUBIN, J. A computer program for the analysis of matched casecontrol studies. Computers and Biomedical Research, 14: 13843,1981 .

58 MACLENNAN, R. Épidèmiologie du cancer colo-rectal. Bull, Cancer, 62: $411-8,1975$.

59 MACQUART-MOULIN et al. Alimentation et cancer recto-colique. Gas troenterol. Clin. Biol., 7: 277-86, 1983.

60 MANTEL, N. \& HAENSZEL, W. Statistical aspects of the analysis of data from retrospective studies of disease. J.Natl. Cancer Inst. $\underline{22}(4): 719-48,1959$.

61 MANTEL, N. Chi-square tests with one degree of freedom, extensions of the Mantel-Haenszel procedure. J.Am.Stat.Assoc., 58: $690-700,1963$.

62 MANUAL de Classificação Estatística Internacional de Doenças, Lẹ sões e Causas de Óbito, 8a Revisão. Washington, D.C., Organização Pan-Americana de Saúde, 1969 (Publ.Cient., 190).

63 MANUAL de Classificação Internacional de Doenças, Lesões e Causas de Óbito. 9a Revisão. Washington, D.C., organização PanAmericana de Saúde, 1978.

64 MARIGO, C. et al. Cancer and "Cancer Related" colorectal lesions in são Paulo, Brazil. Int. J.Cancer 22: 645-54, 1978. 
65 MARTINEZ, I. et al. Factors associated with adenocarcinomas

of the large bowel in puerto Rico. In: BIRCH, J.M., ed. Advances in medical oncology, research and education. New York, Pergamon Press, 1979. p.45-42, vol.3. apud GRAHAM, S. Toward a dietary prevention of cancer. Epidemiol. Rev. , ㅍ: 38-49, 1983.

66 MIETTINEN, 0.S. Individual matching with multiple controls in the case of all or none responses. Biometrics, 25: 339-55, 1969.

67 MILLER, A.B. et al. Food itens and food group as risk factors in a case-control study of diet and colo-rectal cancer. Int. J. Cancer, 32: 155-61, 1983.

68 MIRRA, A.P. et al. Estudo epidemiológico do câncer da mama numa área de alta paridade: São Paulo, Brasil. Rev.Ass.méd.bras. 18: $357-64,1972$.

69 MIRRA, A.P. Incidência e mortalidade dos cânceres do estômago, co lon e reto no Município de São Paulo. In: SEMINÁRIO NACIONAL sobre Prevenção e Detecção do Câncer do Estômago e do Intestino Grosso, lo , são Paulo, Brasil, 1978.

70 MODAN, B. et al. Low-fiber intake as an etiologic factor in cancer of the colon. J.Natl.Cancer Inst., 55(1): 15-18, 1975.

71 MODAN, B. et al. Dietary factors and cancer in Israel. Cancer Res., 35: 3503-06, 1975.

72 MUTO, T. et al. The evolution of cancer of the colon and rectum. Cancer, 36: 2251-70, 1975 . 
73: NAKAMURA, G.L. et al. Colorectal cancer and bowel habits. Cancer 54: $1475-77,1984$.

74 NETTER, F.H. Digestive system: lower digestive tract. New York, CIBA, 1969. vol. 2 (The CIBA Collection of Medical Illistrations v. 3).

75 ODONE, $V$ et al. The natural history of colorectal carcinoma in Adolescents. Cancer $\underline{49}$ : 1716-20, 1982.

76 PERNU, J. An epidemiological study on cancer of the digestive or gans and respiratory system - a study based on 7078 cases. Ann.Med. Intern. Fenn. , 49: 33, 1960 apud WYNDER, E.L.\& SHIGEMATSU, T. Environmental factors of cancer of the colon and rectum. Cancer, 20: 1520-61, 1967.

77 PHILLIPS, R.L. Role of life-style and dietary habits in risk of cancer among seventh-day adventists. Cancer Res., 35:3513-22, 1975 apud HAENSZEL, W. et al. A case-control study of large bowel cancer in Japan. JNCI, 64: 17-22, 1980.

78 PICKE, L.W. et al. Colorectal cancer in rural Nebraska. Cancer Res. . 44: 363-69, 1984.

79 SCHLESSELMAN, J.J. Case-control studies. New York, Oxford Univer sity Press, 1982. (Monogr, Epidemiology and Biostatistics).

80 SPILLER, G.A. \& FREEMAN, H.J. Recent advances in dietary fiber and colorectal diseases. Am.J.Clin.Nutr. , 34: 1145-52, 1981. 
81 STOCKS, P. Cancer indicence in North Wales and Liverpool region in relation to habits and environment. London, Brist. Empire Cancer, 1958. (35th. Manual Report Suppl., 2:2)

82 TUYNS, A.J. Epidémiologie des cancers du colon et du rectum. Acta Gastro-Enterologica Belgica, 45: 146-57, 1982.

83 VAN DER WERF, S.D.J. Epidemiology and aetiology of large bowel carcinoma. Neth J.Med. , 26: 240-46, 1983.

84 WARD, J.M. et al. Pathology of intestinal neoplasms and other lesions in rats exposed to azoxymetane. J.nat.Cancer Inst. 5 l: $1029,1973$.

85 WATERHOUSE, $\mathrm{J}$. et al. Cancer Incidence in Five Continents. Lyon, International Agency for Research on Cancer, 1976. vol: 3 (IARC Scient. Publ., 15).

86. WATERHOUSE, J. et al. Cancer Incidence in Five Continents. Iyon, International Agency for Research on Cancer, 1982 vol. 4 (IARC Scient. Publ., 42).

87 WATTENBURG, L.W. Studies on the polycyclic hidrocarbon hydroxyla ses of the intestine possibly related to cancer. Cancer, 28: 99-104, 1971.

88 WEISBURGER, J.H. Chemical carcinogens and their mode of action in colonic neoplasia. Dis.Col. \& Rect. , 16: 431-37, 1973.

89 WYNDER, E.L. \& SHIGEMATSU, T. Environmental factors of cancer of the colon and rectum. Cancer, 20: 1520-61, 1967. 
90 WYNDER, E.L. et al. Environmental factors of cancer of the colon and rectum. II. Japanese epidemiological data. Cancer, 23 5: $1210-20,1969$.

91 ZARIDZE, D.G. Environmental aetiology of large-bowel cancer. JNCI, $\underline{70}(3): 389-400,1983$. 
$\underline{A} \mathrm{~N} E \mathrm{X} O$

Sence do LIbllofece o Docomenteģ̃o FACULDAOE DE SAǴdE PÚBLICA

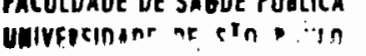




19 CASO ESOFAGO
28 CASO RETO
38 CONTROLE ESOFAGO
48 CONTROLE RETO

1. HOSPITAL REG.HOSP.NP

2. CLINICA

3. NOME

4. RESIDENCIA - RUAa N8

BAIRRO
ESTADE
PAIS 5.ZONA: 1.URBANA ( )
2.RURAL ( )
3NAO SABE )

6. DATA DE NASCIMENTO

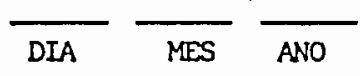

7. IDADE ANOS

8. SEXO
1. MASC. ()

2. FEM. ()

9. NATURALIDADE DO PAI:

10. NATURALIDADE DA MAE:

11. ESTADO MARITAL

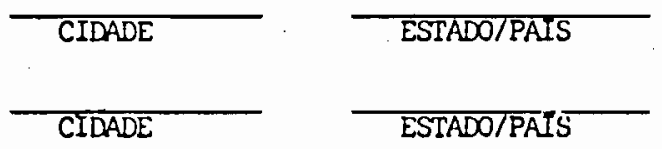

1. SOLTEIRO

2. CASADO (de direito/de fato)

3. VIUVO

4. DESQUTTADO/DIVORCIADO

12. RELIGIXO (DE FATO) HA QUANTO TEMPO?

13. HABTTOS RELIGIOSOS ESPECIFICOS:

14. ESCOLARIDADE:

15. QUANTOS IRMAOS O SR. TEM?
1. ANALFABETO(lè e escreve mal) ( )

2. PRIMARIA. ......... ( )

3. GINASIAL. . . . . . . . ( )

4. COLESIAL, OU TECNICA aI NORMAL. . ( )

5. SUPERIOR. .......... ( ) TOTAL $:$ WJVOS MORTOS $:$ CALISA - 
10. ALENNS DOS SEUS IRMAOS E SEI IRMAO GEMEO:

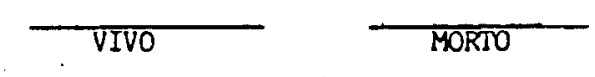

1\%. SE VIVO, COMO ESTÁ A SAIDEE NELE"?

SE MORTO, QUAL A CAUSA DE MORTL:

1\%. QUANTOS FILHOS O SR. TEM? $\frac{\vdots}{\text { TOTAL }}$ '

19. IDCAL DE NASTIMENTO:

1. MUNÍCIPIO DE SAOO PAULO ( )

2. EST'.SAO PAULO ()

3. OUIRO ESTAD CIDADE

4. OUTRO PAIS

QUAL? $($ )

21. O LOCAL ONDE NASCEU ERA ZONA:

1. URBANA ...... ()

2. RURAL. ......... ( )

3. NAO SABE. ...... ( )

21. TEMPO DE RESIDENCIA NO LOCAL DE NASCIMENTO:

1. 7ONA URBANA ANOS

2. ZONA RURAL_ ANOS

27. TRABALHOU NO LOCAL ONDE NASCEU?

1. NAO

( )

2. SIM (), se sim:

\begin{tabular}{l|c} 
TIPO DE DCUPACAO (especificar) & TEMPO \\
\hline & \\
\hline & \\
\hline & \\
\hline & \\
\hline
\end{tabular}

23. MDOU-SE PARA:

0. NAO SE APLICA ( )

1. MUNICIPIO DE SAOO PAULO ( )

2. EST. SAO PAULO ( )

3. aTRO ESTALO CIDADE

4. UUTRU PAIS

0. NAO SE APLICA

24. TEMPO QUE RESIDIU NESTE LOCAL

1. ZONA RURAL

2. TONA URBANA ANOS

ANOS

25. TRABALYOU NESTE LOCAL?

0. NAO SE APLICA ()

1. Who

( )

2. SIM

(), se sim:

\begin{tabular}{l|l} 
TIPO DE COUPACAO (especificar) & TTMPO \\
\hline & \\
\hline & \\
\hline & \\
\hline & \\
\hline
\end{tabular}


'.$\wedge$. MUDOU-SE PARA:

1). NAO SE APLICA

( )

1. MUNICIPIO DE SÃO PAULO

フ.EST.SAOO PAULO ( )

3.OUTRO ESTADO ( )

4. OMIRRO PAIS ( )

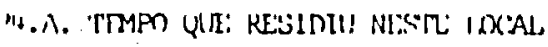

1. \%NA RUNAL

2. ZUNA URBANA

1. NAOO ( )

2b.A. 'TRABALHOU NESTE LOCAL?

2. $\operatorname{SIM}()$, se sim: TIPO DE OCUPASAO (especificar) TEMPO

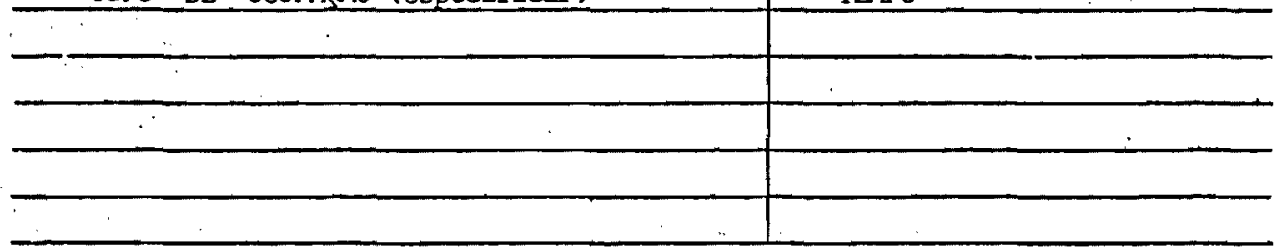

23.B. MUDOU-SE PARA:

0. NÃO SE APLICA ( )

i. MNICIPJO DE SAO PAULO ( )

2. EST.SAO PAULO

3. OUTRO ESTADO ( )

4. OUIRO PAIS ()

24.B. TEMPO QUE RESIDIU NESTE LOCAL

1. ZONA RURAL

2. ZONA URBANA

25.B. TRABALHOU NESTE LOCAL?

1. NAOO ()

7. SIM ( ), se sim:

\begin{tabular}{l|l|} 
TIPO DE OCUPAÇAO (especificar) & TEMPO \\
\hline & \\
\hline & \\
\hline & \\
\hline & \\
\hline
\end{tabular}


N:

'H. "SK. TMMA U' FUMAVA:

1. NUNCA (näo preencher a tabela) ()

2. NAO AGORA, MAS:IM NO PASSADO ( )

3. SIM. . . . . . . ( )

it (2) (xi ( 3): 1) 1) Uf??

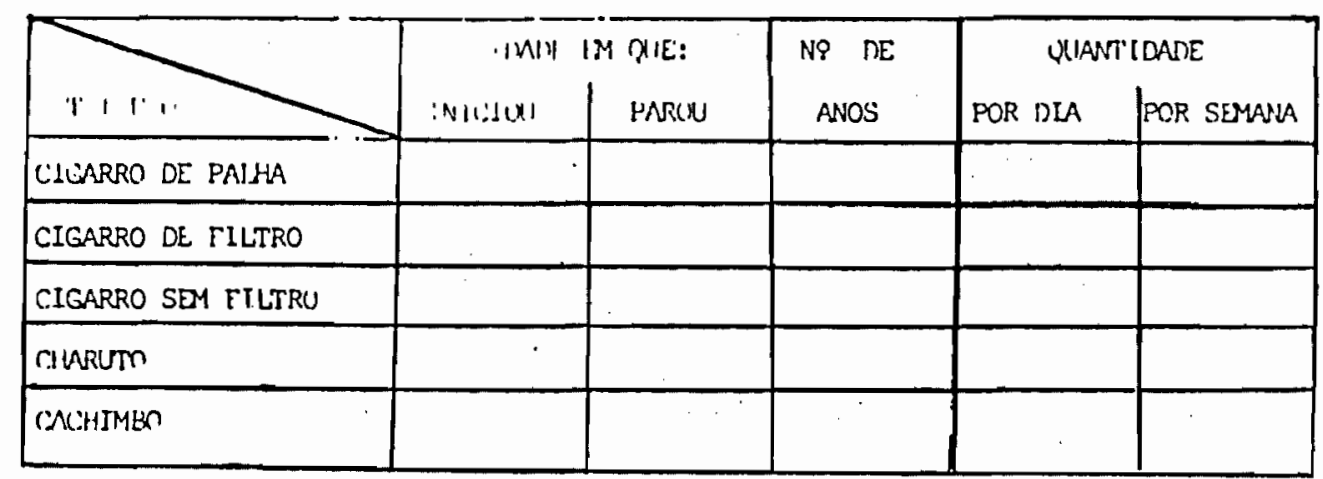

URSERVAÇAU:

27. O SR. TEM O HAHITI DE MASCAR? 1 1. NNNCA. ......... ( )

2. NAO AGORA, MAS SIM NO PASSALUU, )

3. SIM. . . . . . . . . ( )

CASO (2) OU (3): O QUE?

IDADL: QUE INICIOU?

IDADE EM QUE PAROU?

28. O SR, COSTUMA TOMAR RTEIDAS ALCOULICAS?

1. MNCA(riao preencher a tatala) ( 1

$\because$ NAO AGORA, ML SIM NI PASSAIY ( )

3. SIM. . . . . . . ( )

SE (2) W (3): O QUL?

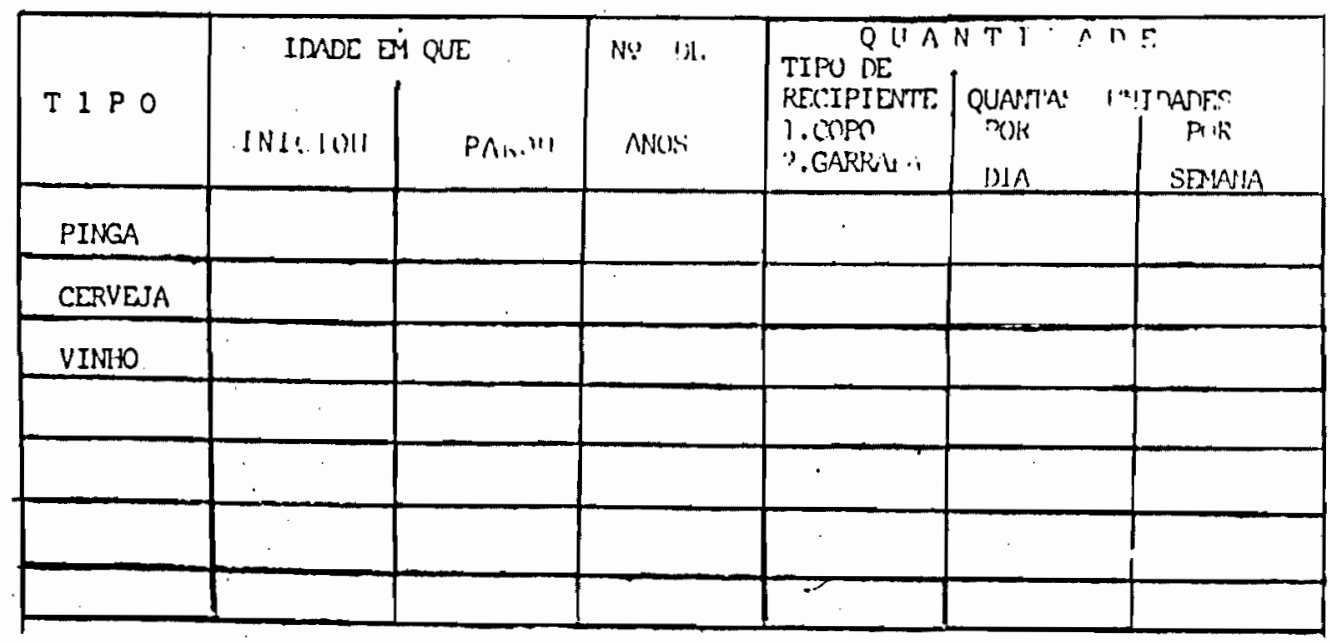

OBSERVAÇŌES: 
N9

29. A QIT "VEMPERATIRA " IR. (YISTIMA TOMAR?

\begin{tabular}{|c|c|c|c|c|c|c|}
\hline$\cdot$ & "4T. $A D^{\prime \prime}$ & "FRIO" & "MORNO" & "QUENTE" & "PELANDO" & QUANITD. \\
\hline CALF. . . . . . . : . & & & & & & \\
\hline HA. • • • • . . . & & & & & & \\
\hline 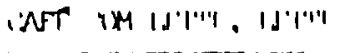 & & & & & & \\
\hline :UHA. • • • • • • & & & & & & \\
\hline AGUA. . . . . . & & & & & & \\
\hline BERIDAS. $\cdot \cdot \cdot \cdot \cdot$ & · & & & & & \\
\hline
\end{tabular}

S1. " SK. TUMA I $x_{i}$ TOMOL CHLMARRAJ?

1. NUNCA. . . . . . . . . . )

2. NAOU AGURA, MAS SIM NO PASSADU ( )

3. SIM. . . . . , . , ( )

'il (2) IXI (:). QUANTA: HOMBA: POR MIA?

ILADE QUV: INICIOU ANOS IDADE QUE PAROU ANOS

31. O SR. TOMA WI TOMOU 'TERERE?

1. NINCA. . . . . . . . . ( )

2. NATU AGORA, MAS SIM NO PASSAXX ( )

$\because$ IM. . . . . . . . 1,

if (i) n!! (3). QIIANTAS. BUYHAS IOR DLA?

IDADE QUE INICIOU ANOS IDADF, QUE PAROU NNDS

32. O SR. COSTUMA COMER:

\begin{tabular}{|c|c|c|c|c|c|}
\hline \multirow{2}{*}{$\begin{array}{l}\text { ALIMENTOS MA } \\
\text { IS ITILILADOS }\end{array}$} & \multirow{2}{*}{ PRLPARO it } & \multicolumn{3}{|c|}{ FREQUENCIA: UUANTAS VE/LS } & \multirow{2}{*}{ ORSLRVACAO } \\
\hline & & POR DIA & POR STIANA. & POR ME: & \\
\hline \multicolumn{6}{|l|}{ 1. CARNES: } \\
\hline & & & & & \\
\hline & & & & & \\
\hline & & & & & \\
\hline & & & & & \\
\hline & . & & & & \\
\hline \multicolumn{6}{|l|}{$\begin{array}{l}\text { 2. PFIXES, } \\
\text { MARLINOAS I: } \\
\text { CRUSOCLIS: }\end{array}$} \\
\hline & & & & & \\
\hline & & & & & \\
\hline & & & & & \\
\hline & & & & & \\
\hline & & & & & \\
\hline & & & & & \\
\hline
\end{tabular}
* 11. Naturul
1. Proparake
1. Sijgrode.
1. Dofumude
2. En]atacto
5. Consinrvado 


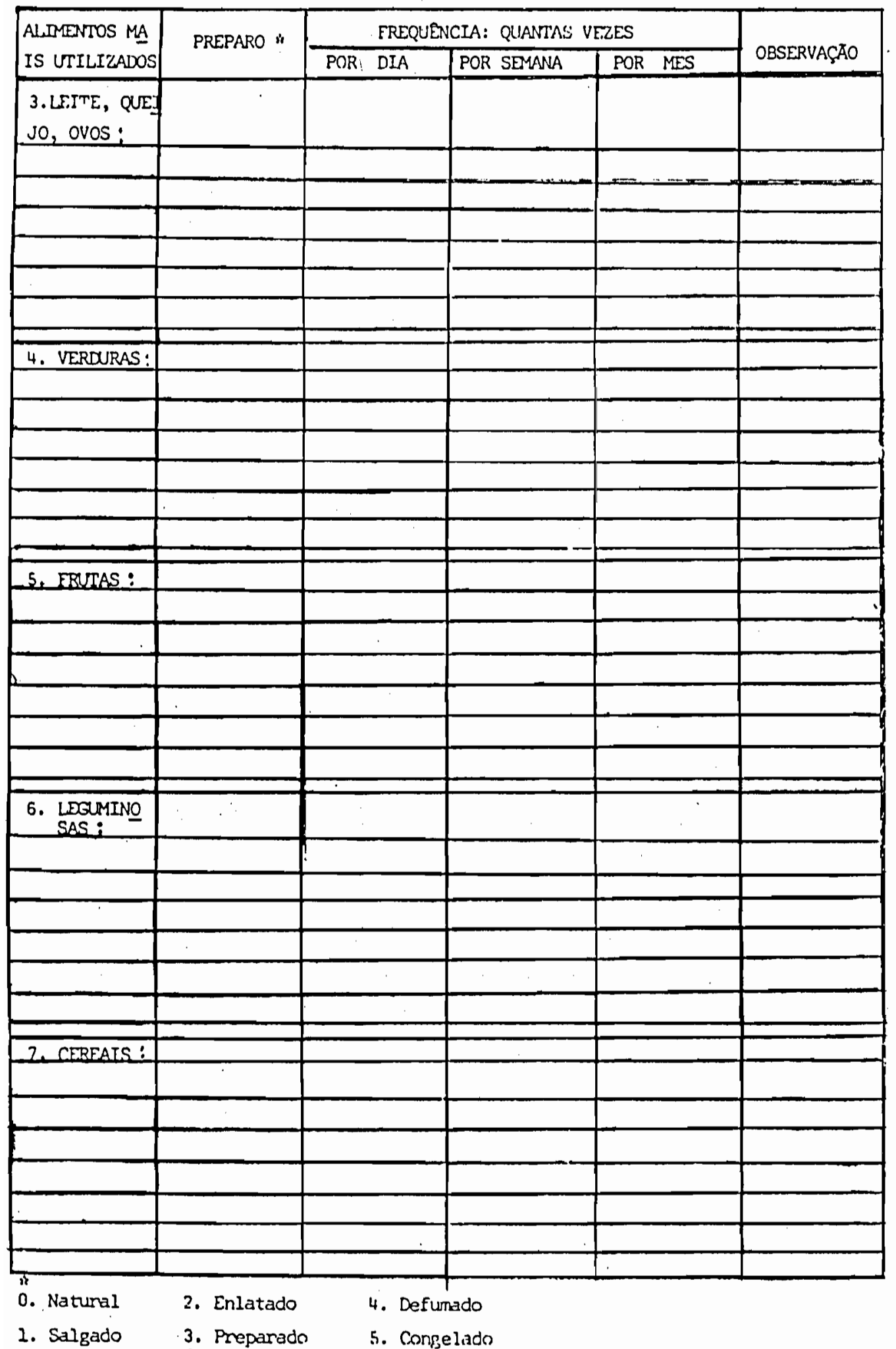




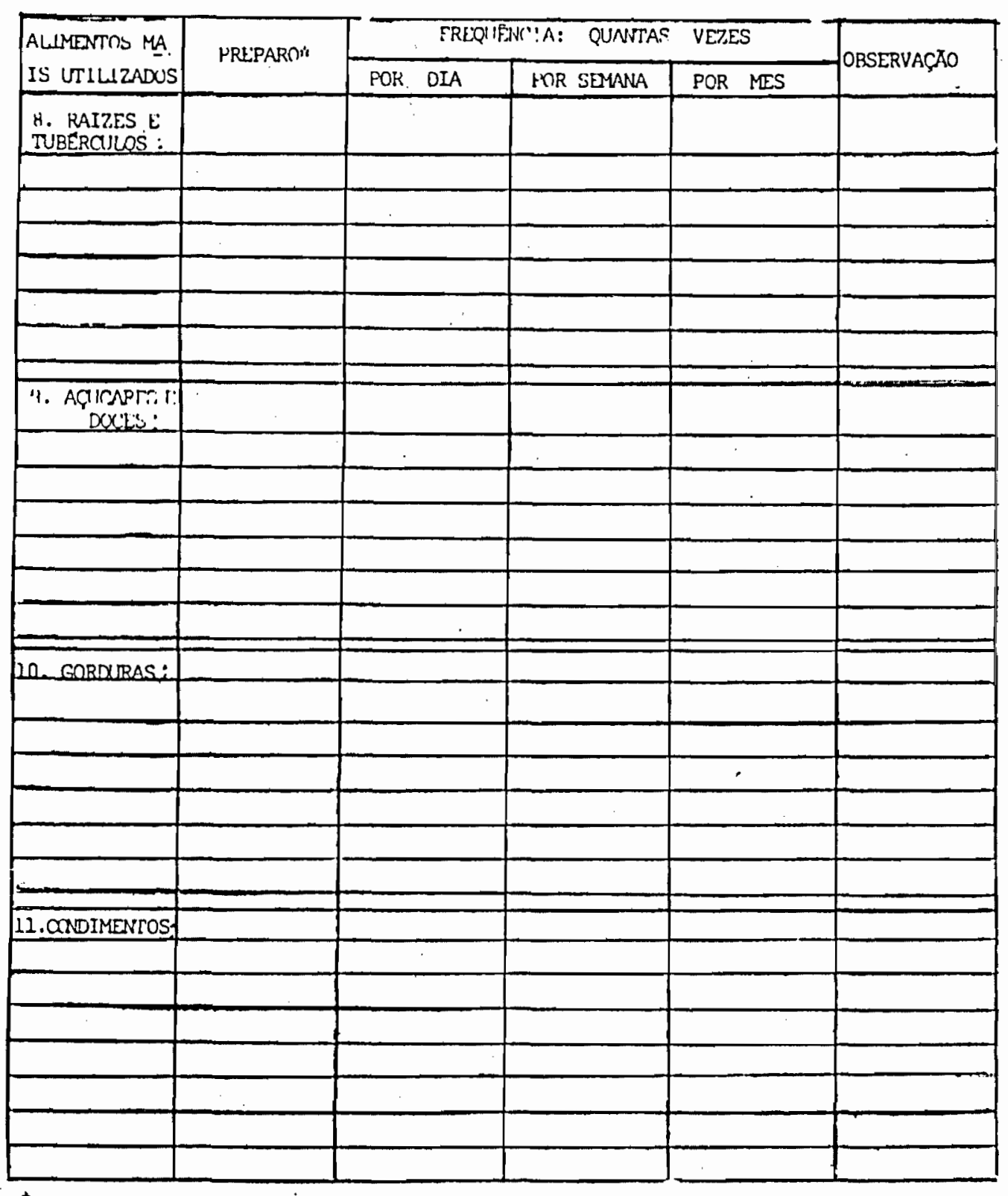
U. Natura]
1. Salpadn
2. Enlatado
3. Preparado
4. Defumado
5. Congelado 
N8

33. ANIES DE ADOECER, QUANTAS VEZES POR DIA O SR. COSTUMAVA EVACUAR?

34. O SR. SBMPRE APRESENTOU ESTA FRFQUFTNCLA?

$$
\begin{aligned}
& \text { 1. NAOO ( ) } \\
& \text { 2. SLM ( ) } \\
& \text { i. NAOO SEI( ) }
\end{aligned}
$$

3b. N(I PASSADO, QUANTOS DIAS O SR. MIAVAA SEM EVACUAR?

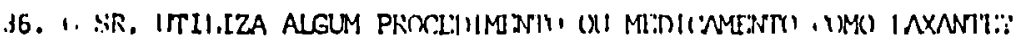

1. NUNIA. . . . . . : (.)

2. NAT AGORA, SIM NO PASSADU. . . ( )

3. SIM. . . . . . . . ( )

CASI (2) OU (3):

1) QUE?

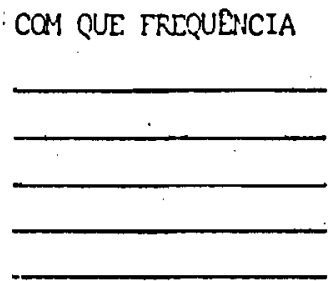

DURANTE' QUANTO TEMPO

QUANDO PARX.
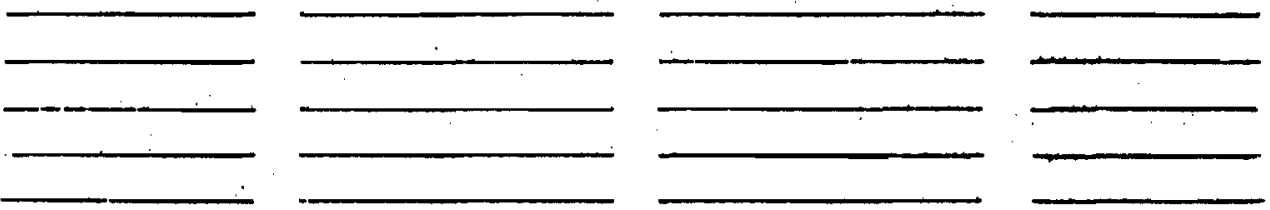

37. ANTES DE ADOECER (IMEDLATAMENTE), COMO ERA A C.ONSISTENIIA DE. SUAS FELL':?
1. PETREAS
()
7. DURAS
()
3. FIRMES
( )
4. AMOLECIIA:
( )
h. DIARREEICA:
( )

38. DURANTE QUANTO TEMPO APRESENTOI ESTA CONSIISTENCIA:

39. NO PASSADO, A CONSISTENCIA !I SIIAL: FE\%ES: ERA DIFERINTT?
1. NÃO
( )
2. $: \mathrm{SM}$
( ), in : im:

41. QUAL EKA $\wedge$ CONSISTENCIA DE :ULAE TE:IS:

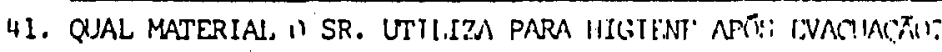

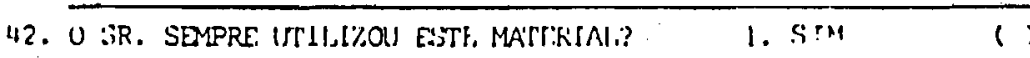

43. ALGIEM DA SUA FAMII,IA T'EM OU TEVE:

2. $-4 \pi_{1}$ ( ) QUA!?
a. !IABETE'S?
1. $N$ in ( )
$\because$ SilM (.) Q Q IIII?
b. DUENCA DO CORACAO?
3. $N \pi 0()$
$\% \operatorname{SIM}()$ QISEM?
c. CANNCER?
1. NÃO (.)
d. PRESSAO ALT'A?
2. $\operatorname{SIM}()$ QUEM?
1. NKO. ( )
2. SIM ( ) QUEM? 

e. ILWSE!
1. NAO ()
i. $\operatorname{SIM}($ ) QUEM?
F. DOENÇCA SEMELHANTE A SUA?
1. NAO ( )
2. SIM ( ) QUEM?

44. O SR. TEM OU TEVE H:SQUISJOSSOMOSE?

1. NAO ( )
2. SIM (), se sim:

QIE: IOADE TINU, QUANIO IVI TI:ITU O MTAGNGSTIM?

QUE: IDAIJE TINIA, QUANDO FOI FLITO O TRATAMENYIO? L.NAO FEZ.( )

2.

45. O SR. JA FOI OPERADO DO ESTŐMAGO?

1. $\mathrm{NAO}^{-}($)

2. SIM (), se sim:

POR QUE?

QUE IDADE TINHA NA EPOCA DA CIRURGIA?

16. NO PASSADO TEVE ALGUMA DOENCAA DO REM? NAO () SIM (.)

QUAL? QUANDO?

47. NO PASSADO TEVE ALIUMA DOENCA NO ANUS? QUAL?

NASO ( ) SIM . ( ) QUANDO?

48. TEVE PAPILOMA?

NATO ( ) SIM ( )

LOCALIZACAO:

1. RETO ( )

QUANDO?

2. OUTRA QUANDO?

49. TEVE ALGUMA DOENCA VENEREA ? NATO (). SIM

\begin{tabular}{|l|l|l|l|}
\hline QUAL & QUANDO & LOCALIZACAO & COMO TRATOU \\
\hline & & & \\
\hline & & & \\
\hline & & & \\
\hline & & & \\
\hline & & & \\
\hline
\end{tabular}

COITO ANAL -

NAOO ( ) SIM ( ) 
DIAOTSTIOO DO HOSPITAL

LOCALIZACAAC BXATA DO TUMOR

FXAME HISTOLESICOS:

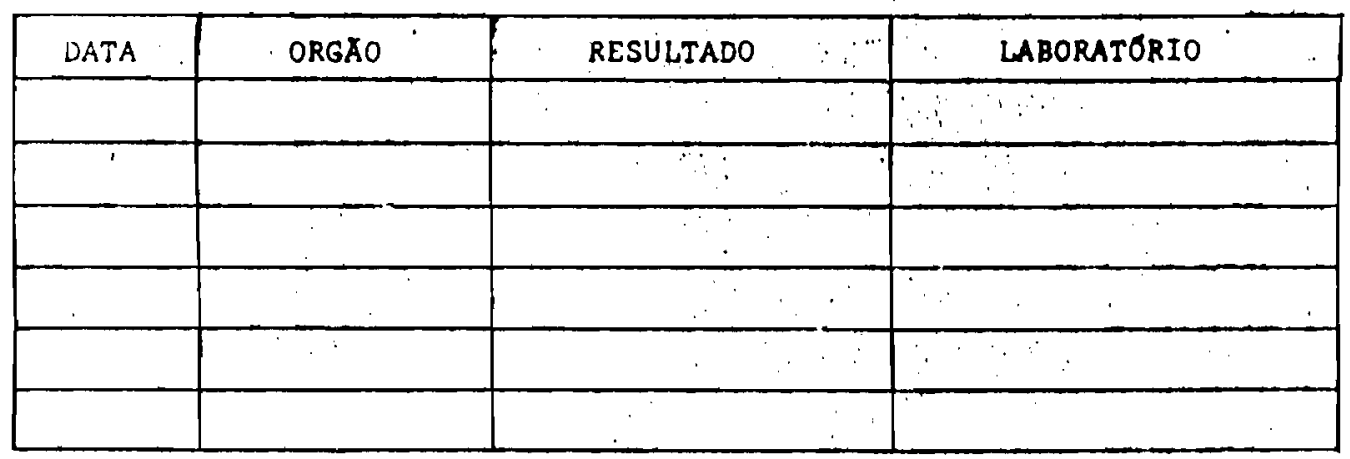

MEIASTASE: 2. NAOO ( )

2. $\operatorname{SIM}()$, se sim:

LOCALIZACAO:

OIFOS DIAGVOSIICOS CONFIPMADOS:

TIPO SANQUINEO E RH:

MEOTOO RESPONSAVEL;

DNIREVISTADOR :

DATA

OBSERTACOES: 